\title{
Immobilization and Limited Reoxidation of Technetium-99 by Fe(II)-Goethite
}
W Um
EC Buck
H Chang
RK Kukkadpu
JP Icenhower
ME Bowden
NP Qafoku
$\mathrm{JH}$ Westsik
SC Smith
WW Lukens
RJ Serne

September 2010

\section{Pacific Northwest}

NATIONAL LABORATORY

Proudly Operated by Battelle Since 1965 


\section{DISCLAIMER}

This report was prepared as an account of work sponsored by an agency of the United States Government. Neither the United States Government nor any agency thereof, nor Battelle Memorial Institute, nor any of their employees, makes any warranty, express or implied, or assumes any legal liability or responsibility for the accuracy, completeness, or usefulness of any information, apparatus, product, or process disclosed, or represents that its use would not infringe privately owned rights. Reference herein to any specific commercial product, process, or service by trade name, trademark, manufacturer, or otherwise does not necessarily constitute or imply its endorsement, recommendation, or favoring by the United States Government or any agency thereof, or Battelle Memorial Institute. The views and opinions of authors expressed herein do not necessarily state or reflect those of the United States Government or any agency thereof.

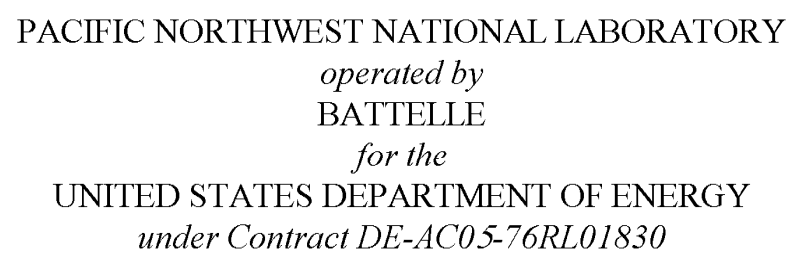

Printed in the United States of America

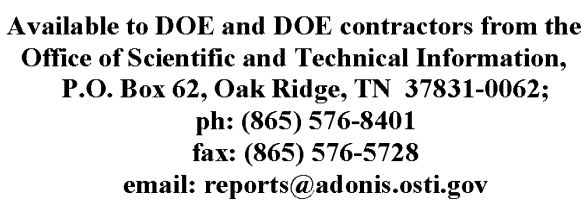

Available to the public from the National Technical Information Service, U.S. Department of Commerce, 5285 Port Royal Rd., Springfield, VA 22161 ph: (800) 553-6847 fax: (703) 605-6900

email: orders@ntis.fedworld.gov

online ordering: http://www.ntis.gov/ordering.htm

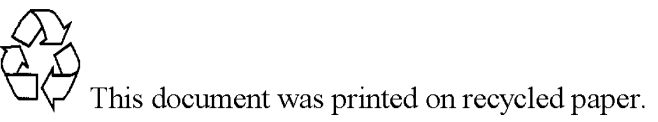

(9/2003) 


\title{
Immobilization and Limited Reoxidation of Technetium-99 by Fe(II)-Goethite
}

\author{
W Um \\ EC Buck \\ H Chang \\ JP Icenhower \\ RK Kukkadpu \\ ME Bowden \\ NP Qafoku \\ JH Westsik \\ SC Smith \\ WW Lukens ${ }^{1}$ \\ RJ Serne
}

September 2010

Prepared for

the U.S. Department of Energy

under Contract DE-AC05-76RL01830

Pacific Northwest National Laboratory

Richland, Washington 99352

\footnotetext{
${ }^{1}$ Lawrence Berkeley National Laboratory, Berkeley, California.
} 


\section{Summary}

Synthesized goethite, $\alpha-\mathrm{FeOOH}$, was successfully used with the addition of aqueous $\mathrm{Fe}(\mathrm{II})$ to sequester technetium (Tc) present in both deionized water and waste solutions simulated to represent tank waste solutions derived from low-activity-waste glass melter off-gas scrubbers used at the Hanford Tank Waste Treatment and Immobilization Plant (WTP). Perrhenate, Re(VII), was also tested as a nonradiological surrogate of pertechnetate [Tc(VII)]. In a slurry of goethite and dissolved $\mathrm{Fe}(\mathrm{II}), \mathrm{Tc}(\mathrm{VII})$ concentrations in solution decreased immediately when the slurry $\mathrm{pH}$ was raised above 7.0 by adding sodium hydroxide $(\mathrm{NaOH})$. The total amount of Tc present in the final solid as determined by acid digestion showed a high degree of Tc sequestration, $90 \%$ to $100 \%$, in the final Tc-goethite solids. In contrast, a relatively small percentage $(0 \%$ to $43 \%)$ of Re removal was found even though the Re-goethite solid was prepared by the same method as the Tc-goethite. The difference in sequestration is caused by the different Re solubility and redox potential vs $\mathrm{pH}$. Removal of Tc(VII) from solution occurred most likely as a result of heterogeneous surface-catalyzed reduction to $\mathrm{Tc}(\mathrm{IV})$ and subsequent co-precipitation with newly formed magnetite or goethite during the $\mathrm{Fe}(\mathrm{II})$ treatment and $\mathrm{pH}$ adjustment. One of the final Tc-goethite products, Sample 2-5, was subsequently armored through a mineral transformation process that involved adding additional $\mathrm{Fe}(\mathrm{III})$ and $\mathrm{NaOH}$ to isolate the reduced $\mathrm{Tc}(\mathrm{IV})$ from future oxidizing agents. Although the dominant major mineral in Tc-goethite samples prepared without armoring was magnetite, the final Tc-bearing solid in Tc-goethite samples prepared with the additional armoring process was identified as goethite-dominated Fe(III)-(oxy)hydroxide based on x-ray diffraction analysis. The presence of goethite in final Tc-goethite Sample 2-5 was also confirmed with the widespread observation of its characteristic acicular (needle-shaped) habit in transmission electron microscopy/ scanning electron microscopy images. No Fe-carbonate minerals were found in any Tc-goethite samples, even in the experiments conducted with Tc-laden off-gas scrubber waste simulant containing high concentrations of ammonium carbonate. Analysis of the solid precipitate using x-ray absorption fine structure spectroscopy showed that the dominant oxidation state of Tc in the final Tc-goethite solid product was Tc(IV). Further, the Tc(IV) was in octahedral coordination with Tc-O, Fe-O, and Tc-Fe inter-atomic distances that are consistent with direct substitution of $\mathrm{Tc}$ for $\mathrm{Fe}$ in the magnetite or goethite structure.

Powdered solids and monolithic cylindrical pellets of Tc-goethite were exposed to dilute leaching solutions (buffered at $\mathrm{pH}$ values of 4,7 , and 10), synthetic Hanford vadose zone pore water $(\mathrm{pH}=7.2$ and $\mathrm{I}=0.05 \mathrm{M})$, and Integrated Disposal Facility glass leachate solution $(\mathrm{pH}=9.7$ and $\mathrm{I}=1.67 \mathrm{M})$, simulating geochemical conditions in the postulated waste disposal vault for up to 180 days in static batch reactors. Although Tc-sequestered goethite samples were exposed to various fluids and different leaching conditions (air and water), the reduced Tc(IV) was not reoxidized to Tc(VII), even after 180 days of reaction in both solution and air conditions. In the circumneutral Hanford pore water solution, the concentration of leached Tc from the goethite pellet was very low, and an effective diffusion coefficient of $6.15 \times 10-11 \mathrm{~cm}^{2} / \mathrm{s}$ was calculated. Successful incorporation of Tc(IV) within the goethite mineral lattice and subsequent goethite armoring, as prepared for Sample 2-5, limited reoxidation of Tc(IV) and its subsequent release from the Tc-goethite waste form, even when the final product was placed in oxidizing environments that typify shallow waste burial facilities. The more stabilized and strongly coordinated Tc(IV) within the goethite lattice in the Tc-sequestered goethite, especially after additional goethite was precipitated as an armoring layer, provides significant advantages for slowing the release of Tc disposed of in nuclear waste repositories. 


\section{Acknowledgments}

The authors acknowledge the following staff members of the Environmental Sciences Laboratory (ESL) at Pacific Northwest National Laboratory (PNNL) who performed the syntheses, tests, and analyses of the Tc-goethite samples: SR Baum, ET Clayton, C Iovin, B Williams, IV Kutnyakov, MM Valenta, D Smith, K Geizler, and M Lindberg. Without their dedicated efforts, the large amount of data and quality checks would not have met the expedited schedule required to finish the laboratory experiments in a timely fashion. The authors appreciate Dr. Cleveland J Dodge's additional Tc XAFS sample collection at Brookhaven National Laboratory. Finally, we would acknowledge the funding provided by the U.S. Department of Energy Environmental Management (EM-31) Program that allowed us to conduct the laboratory experiments and report the results. 


\section{Acronyms and Abbreviations}

2-D

ABS

BET

BSE

DI

DOE

EDX

EXAFS

GL

HEPES

ICP-MS

ICP-OES

IDF

LI

NSLS

PNNL

PZC

PZNC

RT

SAED

SBS

SE

SEM

SI

SSRL

SSS

TEM

XAFS

XANES

XAS

XRD

WTP two-dimensional

aqueous biphasic systems

Brunauer-Emmett-Teller (method used to measure specific surface area of solid)

backscattered electron

deionized

U.S. Department of Energy

energy dispersive $\mathrm{x}$-ray

extended x-ray absorption fine structure

glass leachate

4-(2-hydroxyethyl)-1-piperazineethanesulfonic acid

inductively coupled plasma mass spectroscopy/spectrometer

inductively coupled plasma optical emission spectroscopy/spectrometer

Integrated Disposal Facility

Leachability Index

National Synchrotron Light Source

Pacific Northwest National Laboratory

point of zero charge

point of zero net charge

room temperature

Selected area electron diffraction

submerged bed scrubber

secondary electron

scanning electron microscopy/microscope

saturation index

Stanford Synchrotron Radiation Laboratory

synthetic scrubber solutions

transmission electron microscope

$\mathrm{x}$-ray absorption fine structure (spectroscopy)

$\mathrm{x}$-ray absorption near edge structure

$\mathrm{x}$-ray absorption spectroscopy

$\mathrm{x}$-ray diffraction

Hanford Tank Waste Treatment and Immobilization Plant 


\section{Contents}

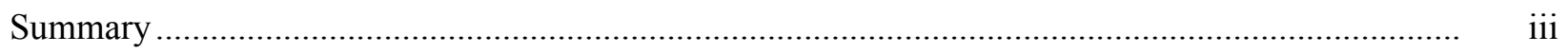

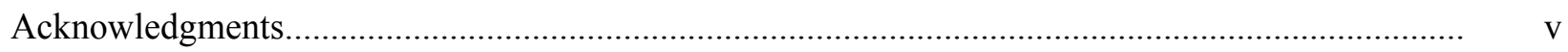

Acronyms and Abbreviations ........................................................................................... vii

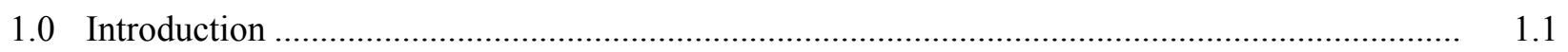

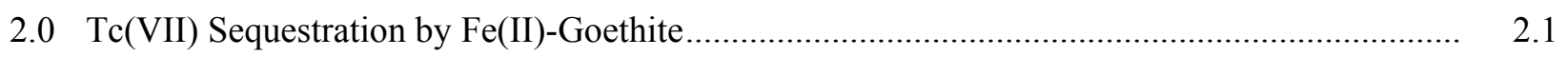

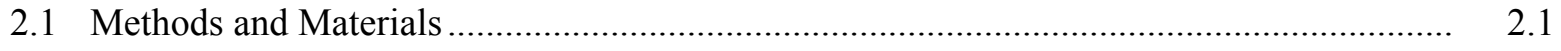

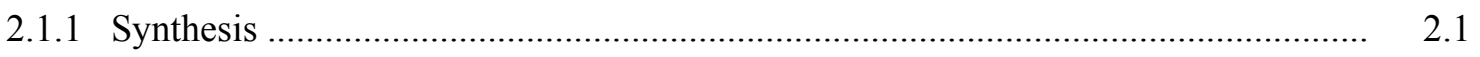

2.1.2 Tc(VII) Removal from Solution Using Fe(II)- Goethite ..................................... 2.1

2.1.3 Fe(II) Removal from Solution with Goethite or Ferrihydrite ................................. 2.2

2.1.4 Tc(VII) Removal Kinetics Using Different Simulants and Concentrations ............. 2.3

2.1.5 Solid-Phase Characterization ..................................................................... 2.4

2.1.6 X-Ray Absorption Fine Structure (XAFS) Spectroscopy …................................. 2.5

2.1.7 Leaching Experiments...................................................................................... 2.6

2.1.8 Effective Diffusion Coefficient Measurement for ${ }^{99}$ Tc....................................... 2.7

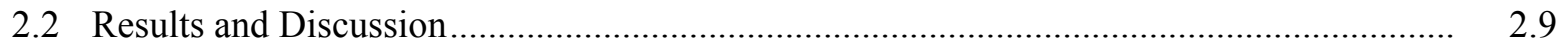

2.2.1 Tc(VII) Sequestration by Fe(II)-Goethite ....................................................... 2.9

2.2.2 Tc(VII) Sequestration by Fe(II)-Goethite with Different Simulants and

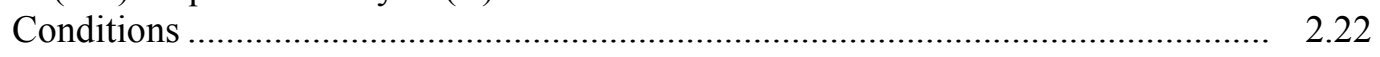

2.2.3 Limited Tc(VII) Release from Fe(II)-Goethite .............................................. 2.31

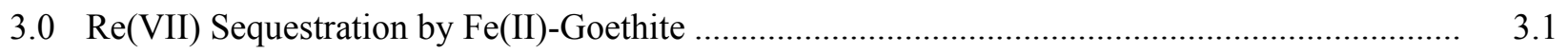

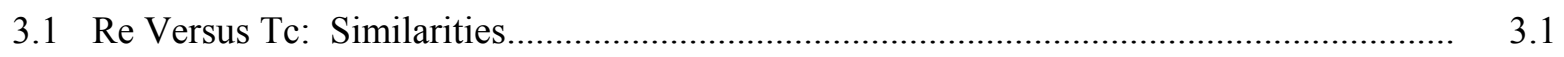

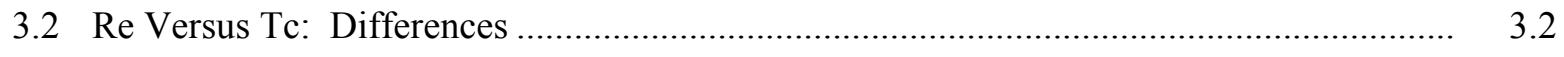

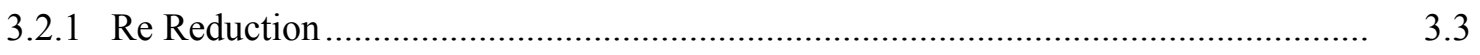

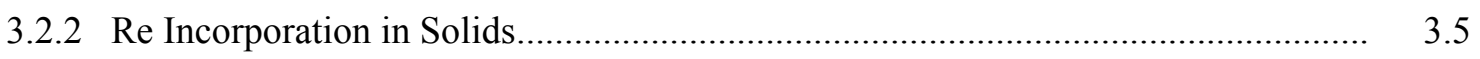

3.2.3 Scientific Objectives .............................................................................. 3.5

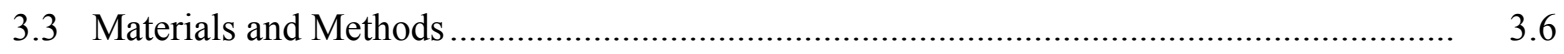

3.3.1 Laboratory Procedure to Synthesize Goethite................................................... 3.6

3.3.2 Laboratory Procedure to Study Re Interaction with Goethite in the
Presence of a Reductant [Fe(II)] …................................................................. 3.6

3.3.3 Experiments Conducted During This Investigation .......................................... 3.7

3.3.4 Laboratory Methods and Instruments Employed During This Investigation ............ 3.10

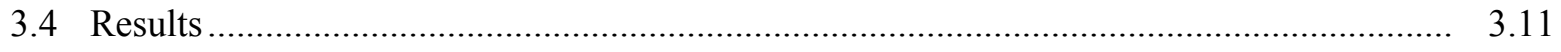

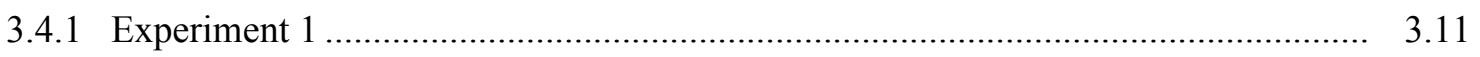

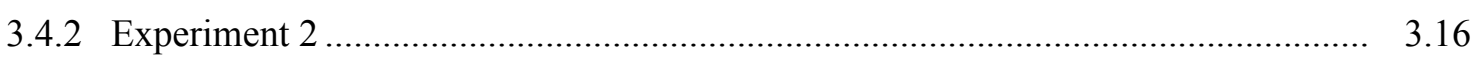

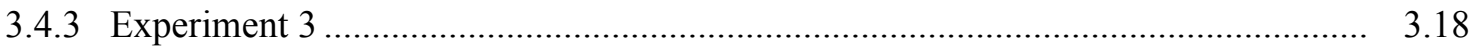




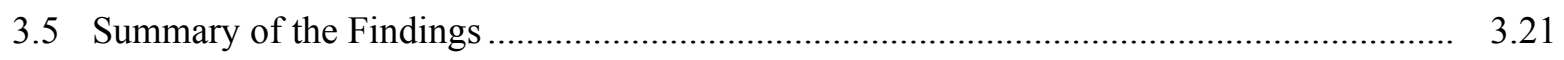

4.0 Conclusions and Summary Statements........................................................................ 4.1

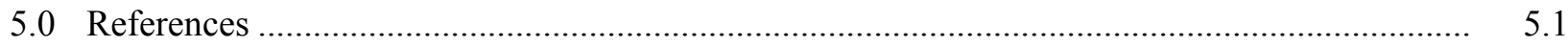

\section{Figures}

2.1 Cylindrical Monolithic Pellets of Tc-Goethite Samples .................................................... 2.8

2.2 Mass of Fe(II), Total Fe, and Tc in Either Solution or the Final Tc-Goethite Solid Sample 2-5

2.3 Mass of Fe(II), Total Fe, and Tc in Either Solution or the Final Tc-Goethite Solid Sample 2-2 .....

2.4 Mass of Fe(II), Total Fe, and Tc in Either Solution or the Final Tc-goethite Solid Sample 2-3

2.5 Mass of Fe(II), Total Fe, and Tc in Either Solution or the Final Tc-Goethite Solid Sample 2-1

2.6 Total Fe Mass Balance for the Synthesis of Tc-Goethite Solids

2.7 X-Ray Diffraction Patterns for Initial Goethite, Ferrihydrite, and Final Tc-Goethite Solids.

2.8 Micro X-Ray Diffraction Pattern and Semiquantitative Fit Using Different Ratios Between Goethite and Magnetite for Sample 2-2 and Sample 2-3

2.9 Solubility Curves for $\mathrm{Fe}(\mathrm{OH})_{3}(\mathrm{~s})$ and $\mathrm{Fe}(\mathrm{OH})_{2}$ (s) Along with Measured $\mathrm{Fe}(\mathrm{II})$ Solution Concentrations at Different $\mathrm{pH}$ Levels and with and Without Presence of Goethite and Ferrihydrite.

2.10 Micro X-Ray Diffraction Pattern of White Rust Sample and Reference Pattern of $\mathrm{Fe}(\mathrm{OH})_{2(\mathrm{~s})}$ from JADE PDF Database

2.11 SEM Images for Tc-Goethite Samples Initial Goethite; Final Tc-Goethite

Sample 2; Final Tc-Goethite Sample 2-2; and Final Tc-Goethite Sample 2-5

2.12 TEM Images of Tc-Goethite Samples: High Magnification Image of Tc-Goethite Sample 2-2; Presence of Visible Magnetite with Goethite in Agreement with XRD in Sample 2-2; Electron Diffraction Pattern Taken Along the B[001] Direction of Sample 2-2; TEM Image of Sample 2-3 Showing Both Magnetite and Goethite; and TEM/EDX Analysis of Tc in Sample 2-2

$2.13{ }^{57} \mathrm{Fe}$ Transmission Mössbauer spectra of Tc-Goethite Sample 2: Room Temperature; and $77 \mathrm{~K}$ Temperature.

2.14 Normalized XANES Spectra for Tc(VII) and Tc(IV) Standards and Tc-Goethite Samples 
2.16 Dissolved Fe(II) and Fe(tot) Concentrations in Solutions with and Without Tc(VII)

at Different pHs Without Fe(III) Oxide Solids and Tc Removal in Fe(II) Solution

Without Fe(III) Oxide Solids at Different pHs .

2.17 Dissolved Fe(II) and Fe(tot) Concentrations in Experiments Conducted at Different pHs with Fe Oxides Present and Tc Removal in Fe(II) Solutions with Fe Oxides Present at Different $\mathrm{pHs}$

$2.18 \mathrm{Tc}$ (VII) Removal in Simulant SSS-2 Solution by Fe(II)-Goethite as a Function of Time

2.19 Tc(VII) Removal in Simulant SSS-3 Solution by Fe(II)-Goethite as a Function of Time

2.20 SEM/EDX for Tc-Goethite Samples Prepared Using Simulant-3 with $2.0 \mathrm{~g}$ of Initial Goethite and 0.1 M of Fe(II) Without Additional Armoring Process, Sample 2-3.

$2.21 \mathrm{Tc}$ (VII) Removal in Simulant SSS-4 Solution by Fe(II)- Goethite as a Function of Time.

2.22 Anion Effects on Tc Removal in Simulant 1 Solution by Fe(II)-Goethite System.

2.23 Batch-Leaching Results for Tc-Goethite Samples as a Function of Reaction Time with Different pH Buffer Solutions, IDF Pore Water, and GL

2.24 A Linear Relation Between Total Dissolved Fe and Released Total Tc Concentrations in $\mathrm{pH}=10$ Solution

2.25 Calculated Tc Effective Diffusivities for Samples 2, 2-2, and 2-5 as a Function of Cumulative Leaching Time and the Linear Dependence Between Cumulative Tc

Release and Cumulative Leaching Time, $\mathrm{t}^{1 / 2}$ for Sample 2-5

2.26 Cylindrical Monolithic Pellets of Tc-Goethite Samples

2.27 XRD Patterns of the Tc-Fe(II) Goethite Sample 2 and Tc-Fe(II) Goethite Samples 2-2 and 2-5.

2.28 Normalized XANES Spectra for Tc(VII) and Tc(IV) Standards as Well as Tc-Fe(II) Goethite Samples.

3.1 A Cluster of Doubly Terminated Trapezohedral Crystals of Synthetic Perrhenate

Sodalite and a Model of the Crystal Structure of Perrhenate Sodalite

3.2 XRD Analysis Pattern for the Final Powder Goethite

3.3 SEM Micrographs of Initial and Final Goethite Product

3.4 Additional SEM Micrographs Taken in the Final Goethite Product.

3.5 EDS Spectrum Taken in the Same Goethite Powder as the One Presented in the Previous Figure

3.6 Changes in Re Concentration with Time in the Experiment Conducted with Rhenium Pentachloride.

3.7 XRD Analysis Pattern Taken in Powder Goethite.

3.8 Changes in Total $\mathrm{Fe}$ and Fe(II) Concentration with Time in Experiment 3 While Slurry was Kept Acidic

3.9 Changes in Re Concentration with Time in Experiment 3 While Slurry was Kept Acidic......

3.10 Changes in Re Concentration with Time in Experiment 3 ................................................ 3.19

3.11 Changes in Re Concentration with Time ...................................................................... 3.20 


\section{Tables}

2.1 Summary of Tc-Goethite Preparation Methods and Tc Removal Efficiencies........................... 2.3

2.2 Composition of Hanford Tank Waste Treatment and Immobilization Plant

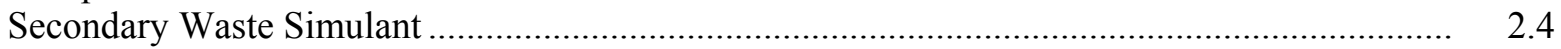

2.3 Chemicals Used to Prepare the IDF Pore Water in the Hanford 200-East Area

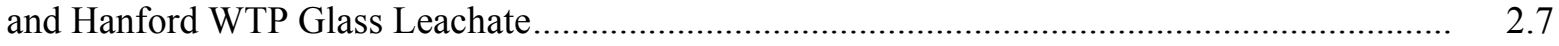

2.4 Structural Parameters of Tc Derived from EXAFS Analysis ................................................. 2.21

3.1 Chemical Properties of Re and Tc ............................................................................... 3.2

3.2 Chemical Constituents for SBS Simulants Used in the Re-Goethite Experiment ...................... 3.9

3.3 Data from Experiments Conducted with Tc and Re ......................................................... 3.12 


\subsection{Introduction}

Technetium (Tc) is produced in large quantities as a fission product during the irradiation of ${ }^{235} \mathrm{U}$-enriched fuel for commercial power production and plutonium genesis for nuclear weapons. The most abundant isotope of Tc present in the wastes is ${ }^{99} \mathrm{Tc}$ because of its high fission yield ( $\left.6 \%\right)$ and long half-life $\left(2.13 \times 10^{5}\right.$ years $)$ (Kotegov et al. 1968; Luykx 1986). During the Cold War era, generation of fissile ${ }^{239} \mathrm{Pu}$ for use in America's atomic weapons arsenal yielded nearly $1900 \mathrm{~kg}$ of ${ }^{99} \mathrm{Tc}$ at the U.S. Department of Energy's (DOE) Hanford Site in southeastern Washington State (Darab and Smith 1996). Most of this ${ }^{99} \mathrm{Tc}$ is present in fuel reprocessing wastes temporarily stored in underground tanks awaiting retrieval and permanent disposal. After the wastes are retrieved from the storage tanks, current disposal plans call for their separation into a high-activity stream and a low-activity stream, which will be vitrified and disposed of separately. The bulk of the low-activity waste (LAW) stream will be converted into a borosilicate glass waste form that will be disposed of in a shallow burial facility at the Hanford Site (McGrail et al. 2001). The high-level waste (HLW) stream will also be vitrified and stored until a deepgeologic repository becomes available. Even with careful engineering controls, volatilization of a fraction of the ${ }^{99} \mathrm{Tc}$ during the vitrification of both the HLW and LAW streams is expected. Although this volatilized Tc will be captured in melter off-gas scrubbers and returned to the melter, some of the Tc is expected to become part of the secondary waste stream from the LAW vitrification process. The off-gas scrubbers downstream from the melters will generate a high $\mathrm{pH}$, sodium-ammonium carbonate solution containing the volatilized ${ }^{99} \mathrm{Tc}$ and other fugitive species. Effective and cost-efficient disposal of the ${ }^{99} \mathrm{Tc}$ found in the off-gas scrubber solution remains difficult.

Environmental concerns have been raised because of the long half-life and high mobility of ${ }^{99} \mathrm{Tc}$ in oxidizing subsurface environments (Bondietti and Francis 1979). The highly soluble pertechnetate oxyanion, ${ }^{99} \mathrm{Tc}(\mathrm{VII}) \mathrm{O}_{4}^{-}$, does not sorb onto sediments (Kaplan et al. 1998), so $\mathrm{TcO}_{4}{ }^{-}$migrates at nearly the same velocity as groundwater (Rudin et al. 1992) under common subsurface conditions (i.e., $\mathrm{pH}$ close to neutral or slightly alkaline and suboxic conditions). Under reducing conditions, Tc can precipitate as $\mathrm{Tc}(\mathrm{IV}) \mathrm{O}_{2} \cdot 2 \mathrm{H}_{2} \mathrm{O}$ (Lee and Bondietti 1983; Lukens et al. 2002), sorb to mineral phases (Bondietti and Francis 1979), and be retained in different natural environments (Keith-Roach et al. 2003; Fredrickson et al. 2004; Burke et al. 2006) and engineered waste forms (Gilliam et al. 1990; Lukens et al. 2005). However, the reoxidation of pertechnetate [Tc(IV)] by changing conditions, such as contact with atmospheric oxygen, can result in a subsequent release of Tc into the environment (Burke et al. 2006), leading to the prediction of high Tc release rates in many performance assessments (Smith and Walton 1993; Lukens et al. 2005).

Numerous waste forms have been proposed to accommodate and immobilize Tc, including cement/ grout (Lockrem 2005; Lukens et al. 2005), glass (Bacon and McGrail 2001), hydroceramics (Siemer 2002; Bao et al. 2005), phosphate-bonded ceramics (Siemer 2002; Singh et al. 2006), resins (Gu et al. 2000), aqueous biphasic systems (ABS) (Rogers et al. 1997), nanoporous tin(II/IV) phosphates (Wellman et al. 2006), and other sorbent materials (Liang et al. 1996; Wharton et al. 2000; Mattigod et al. 2003; Pepper et al. 2003). While each of these waste forms has merit and may ultimately prove to be the best candidate, none has yet been demonstrated to immobilize Tc over the hundreds of thousands or millions of years desired to alleviate human and environmental risks. Most of the Tc sequestering agents mentioned above remove $\mathrm{Tc}(\mathrm{VII})$ from the waste stream solution using redox processes where pertechnetate is reduced to Tc(IV) and immobilized in a solid matrix. However, upon contact with oxygen, Tc(IV) has been found to reoxidize rapidly to pertechnetate, which is very soluble and mobile 
(Lukens et al. 2005). Thus, the longevity of the waste from material and its capability to prevent reoxidation of $\mathrm{Tc}(\mathrm{IV})$ to $\mathrm{Tc}(\mathrm{VII})$ are key to the success of any proposed immobilization strategy. While many of the proposed disposal options rely on isolating Tc(IV) from oxidizing components in the air or aqueous fluids, the reductive capacity of the material hosting reduced $\mathrm{Tc}(\mathrm{IV})$ and the reoxidation kinetics affecting Tc-remobilization have not been clearly demonstrated. However, experimental results hint at a long-term immobilization strategy for ${ }^{99} \mathrm{Tc}$.

Previous investigations into the interaction of Tc with iron (oxy)hydroxide and sulfide minerals have shown that once $\mathrm{Tc}$ (VII) is reduced, the association of Tc(IV) with iron is strong (Wharton et al. 2000; Watson et al. 2001; Livens et al. 2004; Morris et al. 2008), and the possibility of limited reoxidation of $\mathrm{Tc}(\mathrm{IV})$ is proposed. The iron $(\mathrm{Fe})$ phase most commonly reported in these studies is goethite $[\alpha-\mathrm{FeO}(\mathrm{III}) \mathrm{OH}]$, but the exact nature of the interaction between goethite and $\mathrm{Tc}$ is still unclear. It is possible to directly substitute $\mathrm{Tc}(\mathrm{IV})$ for $\mathrm{Fe}(\mathrm{III})$ in the goethite structure during goethite precipitation and crystal growth reactions because of the similarity in the interatomic distances between $\mathrm{Fe}(\mathrm{III})-\mathrm{O}$ and $\mathrm{Tc}(\mathrm{IV})-\mathrm{O}(2.06$ and $2.01 \AA$, respectively) (Yang et al. 2006) and in Eh values (ca. $+20 \mathrm{mV}$ at $\mathrm{pH}=7$ ) for a redox couple between $\mathrm{Tc}(\mathrm{VII}) / \mathrm{Tc}(\mathrm{IV})$ and $\mathrm{Fe}(\mathrm{III}) / \mathrm{Fe}(\mathrm{II})$ (Burke et al. 2006), provided that a chargebalancing cation is part of a coupled substitution in the goethite structure. Alternatively, substitution of trace Tc(IV) for Fe(III) may occur if a defect-bearing solid is stable. Goethite is also easily synthesized in the laboratory with particle sizes and surface areas that can be manipulated readily (Schwertmann and Cornell 1991). In addition to its facile synthesis, goethite is resistant to chemical weathering because the hydrogen and oxygen atoms in the goethite structure are resistant to exchange with the environment for up to $50 \mathrm{Myr}$ (Shuster et al. 2005). Goethite is one of the most common rock-forming minerals on Earth's surface and is thermodynamically more stable than other Fe(III) oxides (Navrotsky et al. 2008) or sulfides under a range of environmental conditions. Further, iron in goethite is Fe(III) so that in oxidizing environments, which will likely prevail in the disposal repository setting, there will be minimal chemical potential for redox reaction that would cause a greater mobility of Tc(IV).

Numerous previous studies of systems containing Fe(III) minerals with aqueous or sorbed $\mathrm{Fe}(\mathrm{II})$ focused on the catalytic effects to remove redox-sensitive contaminants from solution (Elsner et al. 2004; Pedersen et al. 2005). The association of Fe(II) with the Fe(III) solid surface phase showed that both the significantly enhanced reactivity of $\mathrm{Fe}(\mathrm{II})$ and the highest redox activity were found in a goethite with a dissolved $\mathrm{Fe}(\mathrm{II})$ system in comparison to the other $\mathrm{Fe}(\mathrm{II})-\mathrm{Fe}(\mathrm{III})$ (oxy)hydroxide minerals (Elsner et al. 2004; Amstaetter et al. 2010). Therefore, a waste form based on a Fe(II)-goethite system appears to be a simple, durable, cost-efficient, and effective candidate for disposing of technetium from secondary wastes.

Because of the mineral stability of goethite, the release potential of Tc from the Tc-goethite waste form is likely limited by either dissolution of the Tc-hosting goethite mineral or diffusion of Tc out of the solid in the absence of goethite dissolution, depending on the background geochemical conditions. Successful incorporation of Tc(IV) within the goethite mineral lattice is proposed to sequester Tc from waste streams and limit the reoxidation of Tc and its subsequent release from Tc-goethite waste forms, even when the final product is placed in oxidizing environments. Therefore, the experiments described herein investigated the immobilization of Tc in a Fe(II)-goethite system, and attempted to elucidate the association of Tc with Fe in the final Tc-goethite product by various microscopic and spectroscopic analyses. In addition, evaluation of Tc release from the Tc-goethite waste forms under various conditions in batch-leaching experiments and both mineralogical changes and the reoxidation of Tc(IV) in the Tc-goethite solid after 180 days reaction in either air or leachants are also reported. 
The remaining sections of this report describe the sequestration of $\mathrm{Tc}(\mathrm{VII})$ by $\mathrm{Fe}(\mathrm{II})$-goethite and the sequestration of $\operatorname{Re}(\mathrm{VII})$ by Fe(II)-goethite (Sections 2.0 and 3.0, respectively), followed by the associated conclusions of the investigation and related findings statements (Section 4.0). Section 5.0 contains a list of references cited in the text. 


\section{$2.0 \mathrm{Tc}(\mathrm{VII})$ Sequestration by Fe(II)-Goethite}

The methods and materials used to investigate the sequestration of Tc(VII) by Fe(II)-geothite include the synthesis of goethite and the methods, described below, followed by the associated results.

\subsection{Methods and Materials}

The investigative methods and materials included the initial synthesis of goethite and its subsequent use in ${ }^{99} \mathrm{Tc}$ sequestration activities and removal kinetics using different simulants and concentrations, solid-phase characterization, $x$-ray absorption fine-structure spectroscopy, leaching experiments, and effective diffusion coefficient measurement for ${ }^{99} \mathrm{Tc}$.

\subsubsection{Synthesis}

Goethite was synthesized based on a scaled-down procedure of Schwertmann and Cornell (1991). To summarize, ferric nitrate $\left[11.4 \mathrm{~g}\right.$ of $\left.\mathrm{Fe}\left(\mathrm{NO}_{3}\right)_{3} \cdot 9 \mathrm{H}_{2} \mathrm{O}\right]$ was dissolved into NANOpure ${ }^{\circledR}$ water $(100 \mathrm{~mL})$ and reacted with 2-M sodium hydroxide $(\mathrm{NaOH})(150 \mathrm{~mL})$. The slurry was heated in an oven $\left(80^{\circ} \mathrm{C}\right)$ for 7 to 10 days. The solid product was filtered from solution by vacuum filtration, washed with fresh NANOpure ${ }^{\circledR}$ water two times, and air dried overnight. The air-dried solid was then gently crushed to a powder form. In addition to goethite, two-line ferrihydrite $\left(\mathrm{Fe}_{5} \mathrm{HO}_{8} \cdot 4 \mathrm{H}_{2} \mathrm{O}\right)$ was also synthesized using a modified method of Schwertmann and Cornell (1991). The synthesis method for ferrihydrite was similar to that of goethite without the heating step. Briefly, ferric nitrate $\left[8.0 \mathrm{~g}\right.$ of $\left.\mathrm{Fe}\left(\mathrm{NO}_{3}\right)_{3} \cdot 9 \mathrm{H}_{2} \mathrm{O}\right]$ was dissolved into NANOpure ${ }^{\circledR}$ water $(100 \mathrm{~mL})$ in a polyethylene bottle $(250 \mathrm{~mL}) ; 1 \mathrm{M} \mathrm{NaOH}$ was added dropwise while stirring the slurry, until a pH of 6 was obtained. To obtain a $\mathrm{pH}$ of 7 to 8 , additional lowconcentration $\mathrm{NaOH}$ (i.e., $0.01 \mathrm{M}$ ) was added while continuously stirring. The final product was filtered from solution by vacuum filtration, washed with fresh NANOpure ${ }^{\circledR}$ water four times, and air dried overnight before use.

A third iron oxide phase, in addition to crystalline goethite and amorphous ferrihydrite, white rust $\left[\mathrm{Fe}(\mathrm{OH})_{2(\mathrm{~s})}\right]$, was also prepared using $0.07 \mathrm{M}$ of $\mathrm{FeCl}_{2} \cdot 4 \mathrm{H}_{2} \mathrm{O}$ with an increasing $\mathrm{pH}$ close to 7.5 inside an anaerobic chamber (Coy Laboratory Products) equipped with a $\mathrm{H}_{2} / \mathrm{O}_{2}$ gas analyzer and palladium-coated alumina catalyst. A mixture of $\mathrm{N}_{2}(97 \%)$ and $\mathrm{H}_{2}(3 \%)$ was used as the anaerobic gas in the chamber. Because $\mathrm{Fe}(\mathrm{OH})_{2(\mathrm{~s})}$ is very unstable in air, the final powder sample was stored inside the anaerobic chamber before any analysis.

\subsubsection{Tc(VII) Removal from Solution Using Fe(II)- Goethite}

Between 2.75 and $3.5 \mathrm{~g}$ of synthesized goethite powder were resuspended in $250 \mathrm{~mL}$ of deaerated deionized (DI) water in the aforementioned anaerobic chamber to minimize the oxidation of the ferrous solution prior to its use in the treatment of the goethite-Tc slurry. The initially measured $\mathrm{pH}$ for the goethite-DI water slurry was 10.4 and it was adjusted to $\mathrm{pH} \sim 2.0$ by adding nitric acid $\left(2 \mathrm{M} \mathrm{HNO}_{3}\right)$. An aliquot of $\mathrm{FeCl}_{2} \cdot 4 \mathrm{H}_{2} \mathrm{O}(3.48 \mathrm{~g})$ solid was directly added to the goethite slurry as the $\mathrm{Fe}(\mathrm{II})$ source to make $0.07 \mathrm{M}$ of dissolved $\mathrm{Fe}(\mathrm{II})$, while the suspension was continuously mixed at low $\mathrm{pH}(\sim 2.0)$ in the anoxic chamber. After 1 day of mixing, $0.25 \mathrm{~mL}$ of Tc(VII) from a $\mathrm{NaTcO}_{4}$ solution $\left(2.2 \times 10^{-2} \mathrm{M}\right)$ was added to make a total $2.2 \times 10^{-5} \mathrm{M}$ of Tc in the Fe(II)-goethite slurry $(250 \mathrm{~mL})$, while the headspace of the bottle 
was purged with $\mathrm{N}_{2}$ gas to prevent oxygen contact. As soon as the $\mathrm{Tc}(\mathrm{VII})$ was added, the bottle was immediately capped. A subsample from the slurry was collected after complete mixing, filtered using a $0.45-\mu \mathrm{m}$ Nalgene syringe filter, and analyzed for total Tc concentration in the supernate. After 1 to 2 days of additional mixing in a platform shaker, a subsample of the slurry was also collected to determine the residual Tc concentration in solution. After subsampling the slurry a second time, $2 \mathrm{M} \mathrm{NaOH}$ was added and placed in an oven at $80^{\circ} \mathrm{C}$ for 7 days to promote additional precipitation of a Tc-goethite solid. A final slurry subsample was collected immediately after the addition of the $\mathrm{NaOH}$. After 7 days' reaction, the final Tc-goethite solids were separated by filtration, washed using DI water, air dried, and used for additional analysis.

In selected experiments, the Tc-goethite solids were further modified to armor the Tc-goethite solids with additional goethite precipitates using separately prepared $\mathrm{Fe}\left(\mathrm{NO}_{3}\right)_{3} \cdot 9 \mathrm{H}_{2} \mathrm{O}(11.4 \mathrm{~g} / 100 \mathrm{~mL})$ and $2 \mathrm{M} \mathrm{NaOH}(150 \mathrm{~mL})$ solutions. These two solutions were added sequentially into the Tc-goethite slurry in a series of additional experiments. After 1 to 2 days of reaction with added ferric nitrate and sodium hydroxide solutions, the bottle containing the final slurry was placed inside an oven at $80^{\circ} \mathrm{C}$ for 7 days. The final slurry was subsequently filtered and both the solution and solid samples were subjected to further analyses. For Sample 2-5, the order of adding the ferric nitrate and sodium hydroxide was reversed such that $\mathrm{NaOH}$ was added before the $\mathrm{Fe}\left(\mathrm{NO}_{3}\right)_{3} \cdot 9 \mathrm{H}_{2} \mathrm{O}$ was introduced (Table 2.1). The order of adding reagents to generate additional goethite to armor the Tc-goethite solid was reversed to evaluate the efficacy of the armoring process.

Samples 2-2, 2-3, and 2-3* are Tc-goethite solids that had no further Fe(III) armoring performed, whereas Samples 2, 2-1, 2-4, and 2-5 were subjected to the additional Fe(III) armoring. A summary of the conditions to produce different batches of Tc-goethite specimens is provided in Table 2.1.

At each subsampling step during the entire experiment, a small aliquot of filtered solution was used to measure the $\mathrm{pH}$ and the concentrations of Tc, Fe(II), and total Fe. Concentrations of Tc and total Fe in the supernatants were determined using Inductively Coupled Plasma Mass Spectroscopy (ICP-MS) and Inductively Coupled Plasma Optical Emission Spectroscopy (ICP-OES), respectively. The dissolved ferrous $[\mathrm{Fe}(\mathrm{II})]$ concentration was determined using the ferrozine colorimetric method (Gibbs 1976) with a HACH DR/890 colorimeter. Removal of Tc and from the aqueous phase was determined by comparing the aqueous $\mathrm{Tc}$ and $\mathrm{Fe}(\mathrm{II})$ concentrations in the collected subsamples with the initial concentrations of Tc and $\mathrm{Fe}(\mathrm{II})$.

\subsubsection{Fe(II) Removal from Solution with Goethite or Ferrihydrite}

Batch experiments to determine the extent of Fe(II) adsorption onto either goethite or ferrihydrite and the subsequent ability of the iron oxides to sequester Tc were also conducted at different $\mathrm{pH}$ levels. These experiments were conducted to study the effect of $\mathrm{pH}$ on dissolved $\mathrm{Fe}$ (II) concentration and subsequent $\mathrm{Tc}$ (VII) removal by the $\mathrm{Fe}(\mathrm{II})$-goethite or -ferrihydrite solids. Some of the $\mathrm{pH}$ variation tests were performed with only $\mathrm{Fe}(\mathrm{II})$ in solution (i.e., no goethite or ferrihydrite solid present) to determine empirically the solubility of $\mathrm{Fe}(\mathrm{II} / \mathrm{III})$ oxyhydroxides. Solubility diagrams for $\mathrm{Fe}(\mathrm{OH})_{3}(\mathrm{~s})$ and $\mathrm{Fe}(\mathrm{OH})_{2}(\mathrm{~s})$ were also constructed based on the stability constants of $\mathrm{Fe}(\mathrm{II}) / \mathrm{Fe}(\mathrm{III})$ hydrolysis species (Stumm and Morgan 1995) and compared with measured Fe(II) concentrations in the effluent solutions from the various batch tests. Dissolved Fe(II) and Fe(tot) concentrations were measured by HACH colorimeter (HACH DR/890) and ICP-OES, respectively. 


\subsubsection{Tc(VII) Removal Kinetics Using Different Simulants and Concentrations}

After we established that the Fe(II)-goethite could effectively sequester Tc(VII) from a DI water solution, Tc(VII) removal from a more concentrated saline solution relevant to the Hanford Site was investigated. Synthetic scrubber solutions (SSSs) were spiked with Tc(VII) (see Table 2.2 for simulant composition) and similar sequestration tests were performed for Tc removal using the Fe(II)-goethite system. Different synthetic off-gas scrubber solutions were used to investigate the ability of the Fe(II) associated with solid goethite to sequester Tc(VII).

Table 2.1. Summary of Tc-Goethite Preparation Methods and Tc Removal Efficiencies

\begin{tabular}{lccccccc}
\hline & \multicolumn{7}{c}{ Samples $^{(\text {(a) }}$} \\
\cline { 2 - 7 } \multicolumn{1}{c}{ Test Description and Tc Removal } & 2 & $2-1$ & $2-2$ & $2-3$ & $2-3^{*(\mathrm{~b})}$ & $2-4$ & $2-5$ \\
\hline Additional Fe(III) armoring & Yes & Yes & No & No & No & Yes & Yes \\
Initial solution $^{(\mathrm{c})}$ & DI & DI & DI & SSS-1 & SSS-3 & SSS-1 & DI \\
Initial goethite mass (g) & 3.47 & 2.75 & 2.75 & 2.75 & 2.0 & 2.75 & 2.75 \\
Initial pH & 1.78 & 1.47 & 1.47 & 1.47 & 1.58 & 1.47 & 1.47 \\
pH after 1 day reaction with Fe(II) & 2.25 & 2.06 & 2.04 & 2.04 & 1.98 & 2.03 & 3.54 \\
pH after Tc spike & 2.01 & 2.06 & 2.04 & 13.0 & 13.5 & 13.0 & 3.03 \\
Initial spiked-Tc mass $(\mu \mathrm{g})$ & 597 & 551 & 501 & 522 & 5547 & 546 & 615 \\
Reaction time with Tc & 1 day & 2 day & 2 day & 2 day & 1 day & 2 day & 2 day \\
Adjusted pH by NaOH before Fe(III) & NA & NA & NA & NA & 13.5 & NA & 13.3 \\
addition & & & & & & & \\
pH after mixing Fe(III) and NaOH & 13.0 & 13.3 & $13.3^{(\mathrm{d})}$ & $13.0^{(\mathrm{d})}$ & 13.4 & $13.0^{(\mathrm{d})}$ & 13.3 \\
Reaction time in oven $($ day) & 7 day & 7 day & 7 day & 7 day & 7 day & 7 day & 7 day \\
Final pH after heating in oven & 12.9 & 13.3 & 13.3 & 13.0 & 13.3 & 13.3 & 13.4 \\
Final solid mass $(\mathrm{g})$ & 6.53 & 6.05 & 3.24 & 3.51 & 5.10 & 6.43 & 6.41 \\
Final Tc removal on solid $(\mu \mathrm{g} / \mathrm{g})^{(\mathrm{e})}$ & 85.7 & 84.4 & 149.1 & 143.1 & 1020 & 78.9 & 96.0 \\
Tc uptake in goethite $(\%)$ & 93.7 & 92.7 & 96.5 & 96.3 & 93.8 & 92.9 & 100.0 \\
XAFS sample collection & NSLS & NA & SSRL & NA & SSRL & NA & SSRL \\
\hline
\end{tabular}

(a) "No Fe(III)" indicates no armoring process was conducted with additional Fe(III) for Samples 2-2 and 2-3. NA indicates "not applicable"; NSLS = National Synchrotron Light Source; SSRL = Stanford Synchrotron Radiation Laboratory. XAFS = x-ray absorption fine structure (spectroscopy)

(b) Additional Tc-goethite sample, Sample 2-3*, was prepared in a different simulant (SSS-3) with a high Tc concentration, $4.2 \times 10^{-4} \mathrm{M}$ and $0.1 \mathrm{M}$ of $\mathrm{Fe}(\mathrm{II})$.

(c) The initial solution was either deionized (DI) water or synthetic scrubber solution (SSS).

(d) The $\mathrm{pH}$ values were measured after addition of $\mathrm{NaOH}$ in Samples 2-2.

(e) The final concentration of Tc on Tc-goethite was determined by acid digestion.

As mentioned, the scrubber waste stream that captures volatilized species from the proposed vitrification process is a highly alkaline $(\mathrm{pH} \sim 13)$ and highly saline solution consisting mainly of sodium, ammonium, acetate, and carbonate. Two samples of the tests discussed in the previous section, Samples 2-3 and 2-4 (see Table 2.1 for details) had Tc(VII) present in simulated scrubber waste solution based on simulant-1 (Mahoney and Russell 2004). One additional sample, Sample 2-3* was prepared in Tc(VII)-spiked simulant-3 (Josephson et al. 2010). The composition of simulated scrubber waste solutions is shown in Table 2.2. The sample preparation of Tc-goethite using simulant was the same as 
described above (Section 2.1.2). Additional kinetic data were collected for Tc removal at different time frames from 2 hours to 7 days after mixing the two separately prepared solutions, Tc-spiked simulant and $\mathrm{Fe}$ (II)-goethite slurry, in an oven at $80^{\circ} \mathrm{C}$. In addition, the effects of initial goethite mass, aqueous $\mathrm{Fe}(\mathrm{II})$ concentration, and waste stream anion $\left(\mathrm{PO}_{4}{ }^{3-}\right.$ and $\left.\mathrm{SO}_{4}{ }^{3-}\right)$ concentrations on $\mathrm{Tc}$ removal by the $\mathrm{Fe}(\mathrm{II})-$ goethite system were evaluated using either DI or SSS-1 solution. The various slurries of Fe(II)-goethite and the secondary liquid waste simulants were subsampled at the same contact times to evaluate the Tc removal kinetics. The slurry samples were filtered and supernate solutions were analyzed for Tc concentrations using ICP-MS. The solids were also characterized using various analysis techniques, as described below in Section 2.1.5.

Table 2.2. Composition of Hanford Tank Waste Treatment and Immobilization Plant Secondary Waste Simulant

\begin{tabular}{|c|c|c|c|c|}
\hline Elements & $\begin{array}{c}\text { Simulant SSS-1 } \\
\text { (moles/L) } \\
\text { (Mahoney and } \\
\text { Russell 2004) }\end{array}$ & $\begin{array}{c}\text { Simulant SSS-2 } \\
\text { (moles/L) } \\
\text { Adapted from } \\
\text { Melvin (2009) }\end{array}$ & $\begin{array}{c}\text { Simulant SSS-3 } \\
\text { (moles/L) } \\
\text { Caustic Scrubber } \\
\text { Median from } \\
\text { (Josephson et al. 2010) }\end{array}$ & $\begin{array}{c}\text { Simulant SSS-4 } \\
(\text { moles/L) } \\
\text { Submerged Bed } \\
\text { Scrubber from } \\
\text { (Josephson et al. 2010) }\end{array}$ \\
\hline $\mathrm{Na}$ & 1.8 & 2.0 & 2.0 & 2.0 \\
\hline $\mathrm{Al}$ & NI & $2.3 \mathrm{E}-01$ & $1.88 \mathrm{E}-01$ & $9.88 \mathrm{E}-03$ \\
\hline $\mathrm{Cr}$ & NI & $3.7 \mathrm{E}-04$ & $4.06 \mathrm{E}-04$ & $3.46 \mathrm{E}-03$ \\
\hline $\mathrm{Ag}$ & NI & $2.5 \mathrm{E}-06$ & $1.25 \mathrm{E}-05$ & $7.20 \mathrm{E}-05$ \\
\hline $\mathrm{Cd}$ & NI & $5.0 \mathrm{E}-07$ & $3.14 \mathrm{E}-06$ & $7.24 \mathrm{E}-05$ \\
\hline I & NI & $2.9 \mathrm{E}-06$ & $9.14 \mathrm{E}-06$ & $2.10 \mathrm{E}-04$ \\
\hline $\mathrm{Hg}$ & NI & $3.3 \mathrm{E}-05$ & $2.26 \mathrm{E}-05$ & $1.84 \mathrm{E}-06$ \\
\hline $\mathrm{Pb}$ & NI & 7.9E-06 & $1.80 \mathrm{E}-05$ & $1.55 \mathrm{E}-05$ \\
\hline $\mathrm{NH}_{4}$ & 1.84 & NI & NI & 2.08 \\
\hline $\mathrm{CO}_{3}{ }^{2-}$ & $8.1 \mathrm{E}-01$ & $1.5 \mathrm{E}-06$ & $4.56 \mathrm{E}-02$ & $3.32 \mathrm{E}-03$ \\
\hline $\mathrm{NO}_{3}^{-}$ & $1.6 \mathrm{E}-02$ & $6.9 \mathrm{E}-01$ & $6.56 \mathrm{E}-01$ & 3.44 \\
\hline $\mathrm{OH}^{-}$ & 1.92 & 1.2 & $7.96 \mathrm{E}-01$ & $6.66 \mathrm{E}-08$ \\
\hline $\mathrm{PO}_{4}^{3-}$ & NI & $1.7 \mathrm{E}-02$ & $1.37 \mathrm{E}-02$ & 7.62E-03 \\
\hline $\mathrm{SO}_{4}{ }^{2-}$ & NI & $9.7 \mathrm{E}-03$ & $8.82 \mathrm{E}-03$ & $1.44 \mathrm{E}-01$ \\
\hline $\begin{array}{c}\text { TOC } \\
\text { (as acetate) }\end{array}$ & $7.8 \mathrm{E}-02$ & NI & NI & NI \\
\hline $\begin{array}{c}\text { TOC } \\
\text { (as oxalate) }\end{array}$ & NI & $2.3 \mathrm{E}-01$ & $1.88 \mathrm{E}-01$ & $9.88 \mathrm{E}-03$ \\
\hline
\end{tabular}

WTP = Hanford Tank Waste Treatment and Immobilization Plant; NI = not included; TOC = total organic carbon.

\subsubsection{Solid-Phase Characterization}

The initial goethite and ferrihydrite substrates and the final solid product were first characterized using a Scintag XRD unit equipped with a $\mathrm{Cu} K$-alpha radiation $(40 \mathrm{kV}, 35 \mathrm{~mA})$ source. The bulk Tc-goethite samples were homogenized by grinding in an agate mortar and pestle and mounted into a small circular sample holder before scanning from 2 to 75 degrees 2-theta. The $\mathrm{Fe}(\mathrm{OH})_{2(\mathrm{~s})}$ (white rust) 
sample was prepared in an anaerobic chamber and analyzed using micro-XRD on a Rigaku MicroMax diffractometer. The white rust powder was loaded into a glass capillary tube $(0.5 \mathrm{~mm}$ in diameter and $80 \mathrm{~mm}$ high) and the top opening was sealed with grease. The white rust sample in the sealed capillary tube was stored in a centrifuge tube sealed with Parafilm inside an anaerobic chamber before analysis on the micro-XRD to minimize air contact. A rotating anode source at $875 \mathrm{~W}$ was used to generate $\mathrm{Cr} \mathrm{K} \alpha$ $\mathrm{x}$-rays and the beam was collimated to $300 \mu \mathrm{m}$ in diameter for the sample. The diffraction patterns were recorded on a two-dimensional (2-D) image plate detector by integrating between 10 and 150 degrees 2-theta. Data reduction and phase identification were done by Jade software with PDF x-ray diffraction (XRD) database.

Acid extraction, using $8 \mathrm{M} \mathrm{HNO}_{3}$ with heat at $90^{\circ} \mathrm{C}$ or a stronger microwave-assisted digestion with a solution consisting of $16 \mathrm{M} \mathrm{HNO}_{3}(17 \%), 12 \mathrm{M} \mathrm{HCl}(7 \%), 32 \mathrm{M} \mathrm{HF}(3.3 \%), 0.5 \mathrm{~g}^{\circ} \mathrm{H}_{3} \mathrm{BO}_{3}(1.5 \%)$, and DI water $(71.2 \%)$ on a volume basis was used to determine the total Tc or Re in the final Tc/Re-goethite solid.

Transmission electron microscopy (TEM) samples were prepared by dispersing a small amount of the Tc-laden Fe(II)-goethite slurry in methanol and depositing this onto a lacey carbon TEM copper $(\mathrm{Cu})$ grid. TEM characterization was performed using a FEI Tecnai T30 operated at $300 \mathrm{keV}$ equipped with a Gatan ORIUS digital camera. Analysis was performed by identifying the chemical composition and mineralogy of selected particles with energy dispersive x-ray (EDX) spectroscopy and selected area electron diffraction (SAED), respectively. For scanning electron microscopy (SEM) analysis, Tc-laden $\mathrm{Fe}(\mathrm{II})$-goethite particles were mounted on double-sided carbon tape on an aluminum stub and then coated with carbon. The SEM is a JEOL JSM-840, with a $\mathrm{LaB}_{6}$ filament. The final Tc-goethite solid was also analyzed with Mössbauer spectroscopy and SEM/TEM combined with EDX analysis.

The Mössbauer sample was prepared by mixing a dried sample with Vaseline in a $\mathrm{Cu}$ holder sealed at one end with clear tape. After mixing the sample in the holder, the opened end of the holder was sealed with clear tape. The Mössbauer spectra were collected using a $50-\mathrm{mCi}$ (initial strength) ${ }^{57} \mathrm{Co} / \mathrm{Rh}$ singleline thin source and the velocity transducer, MVT-1000 (WissEL), was operated in a constant acceleration mode $(23 \mathrm{~Hz}, 5 \pm$ or $\pm 12 \mathrm{~mm} / \mathrm{s})$. An Ar-Kr proportional counter was used to detect the radiation transmitted through the holder, and the counts were stored in a multichannel scalar as a function of energy (transducer velocity) using a 1024-channel analyzer. Data were folded to 512 channels to give a flat background and a zero-velocity position corresponding to the center shift (CS $\delta$ ) of a metal Fe foil at room temperature (RT). Calibration spectra were obtained with a $25-\mu \mathrm{m}$-thick metal Fe foil (Amersham, England) placed in the same position as the samples to minimize any errors due to changes in geometry. A closed-cycle cryostat (ARS, Allentown, Pennsylvania) was used for below-RT measurements. The Mössbauer data were modeled with the Recoil software (University of Ottawa, Canada) using a Voigt-based structural fitting routine. The coefficient of variation of the spectral areas of the individual sites generally ranged between $1 \%$ and $2 \%$ of the fitted values.

\subsubsection{X-Ray Absorption Fine Structure (XAFS) Spectroscopy}

Solid standards of $\mathrm{KTcO}_{4}, \mathrm{NaTcO}_{4}, \mathrm{TcO}_{4}{ }^{-}$adsorbed on Reillex-HPQ resin and $\mathrm{TcO}_{2} \cdot 2 \mathrm{H}_{2} \mathrm{O}$, and final Tc-goethite samples $\left(2,2-2,2-3^{*}\right.$, and 2-5 in Table 2.1) before leach tests were analyzed to determine the Tc oxidation state and Tc binding information using $\mathrm{x}$-ray absorption near edge structure (XANES) and extended x-ray absorption fine structure (EXAFS) spectroscopy, respectively. The Tc-goethite 
Samples 2, 2-2, and 2-5 were reanalyzed after being leach tested for 180 days to determine the Tc oxidation state using XANES. Another aliquot of the Tc-goethite Sample 2 was separately exposed to atmospheric oxygen for 180 days and used to investigate whether there were any changes in the oxidation state of Tc.

The XAFS spectra were collected either on beamline X10C at the National Synchrotron Light Source (NSLS) or on beamline 4-1 at the Stanford Synchrotron Radiation Laboratory (SSRL). The solid samples were mounted on Teflon sample holders and sealed with Kapton tape. A Si(220) double-flat crystal monochromator was used and the energy was calibrated by using the first inflection point of the Tc K-edge spectrum of the Tc(VII) standard, defined as $21.044 \mathrm{keV}$. The Tc-standards and Tc-goethite spectra were collected in transmission and fluorescence mode, respectively, at room temperature using a 7-element (NSLS) or 13-element (SSRL) germanium detector.

Data reduction and analysis were performed using the software IFEFFIT (Newville 2001) and ATHENA/ARTEMIS (Ravel and Newville 2005) after correction for detector dead-time. The XANES spectra for the Tc-goethite samples were fit using a linear combination of the XANES spectra of Tc(IV) and Tc(VII) standards collected by Lukens et al. (2002). All EXAFS spectra were fitted in R space by Fourier transformation of the $\chi(\mathrm{k})$ data. The back-scattering phase and amplitude information for individual neighboring atoms were determined using the theoretical EXAFS modeling code FEFF6 (Rehr et al. 1991) and the structure of goethite. The amplitude reduction factor $\left(\mathrm{S}_{0}{ }^{2}\right)$ was fixed at 1.0 for all the EXAFS fits. The $\Delta \mathrm{E}_{\mathrm{o}}$ parameter was allowed to vary during fitting, but was constrained to be the same for all scattering shells for a given fit. Three different models were used for EXAFS data analysis of the Tc-goethite samples: (Model 1) Tc substituted for Fe in the goethite structure without any neighboring Tc atoms, (Model 2) Tc substituted for Fe in the goethite structure with a small fraction of neighboring Fe sites occupied by Tc, and (Model 3) Tc substituted for Fe in the goethite structure with some Tc present as separate $\mathrm{TcO}_{2} \cdot 2 \mathrm{H}_{2} \mathrm{O}$ precipitates. The model with the lowest value of reduced chi-squared was the one reported by Newville (2001) and Lukens et al. (2002). In all cases, for the best model, an F-test was performed on each scattering shell. If the probability of $F[p(F)]$ is less than 0.05 , the addition of that shell improves the fit to greater than $2 \sigma$ and that shell was considered to be observed in the experiment.

\subsubsection{Leaching Experiments}

Batch-leaching experiments were conducted with a homogeneously ground Tc-goethite powder sample, Sample 2 (see Table 2.1), at a solid concentration of $1 \mathrm{~g} / \mathrm{L}$ with different leaching solutions. The different leaching solutions were 1) standard Beckman-Colter ${ }^{\mathbb{R}} \mathrm{pH}$ buffer solutions of $\mathrm{pH} 4$ (potassium hydrogen phthalate), $\mathrm{pH} 7$ (mixture of potassium and sodium dihyrogen phosphate), and pH 10 (mixture of sodium bicarbonate-carbonate); 2) synthetic pore water ( $\mathrm{pH}=7.2$ and ionic strength $=0.05 \mathrm{M}$ ) simulating that from the Integrated Disposal Facility (IDF) in the Hanford Site 200 East Area; and 3) simulated Hanford Tank Waste Treatment and Immobilization Plant (WTP) glass leachate (GL) with $\mathrm{pH}=9.7$ and ionic strength=1.67 M, which was developed based on the modeling results of IDF lowlevel waste glass dissolution (Bacon and McGrail 2001; Um et al. 2007). The chemicals used to prepare the latter two Hanford Site-specific leaching solutions are listed in Table 2.3. Additional Tc-goethite powder samples without goethite armoring (Sample 2-2) and with goethite armoring (Sample 2-5) were also leached using only the simulated IDF pore water as the leachant to investigate the effect of the armoring process on Tc release. For each Tc-goethite leach test, a supernate subsample $(1 \mathrm{~mL})$ was periodically collected from 30 minutes after the test commenced to 180 days using a $0.45-\mu \mathrm{m}$ Nalgene 
syringe filter and submitted for analyses of dissolved $\mathrm{Fe}(\mathrm{tot})$ and Tc. The $\mathrm{pH}$ was directly measured in the slurry solution when each of the resulting samples was collected. Analysis methods for Fe(tot) and Tc were the same as described above. After the 180-day leach tests were completed, the powder Tc-goethite samples were separated by filtration and used for solids characterization.

Table 2.3. Chemicals Used to Prepare the IDF Pore Water in the Hanford 200-East Area and Hanford WTP Glass Leachate

\begin{tabular}{lcc}
\hline & \multicolumn{2}{c}{ Concentration (M) } \\
\cline { 2 - 3 } Chemicals & IDF Pore Water & Glass Leachate \\
\hline $\mathrm{CaSO}_{4}$ & $1.2 \times 10^{-2}$ & \\
$\mathrm{NaNO}_{3}$ & $3.4 \times 10^{-3}$ & $2.3 \times 10^{-1}$ \\
$\mathrm{NaHCO}_{3}$ & $3.0 \times 10^{-4}$ & $4.6 \times 10^{-1}$ \\
$\mathrm{Na}_{2} \mathrm{CO}_{3}$ & & \\
$\mathrm{NaCl}_{\mathrm{Na}_{2} \mathrm{SiO}_{3} \cdot 9 \mathrm{H}_{2} \mathrm{O}}$ & $2.1 \times 10^{-3}$ & $1.9 \times 10^{-2}$ \\
$\mathrm{NaCH}_{3} \mathrm{COO}$ & & \\
$\mathrm{NaOH}_{\mathrm{MgSO}_{4}}$ & $2.5 \times 10^{-3}$ \\
$\mathrm{MgCl}_{2}$ & & \\
$\mathrm{KCl}$ & $2.6 \times 10^{-3}$ & \\
$\mathrm{KOH}_{\mathrm{H}_{3} \mathrm{BO}}$ & $2.4 \times 10^{-3}$ & \\
$\mathrm{NH}$ & & \\
\hline IoHic strength & $7.0 \times 10^{-4}$ & $1.3 \times 10^{-2}$ \\
$\mathrm{pH}$ & & \\
\hline $\mathrm{IDF}=$ Integrated Disposal Facility. & 9.7 \\
\hline
\end{tabular}

\subsubsection{Effective Diffusion Coefficient Measurement for ${ }^{99} \mathrm{Tc}$}

The ground-powder Tc-goethite samples (Samples 2, 2-2, and 2-5) were compacted into cylindrical monolithic pellets by mixing with dissolved polyethylene glycol organic binder at about $3 \mathrm{wt} \%$, and were prepared for diffusion leach testing. The Tc-goethite-organic binder slurry was dried overnight in a heated bath at $80^{\circ} \mathrm{C}$ and then pressed with up to $2500 \mathrm{~kg}$ of load force in a 1.3 -cm-diameter die with a Carver Press, giving a resultant pressure of $\sim 150 \mathrm{MPa}$. A minor amount of oleic acid was used on the final monolithic pellet surfaces to aid in preserving the pellet integrity. The resultant monolithic pellets containing the Tc-goethite solids were used to estimate the effective diffusion coefficient for Tc leached from the monolith immersed in IDF pore water solution $(500 \mathrm{~mL})$. Photographs of the monolithic pellets with Tc-goethite (Sample 2-5) with a diameter of $1.3 \mathrm{~cm}$ and a height of $0.32 \mathrm{~cm}$ before and after the diffusion leach testing are shown in Figure 2.1.

For the monolith leach tests, a subsample $(1 \mathrm{~mL})$ of leachate was periodically collected (from 30 minutes after the test commenced to 120 days through the leaching period) using a $0.45-\mu \mathrm{m}$ Nalgene syringe filter and submitted for analyses of dissolved $\mathrm{Fe}($ tot $)$ and Tc. The $\mathrm{pH}$ was directly measured in the slurry solution when each of the leachate samples was collected. Analysis methods for Fe(tot) and Tc 
were the same as described above. After the leach tests were completed, the monolithic Tc-goethite samples were collected and prepared for characterization of the solids.

Because goethite has a low solubility in neutral $\mathrm{pHs}$ similar to that of the IDF pore water (see the leaching results below), the contaminant-specific, effective diffusion coefficient is commonly used to quantify the migration rate of Tc out of the monolithic waste form. The observed effective diffusivity for Tc out of the monolithic waste form was calculated using the analytical solution, Eq. (2.1), for simple radial diffusion from a cylindrical monolithic Tc-goethite pellet into an infinite bath as presented by Crank (1980):

$$
D_{i}=\pi\left[\frac{M_{t_{i}}}{2 \rho C_{o}\left(\sqrt{t_{i}}-\sqrt{t_{i-1}}\right)}\right]^{2}
$$

where $\quad \mathrm{D}_{i}=$ observed diffusivity of Tc for the leaching interval, $i\left[\mathrm{~m}^{2} / \mathrm{s}\right]$

$\mathrm{M}_{t i}=$ Tc mass released during the leaching interval $i\left[\mathrm{mg} / \mathrm{m}^{2}\right]$

$\mathrm{t}_{i}=$ cumulative contact time after the leaching interval, $i[\mathrm{~s}]$

$\mathrm{t}_{i-1}=$ cumulative contact time after the leaching interval, $i-1[\mathrm{~s}]$

$\mathrm{C}_{\mathrm{o}}=$ initial leachable Tc content $[\mathrm{mg} / \mathrm{Kg}]$ in a monolithic pellet; and $\rho$ is the pellet density $\left[\mathrm{Kg}-\mathrm{dry} / \mathrm{m}^{3}\right]$.

The mean observed Tc diffusivity was determined by taking the average of each of the interval-observed diffusivities.

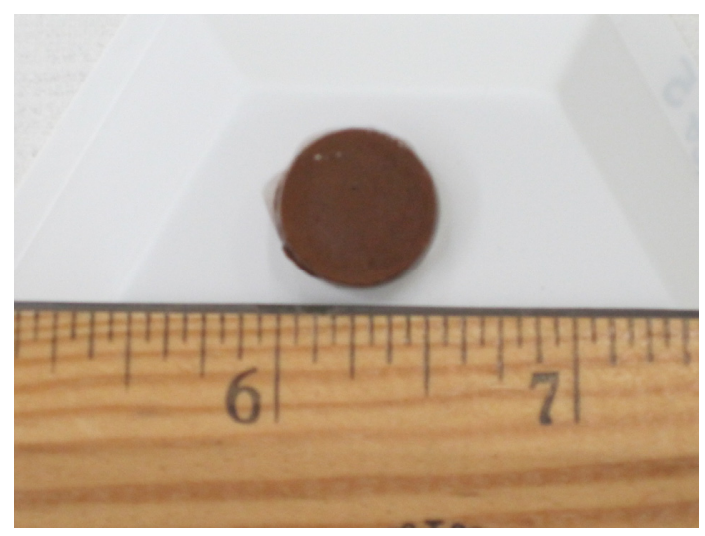

Figure 2.1. Cylindrical Monolithic Pellets of Tc-Goethite Samples. (Left) Samples 2-5 before diffusion leach testing by IDF pore water; (right) Sample 2-5 after diffusion leach testing for 120 days by IDF pore water. The difference in color is from the wetted pellet after leaching.

The leachability index (LI), which is a parameter derived directly from diffusion test results, is also used to evaluate diffusion-controlled contaminant release with respect to time. The LI of Tc is calculated with Eq. (2.2):

$$
L I_{n}=-\log \left(\frac{D_{n}}{c m^{2} s}\right)
$$


where $L I$ is the leachability index and $D_{n}$ is the effective diffusivity for Tc $\left(\mathrm{cm}^{2} / \mathrm{s}\right)$ during the leach interval $n$. Because the LI is the negative logarithm of the measured effective diffusivity of Tc, a larger LI value indicates that less Tc has leached during the leach test.

\subsection{Results and Discussion}

The results of the investigation of the sequestration of $\mathrm{Tc}(\mathrm{VII})$ by $\mathrm{Fe}(\mathrm{II})$-goethite alone and by $\mathrm{Fe}(\mathrm{II})$ goethite or -ferrihydrite with different simulants and conditions, and the limited release of Tc from Fe(II)goethite in the leach test are described in the following sections.

\subsubsection{Tc(VII) Sequestration by Fe(II)-Goethite}

\subsubsection{Tc(VII) Removal by Fe(II)-Goethite}

The total amount of Tc present in the final Tc-goethite solid as determined by acid digestion showed a high degree of Tc removal: $93 \%$ to 100\% (Table 2.1; second to last row in red type). The high degree of Tc sequestration in the final Tc-goethite solids (at least 93\%) indicates that each of the different steps used to prepare the final Tc-goethite solid product was effective. The greatest magnitude of Tc removal, $100 \%$, was found in Sample 2-5 (Table 2.1), which was prepared with the addition of $\mathrm{NaOH}$ prior to the addition of the armoring Fe(III) solution. In Sample 2-5, most of the dissolved Fe(II) and Tc(VII) added to the goethite suspension was removed from solution immediately after adding the $\mathrm{NaOH}$ and before adding the $\mathrm{Fe}(\mathrm{III})$ armoring solution (Figure 2.2).

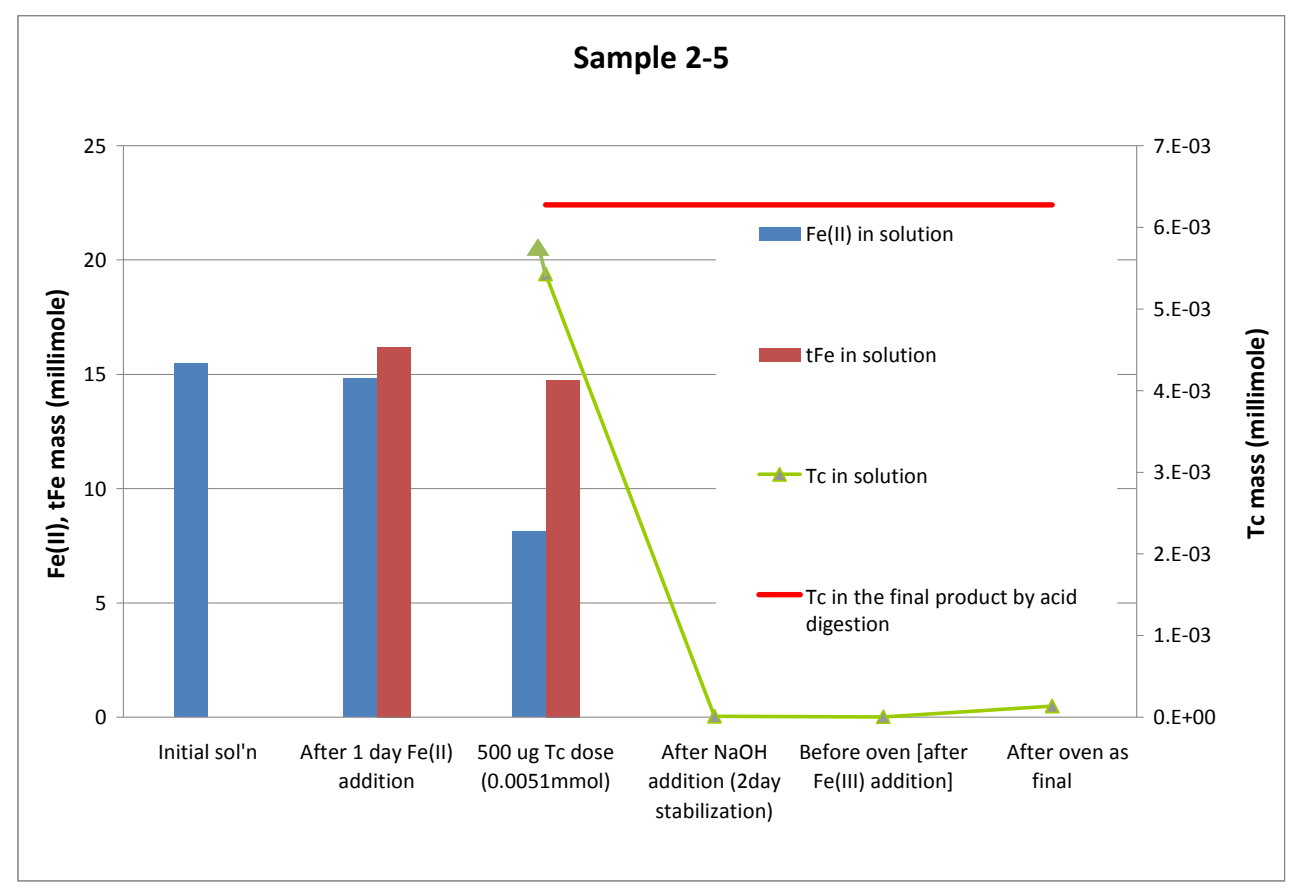

Figure 2.2. Mass of Fe(II), Total Fe, and Tc in Either Solution or the Final Tc-Goethite Solid Sample 2-5 
Similar rapid and complete removal of Tc was also observed in Samples 2-2 and 2-3 that were prepared with DI and synthetic scrubber solution, respectively, without the additional Fe(III) armoring process (Figures 2.3 and 2.4). Most of the added Tc in the highly caustic synthetic scrubber solution $(\mathrm{pH} \sim 13)$ was removed from solution by the Fe(II)-goethite in Sample 2-3 immediately after adding $\mathrm{NaOH}$ to the $\mathrm{Fe}(\mathrm{II})$-goethite slurry prepared at low $\mathrm{pH}(\sim 2.0)$. However, initial Tc masses in solutions of Samples 2-1 and 2-2 were not removed much even after a 2-day reaction (Figures 2.3 and 2.5), indicating no Tc removal in solution by adsorption or co-precipitation occurred before adding $\mathrm{NaOH}$. Sample 2-3 that was prepared with a high caustic SSS showed almost $100 \%$ Tc removal before addition of $\mathrm{NaOH}$ because of the initially high $\mathrm{pH}$ condition in SSS (Table 2.1 and Figure 2.4). This suggests that the key step in Tc sequestration is producing high $\mathrm{pH}$ condition after mixing $\mathrm{Tc}$ with the $\mathrm{Fe}(\mathrm{II})$-goethite slurry.

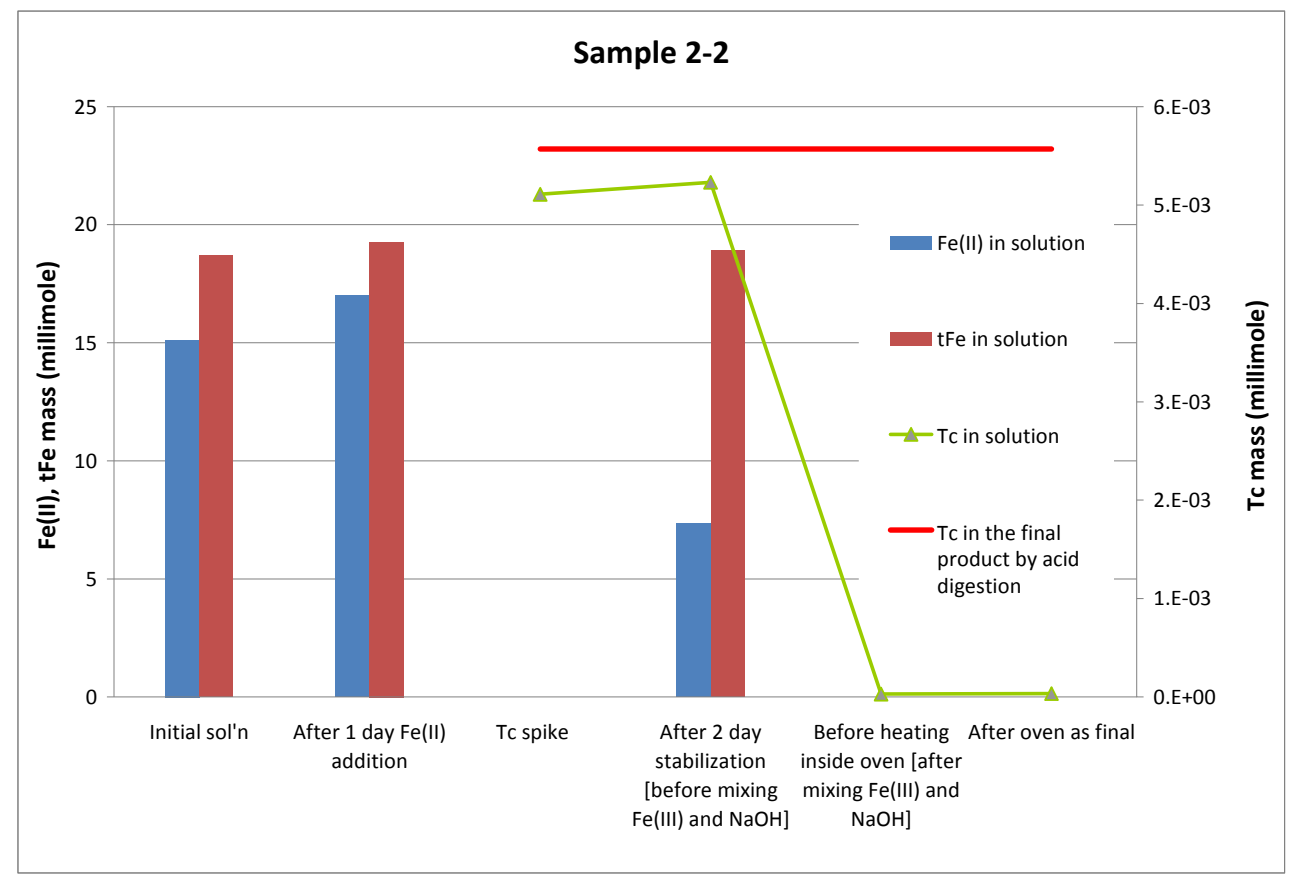

Figure 2.3. Mass of Fe(II), Total Fe, and Tc in Either Solution or the Final Tc-Goethite Solid Sample 2-2 


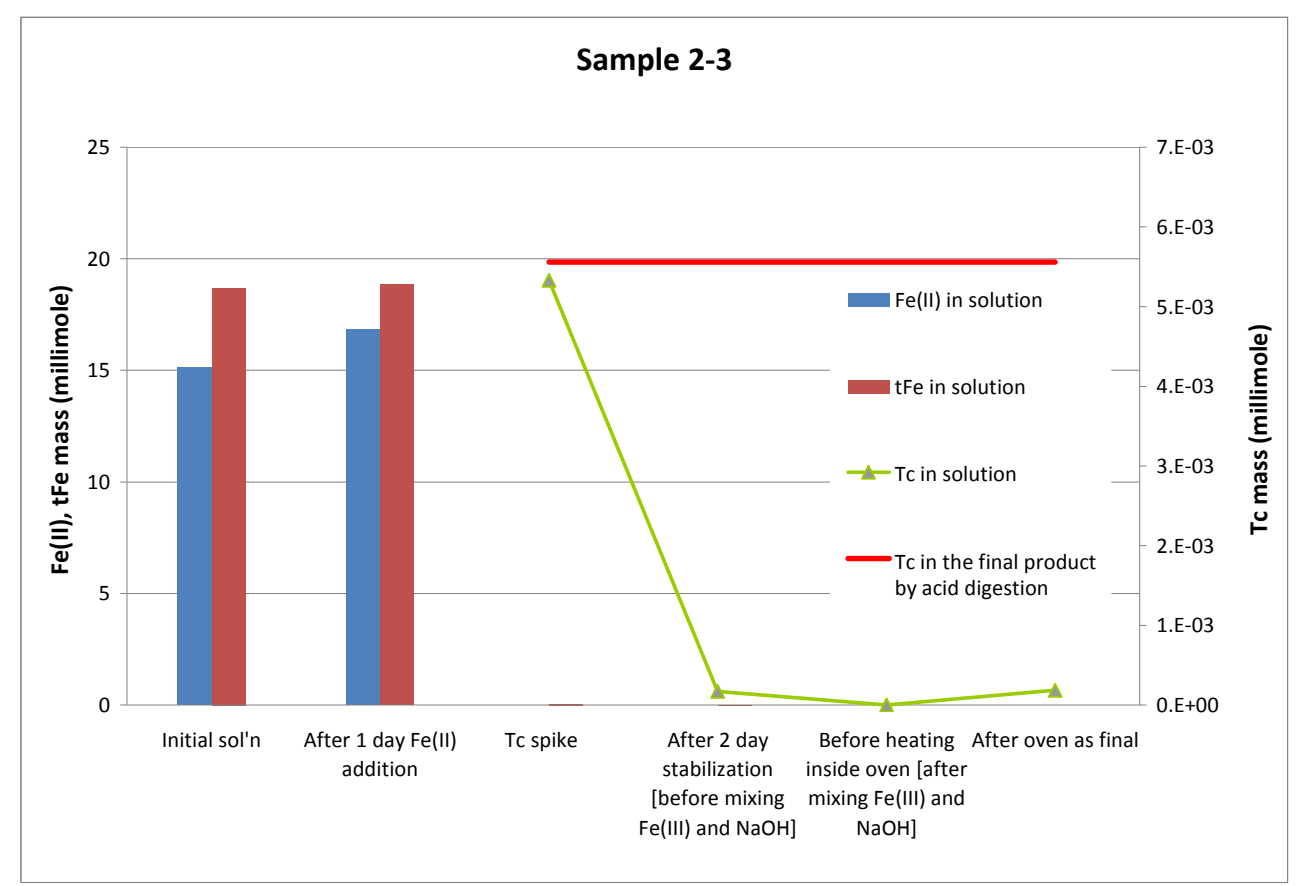

Figure 2.4. Mass of Fe(II), Total Fe, and Tc in Either Solution or the Final Tc-goethite Solid Sample 2-3

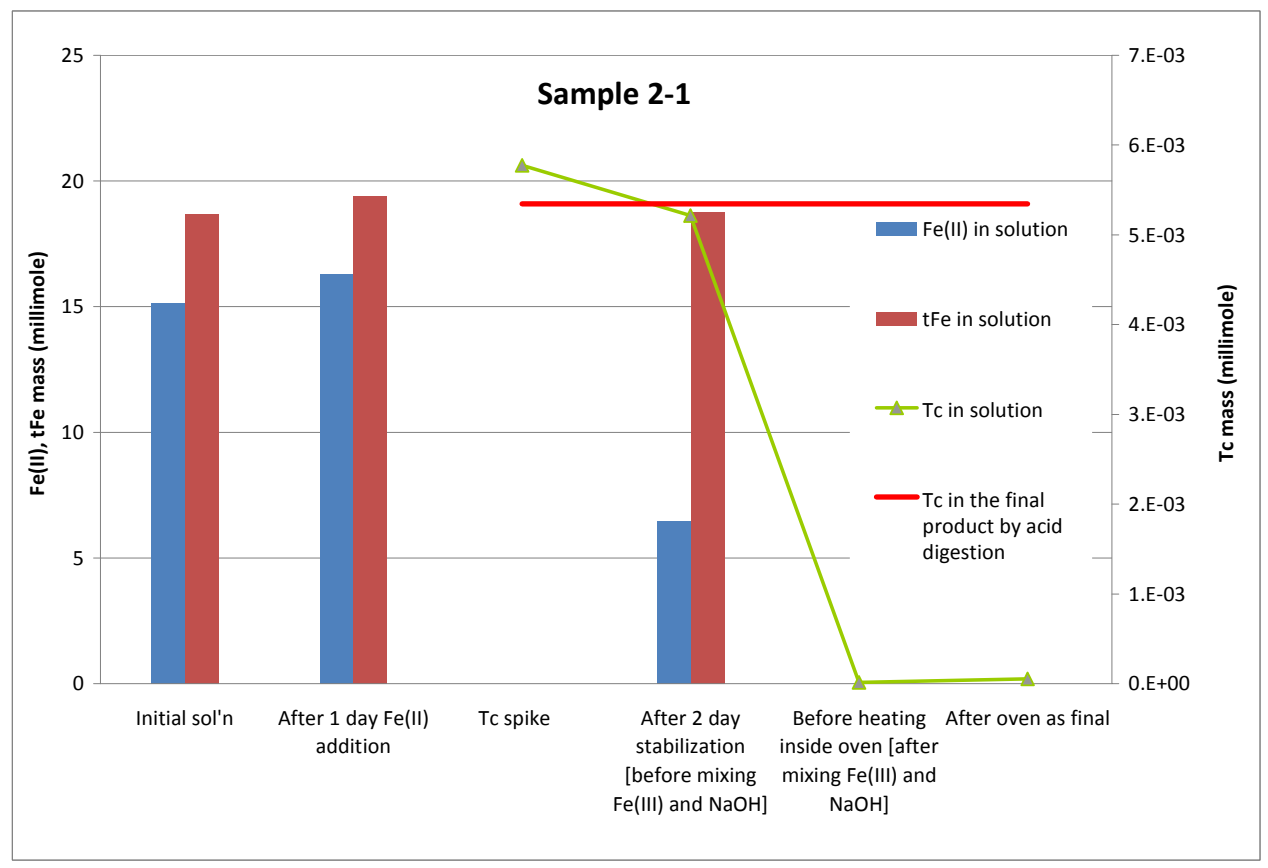

Figure 2.5. Mass of Fe(II), Total Fe, and Tc in Either Solution or the Final Tc-Goethite Solid Sample 2-1

Although the final solid masses of Samples 2-2 and 2-3 (3.2 and 3.5 g, respectively in Table 2.1) were less than those of Samples 2, 2-1, 2-4, and 2-5 (6 to $7 \mathrm{~g}$ ) because of no additional armoring by Fe(III), the total removal of Tc (percent of Tc uptake based on Tc mass initially in the slurry and the Tc mass in the final solid) was still slightly higher in Samples 2-2 and 2-3 than the others, except Sample 2-5. Approximately 96\% of initial Tc(VII) was removed in Samples 2-2 and 2-3 that were prepared without 
additional goethite armoring, suggesting that most of the Tc removal occurred before the armoring process that relied on the addition of $\mathrm{Fe}$ (III) solution and $\mathrm{NaOH}$ to the slurry. In addition, the $100 \% \mathrm{Tc}$ removal observed in Sample 2-5 was also found to occur right after adding $\mathrm{NaOH}$ but before adding $\mathrm{Fe}(\mathrm{III})$, indicating that the amount of additional Tc removed from solution during the $\mathrm{Fe}(\mathrm{III})$ armoring process was not significant (Figure 2.2). That is, as long as the Fe(II)-goethite slurry has a pH above 7.0 after addition of the Tc(VII), effective Tc sequestration occurs in this Fe(II)-goethite system. The mass balance of the total Fe used to create the Tc-goethite samples also showed that about $90 \%$ to $100 \%$ of total Fe used in this system was recovered from the final Tc-goethite product (Figure 2.6). From the bottom to the top, the three color columns in each bar in Figure 2.6 consist of the Fe in the starting goethite, the Fe in the ferrous chloride solid added, and the Fe added to create additional goethite armoring on the $\mathrm{Fe}(\mathrm{II})$-treated goethite.

\subsubsection{Solid-Phase Characterization}

The XRD pattern of the initial goethite solid indicated that only goethite was present in this sample (Figure 2.7). Goethite was also observed, but was not necessarily the dominant mineral in the final Tc-goethite products, which also included noticeable amounts of magnetite (arrows in Figure 2.7) present in Samples 2, 2-1, 2-2, 2-3, and 2-3*. A sharp peak at 35.6 degrees 2-theta indicated the presence of magnetite, and this peak was more discernable in Samples 2-2 and 2-3, which were prepared in a system without $\mathrm{Fe}$ (III) added to armor the Tc-goethite (Table 2.1). A much darker color was observed during preparation of Samples 2-2 and 2-3, and more fine particles were attached on a magnetic stirring bar in the slurry during the formation of the $\mathrm{Fe}(\mathrm{II})$-goethite, indicative of the presence of magnetic separates (i.e., magnetite) in the final product of Samples 2-2 and 2-3. Semiquantitative analysis using standard magnetite and goethite XRD patterns showed approximately $70 \%$ and $60 \%$ magnetite content for Samples 2-2 and 2-3, respectively, with the remainder being goethite (Figure 2.8).

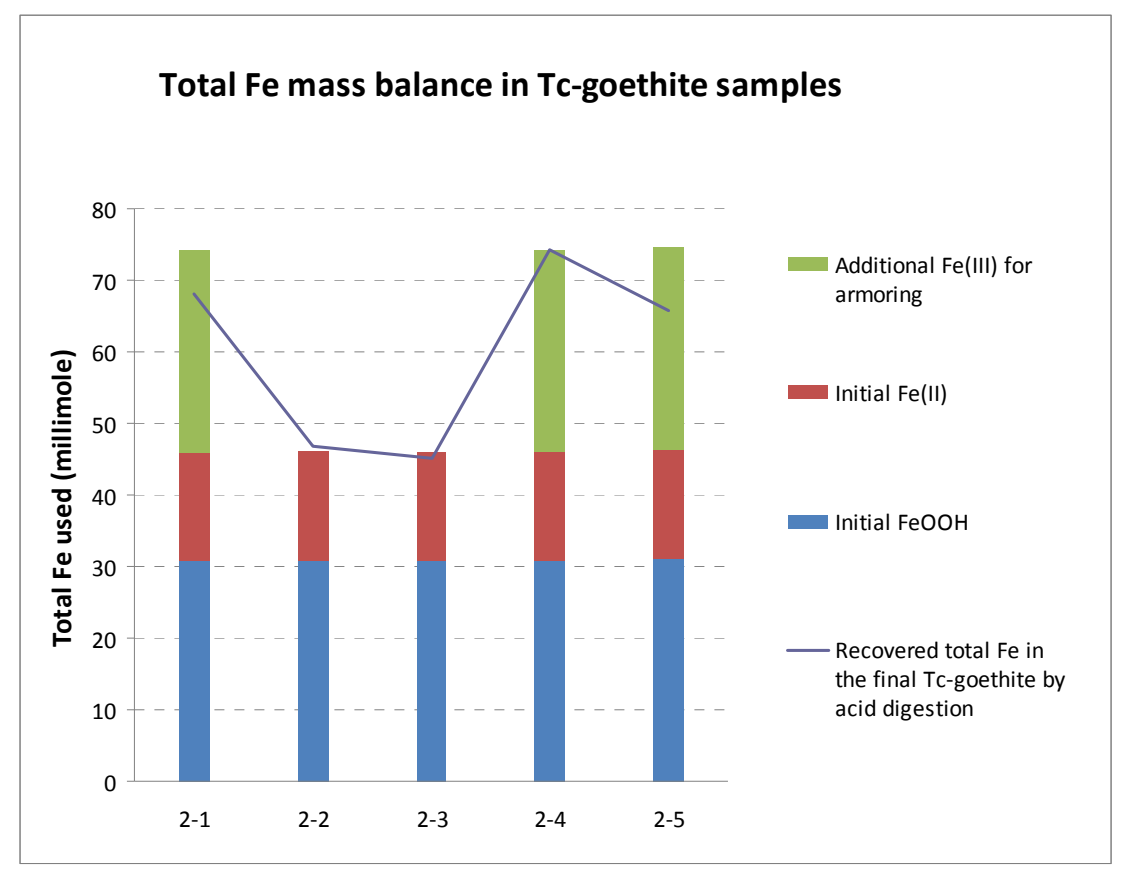

Figure 2.6. Total Fe Mass Balance for the Synthesis of Tc-Goethite Solids 


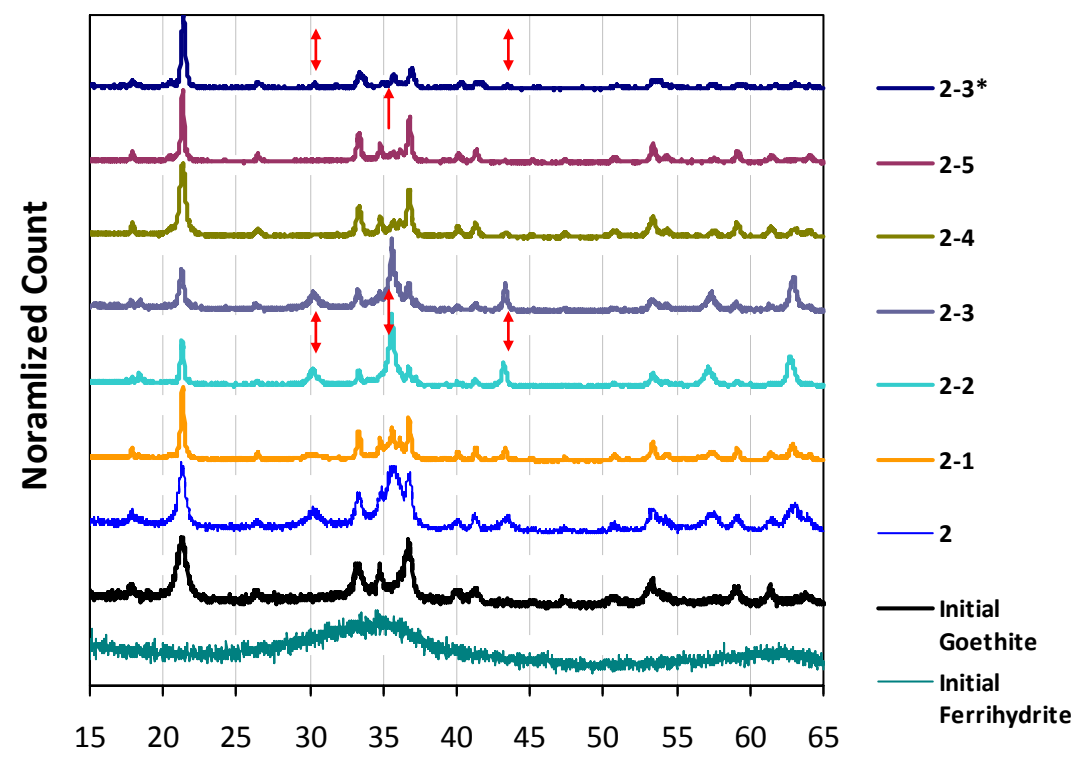

2 Theta

Figure 2.7. X-Ray Diffraction Patterns for Initial Goethite, Ferrihydrite, and Final Tc-Goethite Solids. Arrows (red) indicate presence of magnetite. Sample 2-3* was prepared in simulant SSS-3 with high $\mathrm{Tc}(\mathrm{VII})$ concentration, $4.2 \times 10^{-4} \mathrm{M}$ and $0.1 \mathrm{M} \mathrm{Fe}(\mathrm{II})$ without additional armoring.
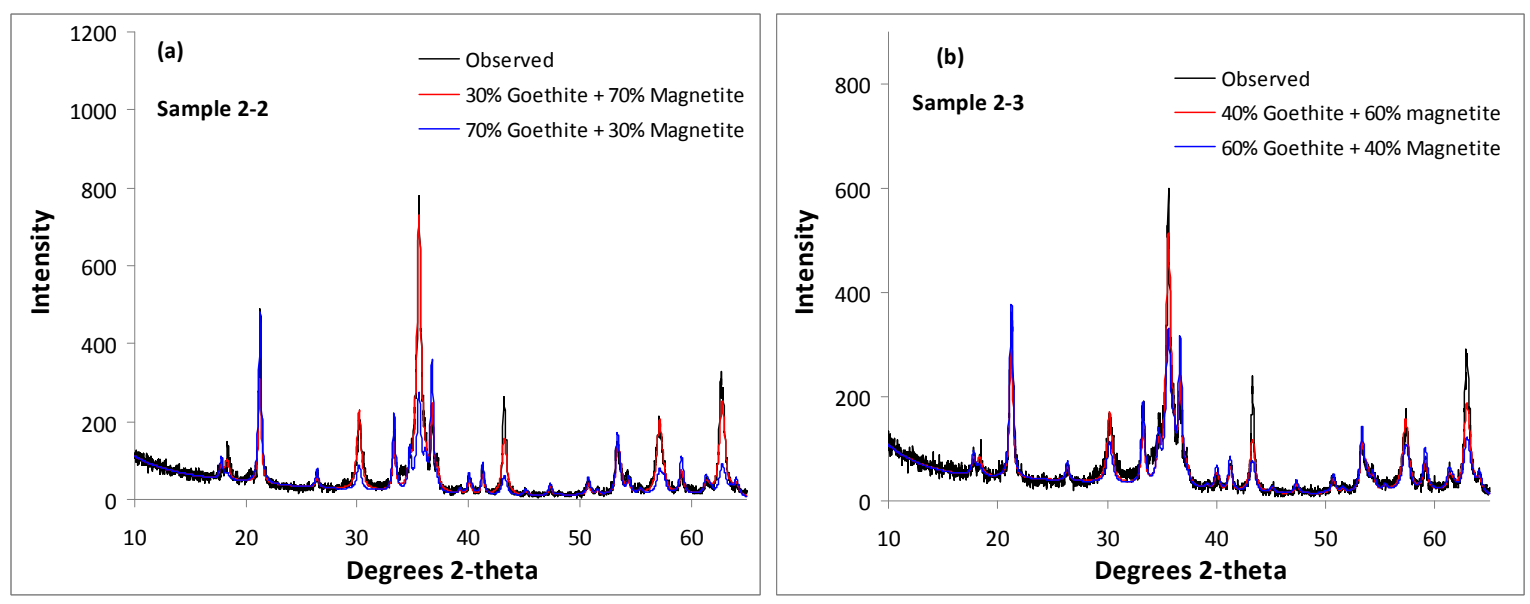

Figure 2.8. Micro X-Ray Diffraction Pattern and Semiquantitative Fit Using Different Ratios Between Goethite and Magnetite for Sample 2-2 (a) and Sample 2-3 (b). Better-fit results are found in Sample 2-2 with 30\% goethite and Sample 2-3 with 40\% goethite, respectively, as shown by the red color.

There are two possible explanations for the formation of magnetite in the Tc-goethite samples without additional $\mathrm{Fe}(\mathrm{II})$ armoring. First, the initial precipitation of ferrous hydroxide, $\mathrm{Fe}(\mathrm{OH})_{2(\mathrm{~s})}$ or white rust, as $\mathrm{pH}$ increases in the $\mathrm{Fe}(\mathrm{II})$-goethite slurry and its rapid mineral transformation to magnetite is possible. Rapid precipitation of $\mathrm{Fe}(\mathrm{OH})_{2(\mathrm{~s})}$ from the $0.07 \mathrm{M} \mathrm{Fe}(\mathrm{II})$ solution, which is the same $\mathrm{Fe}(\mathrm{II})$ concentration used in the Tc-goethite system, can occur when the solution $\mathrm{pH}$ is raised to higher than 7.0 by the addition of $\mathrm{NaOH}(2 \mathrm{M})$, even without goethite being present. The solubility curves for $\mathrm{Fe}(\mathrm{OH})_{3(\mathrm{~s})}$ and $\mathrm{Fe}(\mathrm{OH})_{2(\mathrm{~s})}$, as well as the aqueous Fe(II) concentrations measured in solution, are shown in Figure 2.9. The 
saturation index (SI) for the measured solutions was calculated based on the solubility product of $\mathrm{Fe}(\mathrm{OH})_{2(\mathrm{~s})}$ being $\mathrm{K}_{\mathrm{sp}}=10^{-15}$. The calculated SI was supersaturated with respect to $\mathrm{Fe}(\mathrm{OH})_{2(\mathrm{~s})}$ at $\mathrm{pH}$ higher than 7.0, suggesting that ferrous hydroxide should be actively precipitating. The slurries where the SI calculations were supersaturated with respect to $\mathrm{Fe}(\mathrm{OH})_{2(\mathrm{~s})}$ were in excellent agreement with the XRD spectra of centrifuged solids in tests prepared separately without goethite being present, which suggested the possibility of white rust being present at $\mathrm{pH}=7.5$. The XRD spectra for the precipitate from a test where goethite was not present and only the solution reagents were neutralized beyond $\mathrm{pH} 7.0$ and the standard reference spectra for $\mathrm{Fe}(\mathrm{OH})_{2(\mathrm{~s})}$ are shown in Figure 2.10. The XRD pattern for the precipitate formed agrees well with the $\mathrm{Fe}(\mathrm{OH})_{2(\mathrm{~s})}$ standard reference spectra. Because white rust, $\mathrm{Fe}(\mathrm{OH})_{2(\mathrm{~s})}$, is very unstable, the white rust precipitate that forms in the presence of goethite can be transformed to magnetite and/or goethite immediately with increasing $\mathrm{pH}$ and presence of initial goethite. Second, magnetite can form by the reaction with dissolved $\mathrm{Fe}(\mathrm{III})$ present in the initial $\mathrm{Fe}(\mathrm{II})$-goethite slurry at low $\mathrm{pH}$. There was a noticeable difference between measured masses of Fe(II) and tot Fe after 1 day in the reacted Fe(II)-goethite slurry for Samples 2-2 and 2-3 (Figures 3.2 and 3.3). The difference in solution Fe(II) and total $\mathrm{Fe}$ indicate the presence of dissolved $\mathrm{Fe}$ (III) in the slurry, which can react with $\mathrm{Fe}$ (II) to form magnetite as the $\mathrm{pH}$ increases. However, because of the fast mineral transformation of Fe hydroxides by the catalytic action of aqueous Fe(II), reported by many studies (Cornell and Schwertmann 2003; Pedersen et al. 2005), it is too difficult to distinguish which of these two mechanisms led to the formation of the observed magnetite solids.

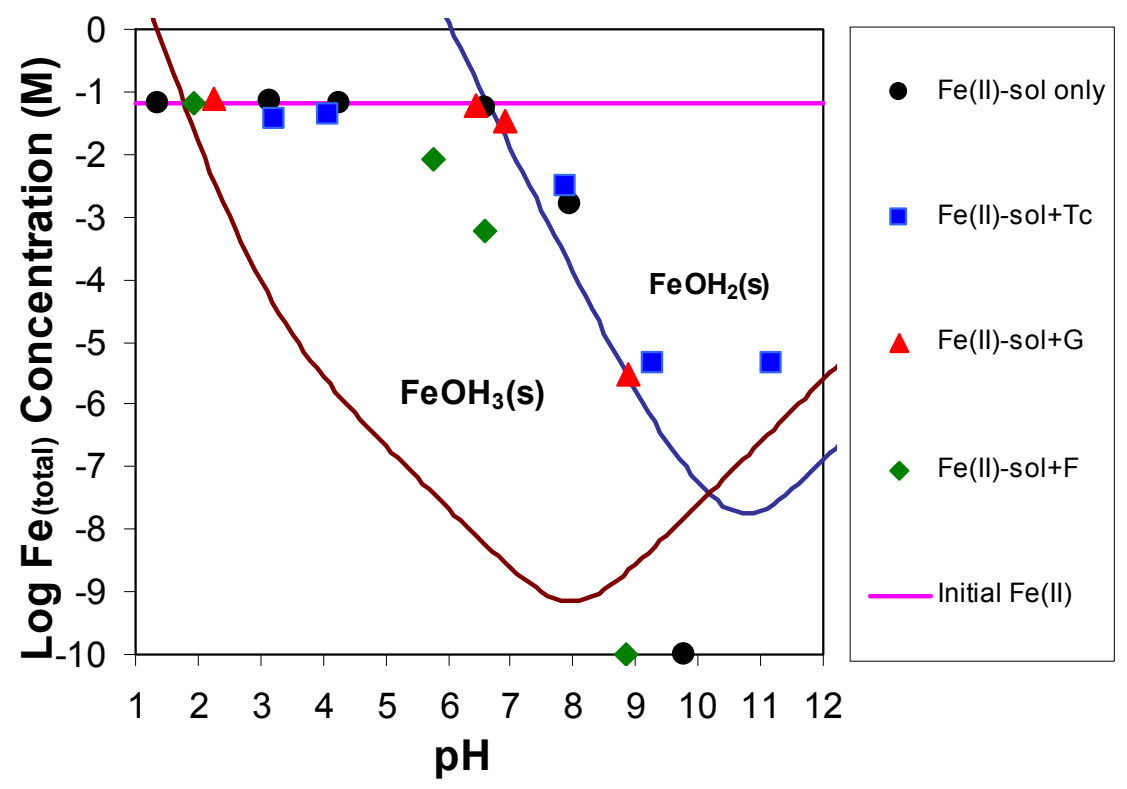

Figure 2.9. Solubility Curves for $\mathrm{Fe}(\mathrm{OH})_{3}(\mathrm{~s})$ and $\mathrm{Fe}(\mathrm{OH})_{2}(\mathrm{~s})$ Along with Measured $\mathrm{Fe}(\mathrm{II})$ Solution Concentrations at Different $\mathrm{pH}$ Levels and with and Without Presence of Goethite $(\mathrm{G})$ and Ferrihydrite (F). The brown line is the calculated solution concentration of Fe(total) controlled by the solubilty of $\mathrm{Fe}(\mathrm{OH})_{3}$ and the blue line is the $\mathrm{Fe}$ (total) controlled by $\mathrm{Fe}(\mathrm{OH})_{2}$. Solubility curves for $\mathrm{Fe}(\mathrm{OH})_{3}(\mathrm{~s})$ and $\mathrm{Fe}(\mathrm{OH})_{2}(\mathrm{~s})$ were calculated based on the stability constants of $\mathrm{Fe}(\mathrm{II}) / \mathrm{Fe}$ (III) hydrolysis species reported by Stumm and Morgan 1995. 


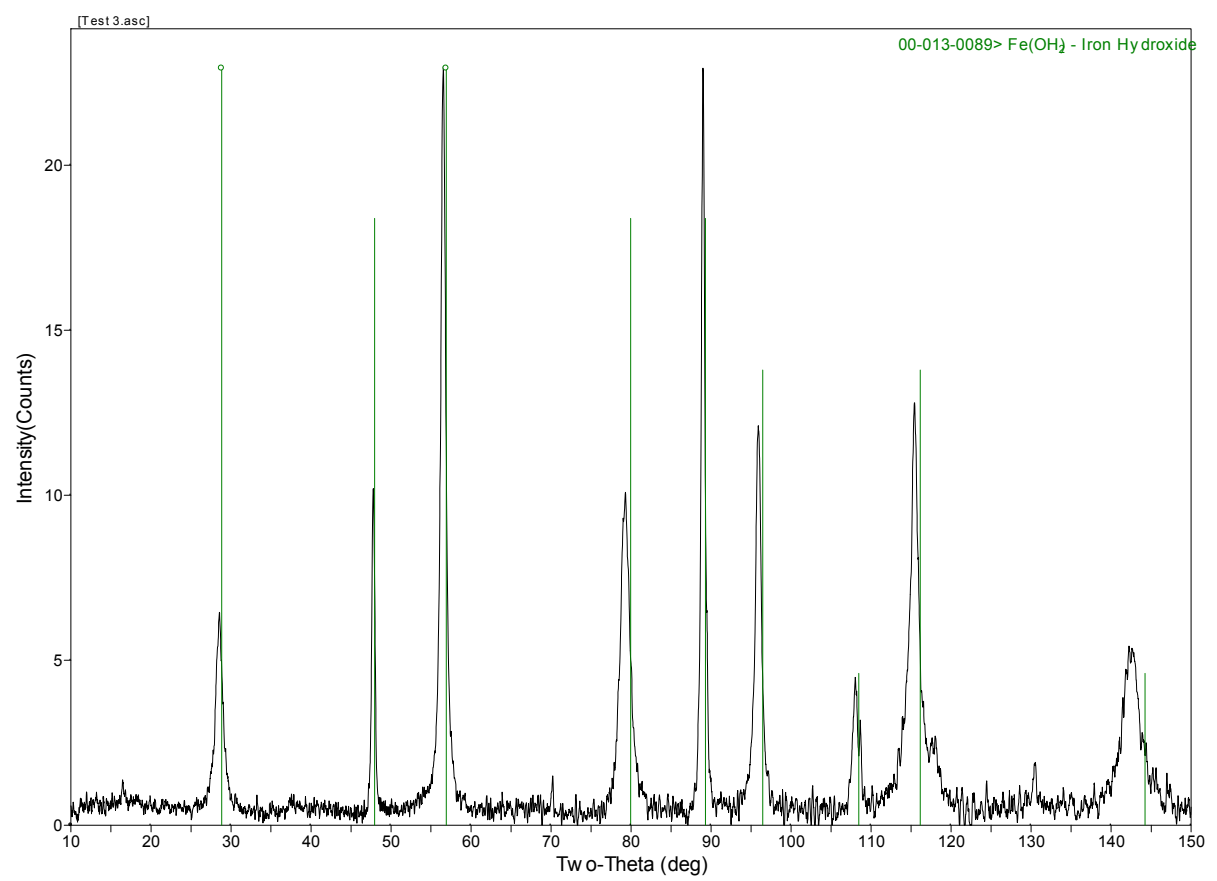

Figure 2.10. Micro X-Ray Diffraction Pattern (black) of White Rust Sample and Reference Pattern (green) of $\mathrm{Fe}(\mathrm{OH})_{2(\mathrm{~s})}$ from JADE PDF Database

Increased XRD peak intensities at 21 degrees 2-theta, indicative of the presence of goethite, were found in the Samples 2-4 and 2-5 prepared with additional Fe(III) armoring process, compared to Samples 2-2 and 2-3 that were prepared without additional Fe(III) (Figure 2.7). Even though synthetic off-gas scrubber solution, which contains $0.8 \mathrm{M}$ of carbonate, was used for the preparation of Tc-goethite Samples 2-3 and 2-4, siderite $\left(\mathrm{FeCO}_{3}\right)$ did not precipitate during these experiments, and it was not present in any of the final Tc-goethite samples (Figure 2.7).

Both initial goethite and the final Tc-goethite solids exhibited the acicular (needle-shaped) shape typical of goethite in SEM images (Figure 2.11, a and d). These goethite particles are larger in size (0.5 to $2 \mu \mathrm{m}$ ) than the attached fine particles, identified as magnetite crystals (Figure $2.11 \mathrm{c}$ ). In addition to the acicular habit, fine particles of goethite are seen aggregated or attached to the main platy or lath-shaped crystals in Sample 2 (Figure 2.11b). The aggregated fine goethite particles may have resulted from a series of reactions involving additional goethite precipitation during the armoring process and/or because of Fe-oxide mineral transformations in Sample 2. Similar acicular-shaped goethite particles were observed in Samples 2-2 and 2-5, but the noted presence of small cubes or pseudocubic crystals, likely magnetite, attached to acicular goethite was only found in Samples 2-2 and 2-3, which is consistent with XRD analysis (Figure 2.7). No cubic-shaped magnetite was found in Sample 2-5 (Figure 2.11d), consistent with the dominance of goethite revealed in the XRD pattern (Figure 2.7). Mineral transformation from magnetite to goethite was found at alkaline $\mathrm{pH}$ conditions (He and Traina 2007), similar to our experimental condition for Sample 2-5 where additional $\mathrm{NaOH}$ was added in the armoring process. There was no maghemite found in any of our samples, but redissolution of maghemite and transformation to goethite at high $\mathrm{pH}$ conditions was also found in the process of magnetite transformation to goethite (He and Traina 2007). 
Additional TEM results revealed similar acicular goethite in Samples 2-2 and 2-3 (Figure 2.12). The elongated shape of goethite particles were readily found in both Tc-goethite Samples 2-2 and 2-3, neither of which were treated with additional Fe(III) to armor the Tc-goethite (Table 2.1). The SAED pattern taken along the $\mathbf{B}[001]$ direction of goethite (Figure 2.12) also clearly indicates the presence of wellcrystallized goethite. Because Samples 2-2 and 2-3 contained a relatively higher Tc concentration per gram of goethite (Table 2.1), Tc was detected in Sample 2-2 by TEM equipped with EDX (Figure 2.12). However, the exact location of Tc on either magnetite or goethite was not clear because the Tc EDX peak was found in the mixture of magnetite and goethite minerals in Sample 2-2. However, an additional Tc EDX peak was found associated with a cubic-shaped particle (magnetite) in Sample 2-3*, which was prepared with high Tc concentration in a different simulant (see Table 2.1 and Section 2.2.2), with a higher Tc concentration. This additional Tc EDX peak suggests that the Tc association with magnetite is preferred over its association with goethite. Silicon was also detected by EDX (Figure 2.12), and likely represents an impurity in the reagents or from the glassware used in the goethite treatment steps. The observed $\mathrm{Cu}$ signal was an artifact resulting from the $\mathrm{Cu}$ TEM sample grid (Figure 2.12). The presence of Tc in the final Tc-goethite product in Sample 2-2 indicates the possibility that Tc is associated as coprecipitates with Fe oxide, either magnetite or goethite (see further discussion below in the XAFS analysis).

The Mössbauer spectra collected at room temperature (Figure 2.13a) did not show the typical sextets feature of goethite (Murad 1982). The Tc-goethite sample (Sample 2 in Table 2.1) at room temperature showed four asymmetrical peaks between -2 and 2 velocities. Two doublet peaks at 0.12 and $0.76 \mathrm{~mm} / \mathrm{s}$ indicated that small-sized goethite particles were present in the Tc-goethite solid, which is consistent with the SEM/TEM results (Figures 2.11 and 2.12). The Mössbauer spectra collected at a low temperature $(77 \mathrm{~K})$ showed a more resolved symmetrical sextets feature and matched well with the simulated goethite spectra (Figure 2.13b). There was no Fe(II) detected in the Mössbauer spectra, confirming that all the Fe present in the final Tc-goethite product was Fe(III) in Sample 2-5. 

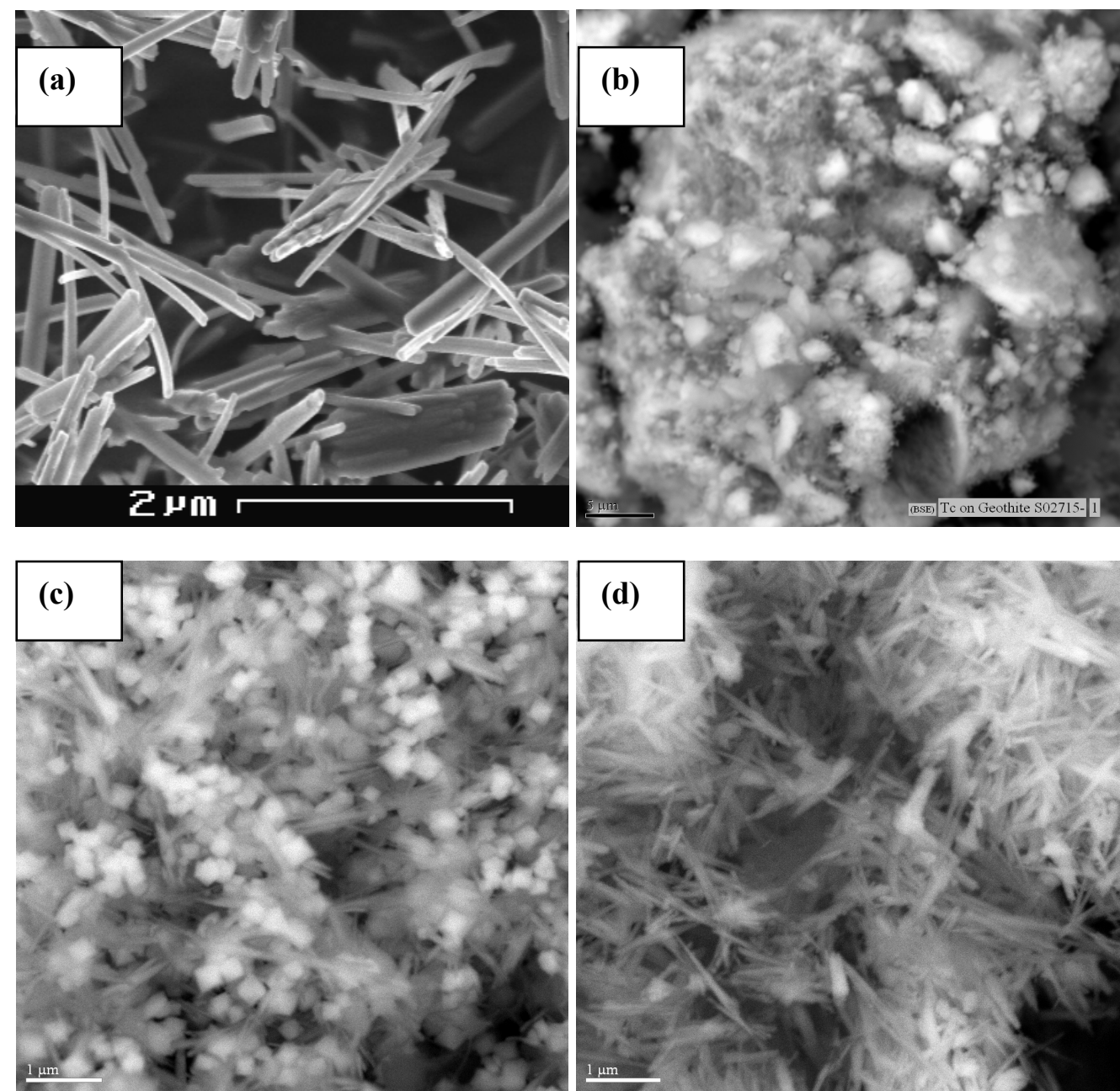

Figure 2.11. SEM Images for Tc-Goethite Samples (a) Initial Goethite; (b) Final Tc-Goethite Sample 2; (c) Final Tc-Goethite Sample 2-2; and (d) Final Tc-Goethite Sample 2-5 

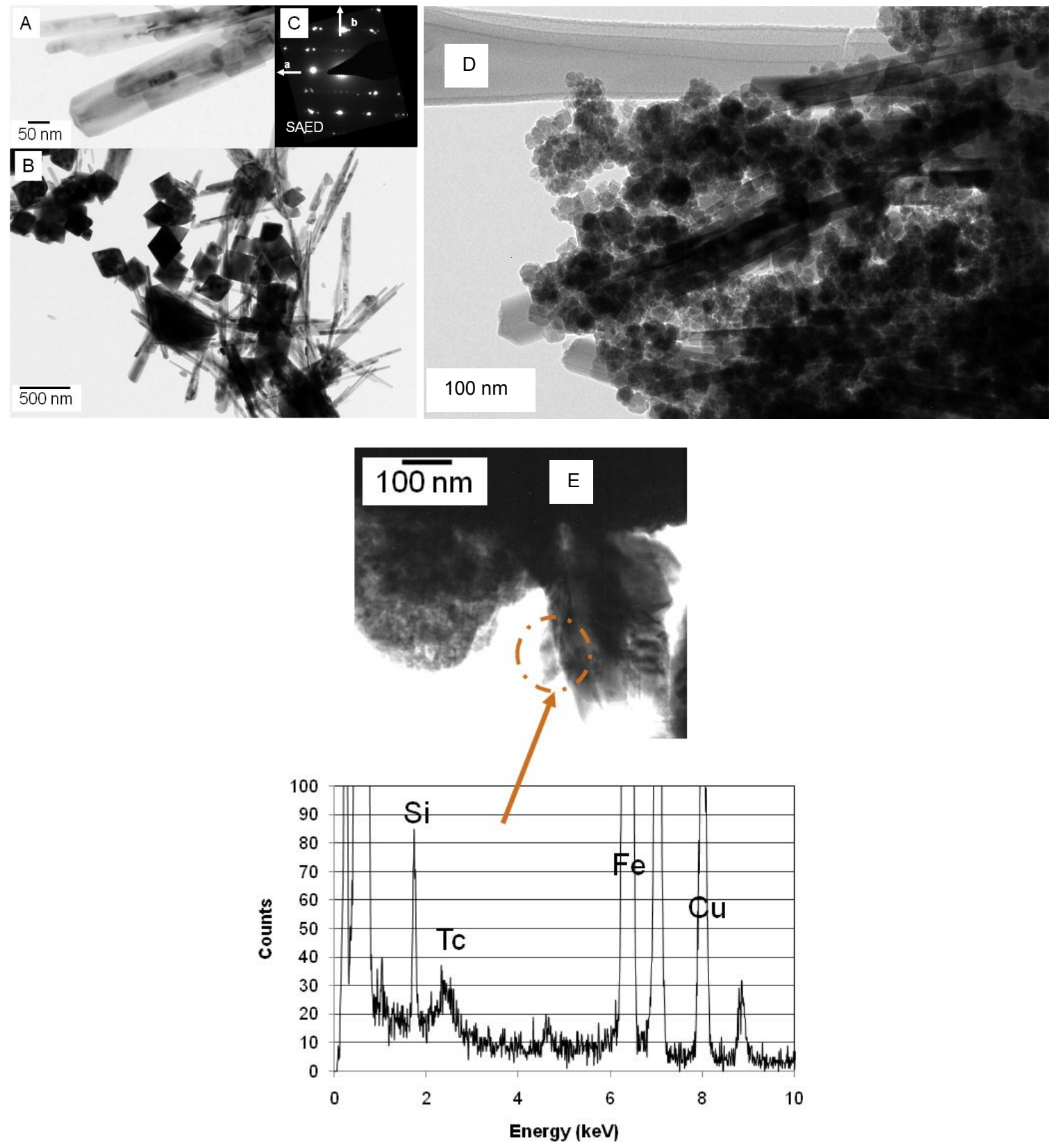

Figure 2.12. TEM Images of Tc-Goethite Samples: (A) High Magnification Image of Tc-Goethite Sample 2-2; (B) Presence of Visible Magnetite with Goethite in Agreement with XRD in Sample 2-2; (C) Electron Diffraction Pattern Taken Along the B[001] Direction of Sample 2-2; (D) TEM Image of Sample 2-3 Showing Both Magnetite and Goethite; and (E) TEM/EDX Analysis of Tc in Sample 2-2. The Tc is identified by the L-lines. The peaks for $\mathrm{Si}$ and $\mathrm{Cu}$ are artifacts of the sample preparation and the specimen holder, respectively. 

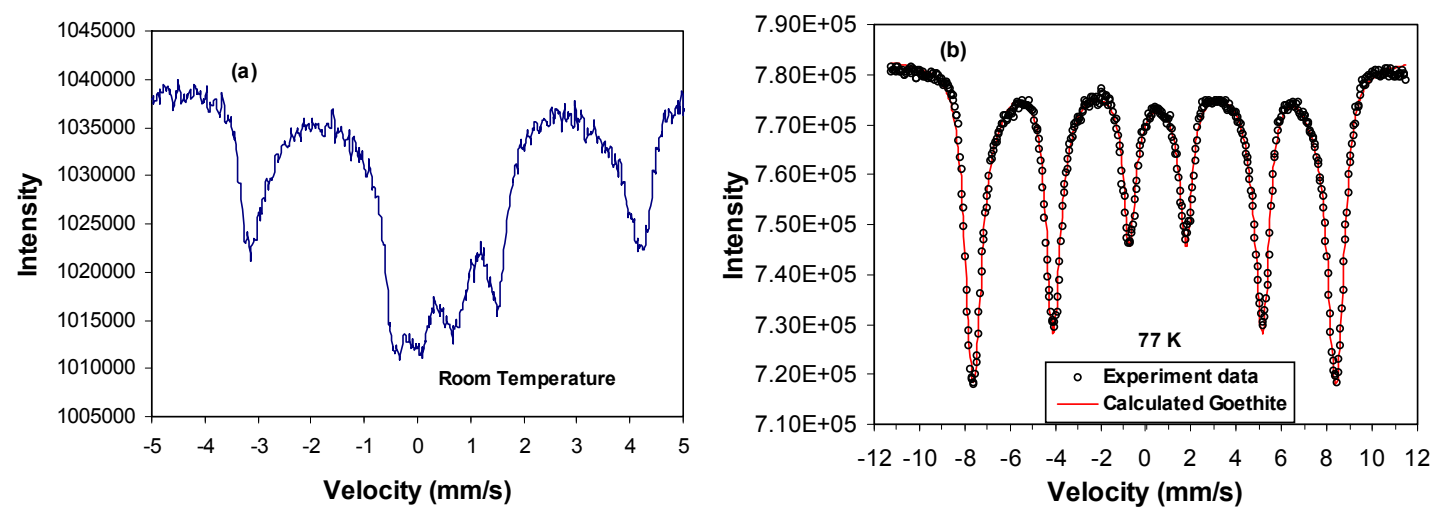

Figure 2.13. ${ }^{57} \mathrm{Fe}$ Transmission Mössbauer spectra of Tc-Goethite Sample 2: (a) Room Temperature; and (b) $77 \mathrm{~K}$ Temperature. Calculated goethite spectrum was obtained with the Recoil software using a Voight-based structural filtering routine (Rancourt and Ping 1991).

\subsubsection{XAFS Analysis of Tc in Tc-Goethite}

The XANES spectra for the following Tc standards, $\mathrm{KTcO}_{4}, \mathrm{NaTcO}_{4}, \mathrm{TcO}_{4}{ }^{-}$adsorbed on ReillexHPQ resin, and $\mathrm{TcO}_{2} \cdot 2 \mathrm{H}_{2} \mathrm{O}$, along with the Tc-goethite Samples 2, 2-2, 2-3*, and 2-5, are shown in Figure 2.14. The spectra for $\mathrm{NaTcO}_{4}, \mathrm{KTcO}_{4}$, and $\mathrm{TcO}_{4}{ }^{-}$adsorbed on ion-exchange resin are very similar and characterized by a strong pre-edge feature due to the $1 \mathrm{~s}$ to $4 \mathrm{~d}$ transition, which is allowed for the tetrahedral $\mathrm{TcO}_{4}{ }^{-}$anion. The XANES spectrum of $\mathrm{TcO}_{2} \cdot 2 \mathrm{H}_{2} \mathrm{O}$ is very different and characteristic of $\mathrm{Tc}(\mathrm{IV})$ coordinated by 6 oxygen atoms in an octahedral geometry. In addition, the absorption edge of $\mathrm{TcO}_{2} \cdot 2 \mathrm{H}_{2} \mathrm{O}$ is $5.5 \mathrm{eV}$ lower in energy than the absorption edge of $\mathrm{TcO}_{4}^{-}$. The oxidation state of $\mathrm{Tc}$ in the Tc-goethite samples was determined by fitting their XANES spectra using the spectra of $\mathrm{TcO}_{4}{ }^{-}$adsorbed on Reillex-HPQ resin and $\mathrm{TcO}_{2} \cdot 2 \mathrm{H}_{2} \mathrm{O}$ as the Tc standards (Figure 2.14). In all cases, the results of fitting indicated that only Tc(IV) was present in Samples 2, 2-2, 2-3*, and 2-5.

The $\mathrm{k}^{3}$-weighted EXAFS spectra and Fourier Transforms for Samples 2, 2-2, 2-3*, and 2-5 solids before leaching are presented in Figure 2.15. The numerical fitting results are in Table 2.4. As described in Section 2.1.6, three different models were examined and the interatomic distances were allowed to vary in the fitting process. Therefore, if the distances between Tc and the neighboring atoms did not correspond to the model, the structure was free to relax.

In all cases, the local environment of Tc is consistent with Tc replacing $\mathrm{Fe}$ in the goethite lattice. This is best illustrated by comparing the Tc local environment to the Fe environment in "pure" goethite, which is also presented in Table 2.4. The main difference between the local environment of Tc in the Tc-goethite and that of Fe in "pure" goethite is that in "pure" goethite, there are two sets of two iron atoms at 3.01 and $3.28 \AA$, while in the structure determined by EXAFS for the Tc-goethite solids, there are four iron atoms at an intermediate distance, $3.1 \AA$. This difference could be either an inability to resolve the two sets of iron neighbors in the EXAFS analysis of the Tc-geothite solids or could be due to disorder in the local environment of Tc-goethite caused by the Tc substituting for Fe. In addition to this slightly changed distance, Sample 2 also displays additional scattering due to a Tc neighbor at $2.51 \AA$, which is not consistent with a neighboring Tc in the goethite lattice. This distance, however, is consistent with the presence of $\mathrm{TcO}_{2} \cdot 2 \mathrm{H}_{2} \mathrm{O}$, and is attributed to the presence of residual $\mathrm{Tc}(\mathrm{IV})$ not incorporated into the goethite lattice in Sample 2. 


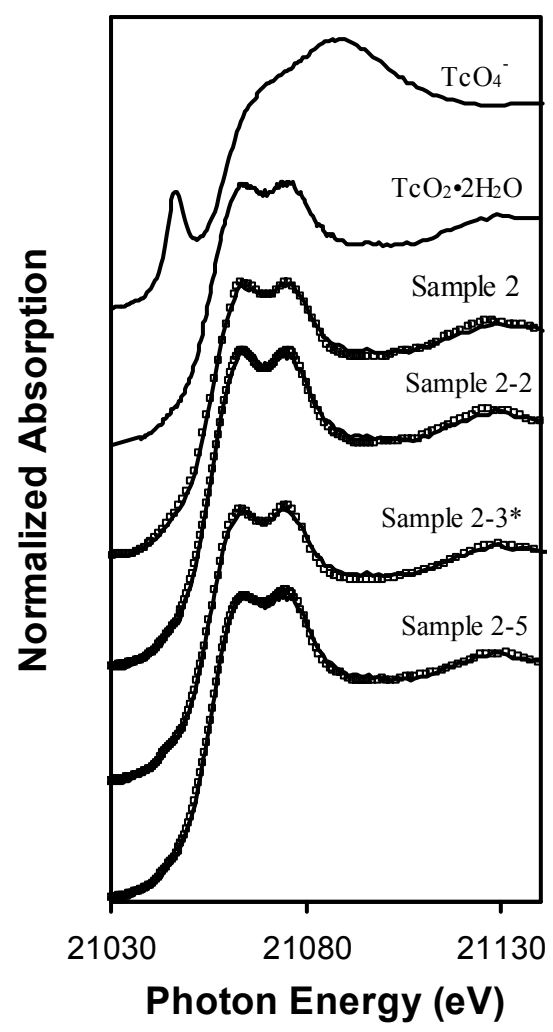

Figure 2.14. Normalized XANES Spectra for Tc(VII) and Tc(IV) Standards and Tc-Goethite Samples. Sample 2-3* was prepared in simulant-3 with high Te(VII) concentration, $4.2 \times 10^{-4} \mathrm{M}$ and $0.1 \mathrm{M}$ Fe(II), without additional armoring. The black symbols (rectangles) and the solid line in Tc-goethite spectra indicate the measured data and a linear combination fit, respectively.
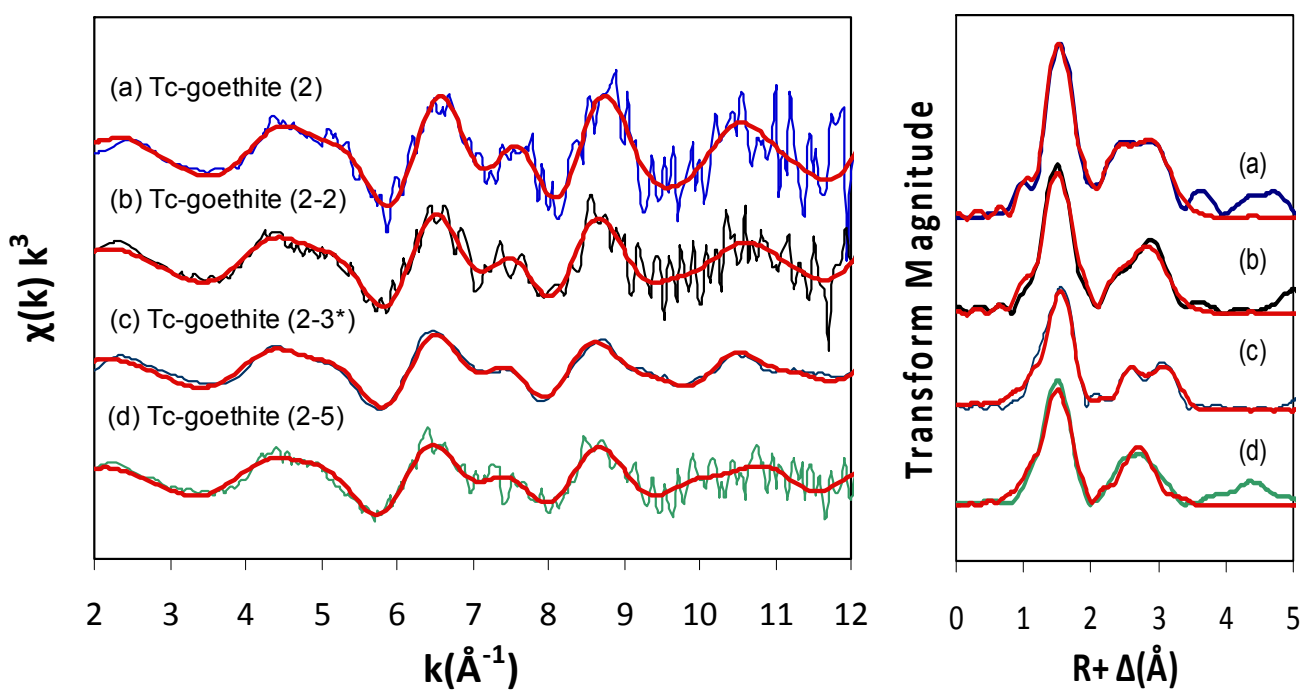

Figure 2.15. EXAFS Spectra (left) and Their Fourier Transforms (right) for Tc-Goethite Samples. (a) Sample 2; (b) Sample 2-2; (c) Sample 2-3*; and (d) Sample 2-5. Sample 2-3* was prepared in simulant-3 with high Tc(VII) concentration, $4.2 \times 10^{-4} \mathrm{M}$ and $0.1 \mathrm{M} \mathrm{Fe}(\mathrm{II})$ without additional armoring. The fits are shown as the bold red lines and the measured data are shown as the different colored lines. 
Table 2.4. Structural Parameters of Tc Derived from EXAFS Analysis

\begin{tabular}{ccccccc}
\hline Samples & $\begin{array}{c}\text { Neighbor } \\
\text { Atoms }\end{array}$ & $\mathrm{CN}$ & $\mathrm{R}(\AA)$ & $\sigma^{2}$ & $\Delta \mathrm{E}_{0}$ & $\mathrm{p}(\mathrm{F})$ \\
\hline Tc-Goethite Sample & $\mathrm{O}$ & 6 & $2.017(5)$ & $0.0023(3)$ & $0(1)$ & $<0.001$ \\
2 & $\mathrm{Fe}$ & 4 & $3.074(8)$ & $0.0064(6)$ & $0(1)$ & $<0.001$ \\
(R-factor $=$ & $\mathrm{Fe}$ & 4 & $3.52(2)$ & $0.0064(6)^{\mathrm{b}}$ & $0(1)$ & $<0.001$ \\
$0.006)$ & $\mathrm{Tc}$ & $0.5(2)$ & $2.51(2)$ & $0.0064(6)^{\mathrm{b}}$ & $0(1)$ & 0.046 \\
\hline Tc-Goethite & $\mathrm{O}$ & 6 & $2.020(6)$ & $0.0040(4)$ & $-2(1)$ & $<0.001$ \\
Sample 2-2 & $\mathrm{Fe}$ & 4 & $3.09(1)$ & $0.0084(7)$ & $-2(1)$ & $<0.001$ \\
(R-factor $=0.011)^{\mathrm{Fe}}$ & 4 & $3.53(1)$ & $0.0084(7)^{\mathrm{b}}$ & $-2(1)$ & $<0.001$ \\
\hline Tc-Goethite & $\mathrm{O}$ & 6 & $2.014(8)$ & $0.0049(5)$ & $-3(2)$ & $<0.001$ \\
Sample 2-3* & $\mathrm{Fe}$ & 4 & $3.08(2)$ & $0.013(2)$ & $-3(2)$ & $<0.001$ \\
(R-factor $=0.033)^{*}$ & $\mathrm{Fe}$ & 4 & $3.54(2)$ & $0.008(1)$ & $-3(2)$ & $<0.001$ \\
\hline Tc-Foethite & $\mathrm{O}$ & 6 & $2.02(1)$ & $0.0060(6)$ & $-2(1)$ & $<0.001$ \\
Sample 2-5 & $\mathrm{Fe}$ & 4 & $3.10(2)$ & $0.009(1)$ & $-2(1)$ & $<0.001$ \\
(R-factor $=0.037)^{\mathrm{F}}$ & $\mathrm{Fe}$ & 4 & $3.53(5)$ & $0.017(6)$ & $-2(1)$ & 0.25 \\
\hline Goethite $^{(\mathrm{a})}$ & $\mathrm{O}$ & 6 & $1.95-2.09$ & & & \\
& $\mathrm{Fe}$ & 2 & 3.01 & & & \\
& $\mathrm{O}$ & 1 & 3.23 & & & \\
\hline & $\mathrm{Fe}$ & 2 & 3.28 & & & \\
\hline
\end{tabular}

Sample 2-3* was prepared in simulant SSS-3 with high Tc(VII) concentration, $4.2 \times 10^{-4} \mathrm{M}$ and $0.1 \mathrm{M} \mathrm{Fe}(\mathrm{II})$, without additional armoring. $\mathrm{S}_{\mathrm{o}}{ }^{2}=1.0$; coordination number $(\mathrm{CN})$; interatomic distance $(\mathrm{R})$; disorder parameter $\left(\sigma^{2}\right)$; energy shift $\left(\Delta \mathrm{E}_{0}\right)$; goodness of fit parameter (R-factor); F-test $[\mathrm{p}(\mathrm{F})]$. For more details about F-test interpretations, see Downward et al. (2006).

(a) Goethite from Szytulstroka et al. (1968).

A similar local environment for $\mathrm{Tc}$ in iron oxides was observed previously in $\mathrm{TcO}_{4}{ }^{-}$reduced using green rust (Pepper et al. 2003). In that case, the initial Tc environment was consistent with Tc incorporated into the lattice of green rust and after the green rust was oxidized, the coordination environment was consistent with Tc substituted for Fe in goethite, because of mineral transformation from the green rust to goethite. The Tc-Fe distances in the oxidized products are very similar to those determined here, although the previously reported Tc-Fe coordination numbers for the oxidized green rust and goethite (Pepper et al. 2003) are smaller than ours.

The local environment of Tc in goethite is distinctly different from that of Tc adsorbed on the surfaces of iron oxides. Peretyazhko et al. (2009) examined Tc(IV) adsorbed on both goethite and hematite. In both cases, a complex coordination geometry was observed with a first shell consisting of six oxygen atoms at $2 \AA$, a neighboring metal atom (either Tc or Fe) at $2.6 \mathrm{~A}$, three oxygen atoms at $3 \AA$, and two iron atoms at $3.5 \AA$. A similar local environment was also observed for Tc adsorbed on ferrihydrite (Zachara et al. 2007). In comparison to these previous reports, it is unlikely that Tc in our Tc-goethite samples is adsorbed onto the iron oxide mineral surfaces.

While the local environment of Tc in our Tc-goethite is distinctly different from Tc adsorbed onto the surface of iron oxides, it is not necessarily distinct from Tc incorporated into other iron oxides. The 
distances of Tc to neighboring atoms in Tc-goethite are similar to those of the octahedral site in magnetite: six oxygen atoms at $2.06 \AA$, six iron atoms at $2.97 \AA$, and six iron atoms at $3.48 \AA$. Although it may be possible to distinguish these two possibilities using the numbers of neighboring iron atoms, this is not done here because coordination numbers determined by EXAFS are not particularly accurate and can be lower than expected if some portion of the Tc is adsorbed on the surface rather than incorporated into the lattice. However, in the case of the Tc-goethite samples examined here-especially Samples 2 and 2-5, which were prepared with additional armoring-assignment of Tc in the final Tc-goethite product, rather than magnetite, is made for the following reasons. First, the Tc-Fe distances in the samples examined here are all similar and somewhat longer than those of the octahedral magnetite site and are more similar to the goethite model. Second, goethite is a major mineral found in those samples (Figure 2.7). However, because magnetite is a major phase (60\% to 70\%) in Samples 2-2 and 2-3

(Figure 2.8) and magnetite can be transformed to goethite by additional armoring process (He and Traina 2007), the possibility of initial removal of Tc by magnetite that can then be transformed to goethite cannot be ruled out. Even though the EXAFS results of Samples 2 and 2-5 are very similar to those found in Samples 2-2 and 2-3 where magnetite and goethite mixture are found, recent new findings of SEM/EDX for Tc location in Sample 2-3* prepared with high Tc concentration and simulant-3 (see Section 2.2.2) without the additional armoring process show that Tc is more closely associated with the cubic-shaped magnetite particles rather than the acicular-shaped goethite. Because of the complex mixture of these two minerals (magnetite and goethite in Tc-goethite samples prepared without the armoring process), more characterization tests are still needed to identify the Tc location in each specific mineral.

Overall, the EXAFS data are consistent with Tc being incorporated into an iron oxide, most likely magnetite or goethite as a Tc-goethite final product, rather than Tc being adsorbed onto the surface of iron oxide particles. In addition, minor amounts of $\mathrm{TcO}_{2} \cdot 2 \mathrm{H}_{2} \mathrm{O}$ solid present in Sample 2 are attributed to residual $\mathrm{Tc}(\mathrm{IV})$ not being incorporated into the goethite lattice and forming discrete $\mathrm{TcO}_{2} \cdot 2 \mathrm{H}_{2} \mathrm{O}$ upon drying. The $\mathrm{TcO}_{2} \cdot 2 \mathrm{H}_{2} \mathrm{O}$ not incorporated into the goethite lattice can be easily reoxidized upon contact with atmospheric oxygen (Lukens et al. 2005; Zachara et al. 2007). However, the EXAFS result for Sample 2-5 confirmed almost total Tc co-precipitation within the goethite lattice rather than showing Tc adsorbed onto the surfaces of goethite or Tc as a discrete $\mathrm{TcO}_{2} \cdot 2 \mathrm{H}_{2} \mathrm{O}$ solid phase. Finding only Tc coprecipitation within goethite lattices in Sample 2-5 is consistent with the Tc leaching results for Sample 2-5 in IDF pore water (see leaching results below) that shows the least Tc release.

\subsubsection{Tc(VII) Sequestration by Fe(II)-Goethite with Different Simulants and Conditions}

\subsubsection{Tc(VII) and Fe(II) Removal in Solutions Containing No Goethite}

Changes in dissolved Fe(II) and Tc concentrations in the final supernatant solution were also investigated as a function of $\mathrm{pH}$ without the presence of Fe-oxide minerals. Results are shown in Figure 2.16. Dissolved Fe(II) and Fe(tot) concentrations in solution were stable (remained at the initial concentrations) when $\mathrm{pH}$ was below 4.5 , thereby indicating that most of the Fe in solution existed as $\mathrm{Fe}$ (II) (Figure 2.16, left). However, the dissolved Fe(II) concentration decreased with increasing $\mathrm{pH}$ and reached nearly zero in solutions with $\mathrm{pH}$ higher than 8.0. Total dissolved Fe concentrations showed the same decreasing trend with increasing $\mathrm{pH}$, and the values were similar to or slightly higher than those for dissolved $\mathrm{Fe}$ (II) concentrations, indicating that $\mathrm{Fe}$ (III) concentrations were negligible in these solutions. Also, no detectable $\mathrm{Fe}(\mathrm{II})$ and $\mathrm{Fe}(\mathrm{tot})$ concentrations were found in solution at $\mathrm{pH}$ higher than 8.0. 

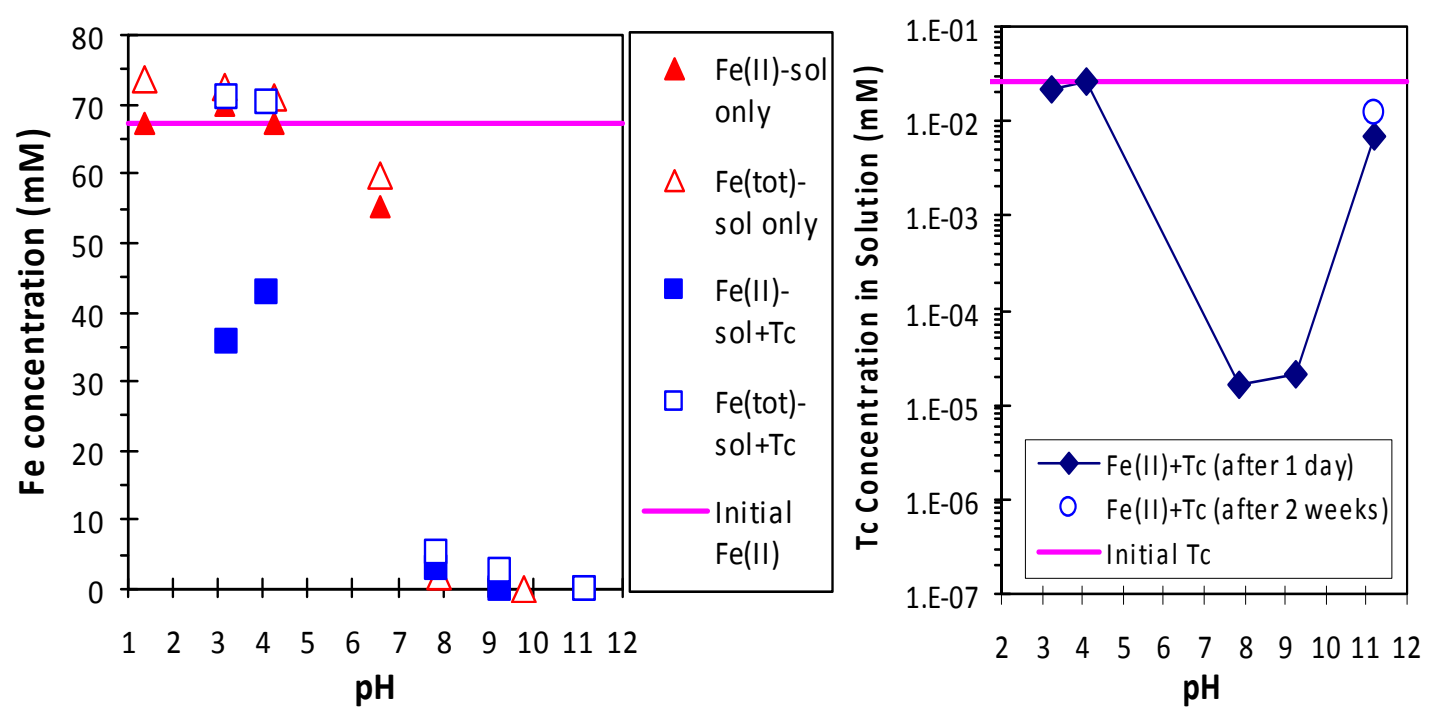

Figure 2.16. Dissolved $\mathrm{Fe}(\mathrm{II})$ and $\mathrm{Fe}$ (tot) Concentrations in Solutions with and Without $\mathrm{Tc}(\mathrm{VII})$ at Different pHs Without Fe(III) Oxide Solids (left) and Tc Removal in Fe(II) Solution Without Fe(III) Oxide Solids at Different pHs (right)

There were minor differences between total $\mathrm{Fe}$ and $\mathrm{Fe}(\mathrm{II})$ concentrations in solution when the $\mathrm{pH}$ was below 4.5, suggesting that minor amounts of Fe(III) could be present in these more acidic solutions. All the experiments were conducted inside an anaerobic chamber that was monitored for oxygen concentrations. Small amounts of oxygen were measured in the chamber during the experiments; thus, one cannot eliminate the possibility that small amounts of $\mathrm{Fe}(\mathrm{II})$ were oxidized to $\mathrm{Fe}(\mathrm{III})$. The greater removal of dissolved $\mathrm{Fe}(\mathrm{II})$ at $\mathrm{pHs}$ higher than 7.0 was attributed to the precipitation of $\mathrm{Fe}(\mathrm{II})$ hydroxide as $\mathrm{Fe}(\mathrm{OH})_{2(\mathrm{~s})}$ (white rust). Independently prepared $\mathrm{Fe}(\mathrm{II})$ precipitate at $\mathrm{pH}=7.5$ from a similar solution showed an identical XRD pattern to crystalline $\mathrm{Fe}(\mathrm{OH})_{2(\mathrm{~s})}$ (white rust) (Figure 2.10).

Dissolved Fe(II) concentrations were slightly different in solutions in the absence or presence of Tc in solution. Lower concentrations of dissolved Fe(II) were found even at low pH levels (3.2 and 4.1) when Tc was also present (Figure 2.16, left), in comparison to acidic solutions (below pH 5.0) containing only $\mathrm{Fe}(\mathrm{II})$. When $\mathrm{Tc}$ is not present in solution, dissolved $\mathrm{Fe}(\mathrm{II})$ concentrations at these $\mathrm{pH}$ levels were stable and similar to both the initial Fe(II) and total Fe concentrations. Because no Tc(VII) had been added to the Fe(II)- only solutions, no significant redox reactions occurred in which Fe(II) would be oxidized to $\mathrm{Fe}(\mathrm{III})$ (Figure 2.16, left). As mentioned, there could have been some minor oxidation of Fe(II) from oxygen absorption in the solution. However, when Tc(VII) and oxygen contamination were also present in the solution, there was a driver for oxidation of $\mathrm{Fe}(\mathrm{II})$ as shown by the noticeable difference between measured $\mathrm{Fe}$ (II) and $\mathrm{Fe}$ (tot) concentrations even at low $\mathrm{pH}(<5.0)$. Because the $\mathrm{Fe}($ tot $)$ concentration in $\mathrm{Fe}(\mathrm{II})+\mathrm{Tc}(\mathrm{VII})$ test solution at low $\mathrm{pH}$ levels $(<5.0)$ showed the same concentration as the initial $\mathrm{Fe}(\mathrm{II})$, the concentrations of dissolved ferric iron, $\mathrm{Fe}(\mathrm{III})$, at low $\mathrm{pH}$ levels could be determined by the difference between measured $\mathrm{Fe}$ (II) and $\mathrm{Fe}$ (tot) concentrations in $\mathrm{Fe}(\mathrm{II})+\mathrm{Tc}(\mathrm{VII})$ test solutions. The calculated $\mathrm{Fe}(\mathrm{III})$ concentration in the $\mathrm{Fe}(\mathrm{II})+\mathrm{Tc}$ (VII) test solutions was about $50 \%$ and $40 \%$ of initial $\mathrm{Fe}$ (II) concentration added to the test tubes at $\mathrm{pH}=3.2$ and 4.1 , respectively. The mass of $\mathrm{Tc}(\mathrm{VII})$ added to the solutions was less than $0.1 \%$ of the mass of starting Fe(II) so that even if all the Tc(VII) was reduced to Tc(IV), the three electrons that each mole of Tc requires to be reduced would be supplied easily by the oxidation of minor amounts of $\mathrm{Fe}(\mathrm{II})$. Complete reduction of all the $\mathrm{Tc}(\mathrm{VII})$ present in the solution would 
not require nearly as much $\mathrm{Fe}(\mathrm{II})$ to be oxidized to $\mathrm{Fe}(\mathrm{III})$ as suggested by the apparent ingrowth of $\mathrm{Fe}$ (III) calculated from the difference in the measured total $\mathrm{Fe}$ and measured $\mathrm{Fe}$ (II) remaining in these solutions . Therefore, transformation of the Fe(II) to Fe(III) might result from redox reactions between $\mathrm{Fe}(\mathrm{II})$ and the oxygen contamination within the Tc(VII) spike solution. Negligible Tc removal from solution at these pHs (Figure 2.16, right) suggests that most of the formation of Fe(III) was caused by oxygen contamination. Independent SI calculations suggest that at the concentrations of Tc in these tests, precipitation of $\mathrm{TcO}_{2} \cdot \mathrm{xH}_{2} \mathrm{O}$ would not occur until $\mathrm{pH}$ values were above 11. Further, the slightly decreased $\mathrm{Fe}$ (III) concentration calculated (from the difference between $\mathrm{Fe}$ (II) and $\mathrm{Fe}$ (tot) concentrations) at the $\mathrm{pH}(\sim 4.1)$ in $\mathrm{Fe}(\mathrm{II})+\mathrm{Tc}(\mathrm{VII})$ solution (Figure 2.16, left) suggests that minor amounts of $\mathrm{Fe}(\mathrm{OH})_{3(\mathrm{~s})}$ precipitation might have started at this $\mathrm{pH}$, even though no visible precipitate was observed in the acidic solutions during these experiments. However, dark green magnetic precipitates were also formed and precipitated out of solution in the tests at higher $\mathrm{pH}$ levels $(>7.0)$ in the $\mathrm{Fe}(\mathrm{II})+\mathrm{Tc}(\mathrm{VII})$ tests. These neophases exhibited magnetic properties and were attracted to the magnetic stirring bar used to stir the slurry. The dark green precipitate was likely a mixture of green rust (layered hydrous oxides containing both $\mathrm{Fe}(\mathrm{II})$ and $\mathrm{Fe}$ (III) and with interlayer anions) and magnetite that resulted from mineral transformation of initial precursor, white rust, $\mathrm{Fe}(\mathrm{OH})_{2(\mathrm{~s})}$ after reacting with dissolved $\mathrm{Fe}(\mathrm{III})$ at high $\mathrm{pH}$. The green precipitate (green rust) also can be formed from both dissolved Fe(II) and Fe(III), which transform quickly to more crystalline ferric oxides dominated by magnetite with minor contents of goethite as were found in the SEM/TEM photos for Samples 2-2 and 2-3 (Figures 2.11 and 2.12). However, this mineral transformation sequence occurs so fast that it cannot be distinguished in this batch test. For high $\mathrm{pH}$ solutions (i.e., $\mathrm{pH}>7.5$ ), dissolved Fe(II) and Fe(tot) concentrations in $\mathrm{Fe}(\mathrm{II})+\mathrm{Tc}(\mathrm{VII})$ solutions were identical and very low, suggesting that essentially all the Fe was precipitated and removed in solution as solid phases.

The concentration of Tc in solution followed a similar trend to that of dissolved Fe(tot) concentrations with varying $\mathrm{pH}$ levels up to 9.0 (Figure 2.16, right). There was no Tc removal in test solutions at low $\mathrm{pH}$ levels (3.2 and 4.1), even though Tc(VII) was expected to be reduced to Tc(IV) by Fe(II) present in solution (Figure 2.16, right). At higher $\mathrm{pH}$ levels (> 7.0), most of the $\mathrm{Tc}(\mathrm{VII})$ in solution was removed by surface-catalyzed reduction by the newly precipitated Fe(II/III) oxides. The final precipitate that dominates in the final Samples 2-2 and 2-3 appears to be magnetite that forms from phase transformation of white rust, $\mathrm{Fe}(\mathrm{OH})_{2(\mathrm{~s})}$ or green rust, or direct precipitation of dissolved $\mathrm{Fe}(\mathrm{II}) / \mathrm{Fe}(\mathrm{III})$.

The lower percentage of Tc removal in solution (or higher Tc concentration remaining in solution) at $\mathrm{pH} 11.2$ after 1 day of reaction (only $69 \%$ of Tc removal from solution; see Figure 2.16, right) was most likely caused by Tc(IV) reoxidation from minor oxygen contamination entering the test tube. Because we found no detectable $\mathrm{Fe}(\mathrm{II})$ or $\mathrm{Fe}(\mathrm{tot})$ concentrations at this high $\mathrm{pH}$ after 1 day of reaction, dissolution of $\mathrm{Fe}(\mathrm{III})$ oxides with subsequent reoxidation of Tc(IV) did not contribute to this increased Tc(VII) concentration in solution at $\mathrm{pH}=11.2$. There was even less $\mathrm{Tc}$ removal from the test solution ( $45 \% \mathrm{Tc}$ removal from solution) after 2 weeks of reaction time (Figure 2.16, right) because of reoxidation of Tc(IV) at longer reaction time where oxygen diffuses into the tubes. This indicates that $\mathrm{Tc}(\mathrm{VII})$ can be reduced to $\mathrm{Tc}(\mathrm{IV})$ by Fe(II)-bearing Fe oxide precipitates, but that the reduced $\mathrm{Tc}(\mathrm{IV})$ can be also easily reoxidized to $\mathrm{Tc}(\mathrm{VII})$ in solution when even low concentrations of oxygen contact the solids at high $\mathrm{pH}$ solution. 


\subsubsection{Technetium and Fe(II) Removal from Solution when Goethite or Ferrihydrite is Present}

Removal of $\mathrm{Fe}(\mathrm{II})$ and $\mathrm{Tc}(\mathrm{VII})$ from solution in the presence of goethite or ferrihydrite was also investigated at varying $\mathrm{pH}$ levels. At low $\mathrm{pH}$ after 1 day of contact, $\mathrm{Fe}$ (II) concentrations remained at the starting levels, suggesting that adsorption onto either goethite or ferrihydrite was negligible (Figure 2.17, left). Adsorption of $\mathrm{Fe}(\mathrm{II})$ onto goethite was insignificant up to $\mathrm{pH}=6.8$, based on the dissolved $\mathrm{Fe}(\mathrm{II})$ concentration, which showed only minor decreases compared to concentration initially added to the slurry. Further, the slightly lower Fe(II) concentration than the initial Fe(II) concentration in solution in the presence of goethite at $\mathrm{pH}=6.8$ (Figure 2.17, left) was also similar to $\mathrm{Fe}$ (II) concentration in solution conducted at $\mathrm{pH}=6.8$ without goethite (Figure 2.17, left). This indicates that $\mathrm{Fe}(\mathrm{II})$ adsorption onto geothite did not contribute significantly to the decrease of Fe(II) concentration at $\mathrm{pH}$ values up to near 6.8 because the same Fe(II) decrease was observed when no geothite was present in solution. Thus, the decreased $\mathrm{Fe}(\mathrm{II})$ concentration in solution with or without goethite was attributed to $\mathrm{Fe}(\mathrm{OH})_{2(\mathrm{~s})}$ precipitation rather than $\mathrm{Fe}(\mathrm{II})$ adsorption onto goethite surfaces. In addition, at $\mathrm{pH}$ values $>6.8$, the $\mathrm{Fe}(\mathrm{II})$ and $\mathrm{Fe}$ (tot) concentrations dropped dramatically with increasing $\mathrm{pH}$ values whether goethite was present or not (Figures 2.16 and 2.17), which is also consistent with rapid precipitation of $\mathrm{Fe}(\mathrm{OH})_{2(\mathrm{~s}) \text {. }}$ However, $\mathrm{Fe}(\mathrm{II})$ removal from solution in the presence of ferrihydrite showed more significant $\mathrm{Fe}(\mathrm{II})$ concentration decreases even at $\mathrm{pH}=5.7$ (Figure 2.17, left). Based on the trend when goethite and ferrihydrite were not present and even when goethite was present, decreasing Fe(II) solution concentrations (Figure 2.17, left) occurred only when $\mathrm{pH}$ exceeded 6.8. Therefore, finding significant decreases in $\mathrm{Fe}(\mathrm{II})$ solution concentrations at $\mathrm{pH}=5.7$ in the tests with ferrihydrite present (Figure 2.17, left) suggests that $\mathrm{Fe}(\mathrm{II})$ adsorption is occurring onto ferrihydrite surfaces at $\mathrm{pH}$ values near and above 5.7 .
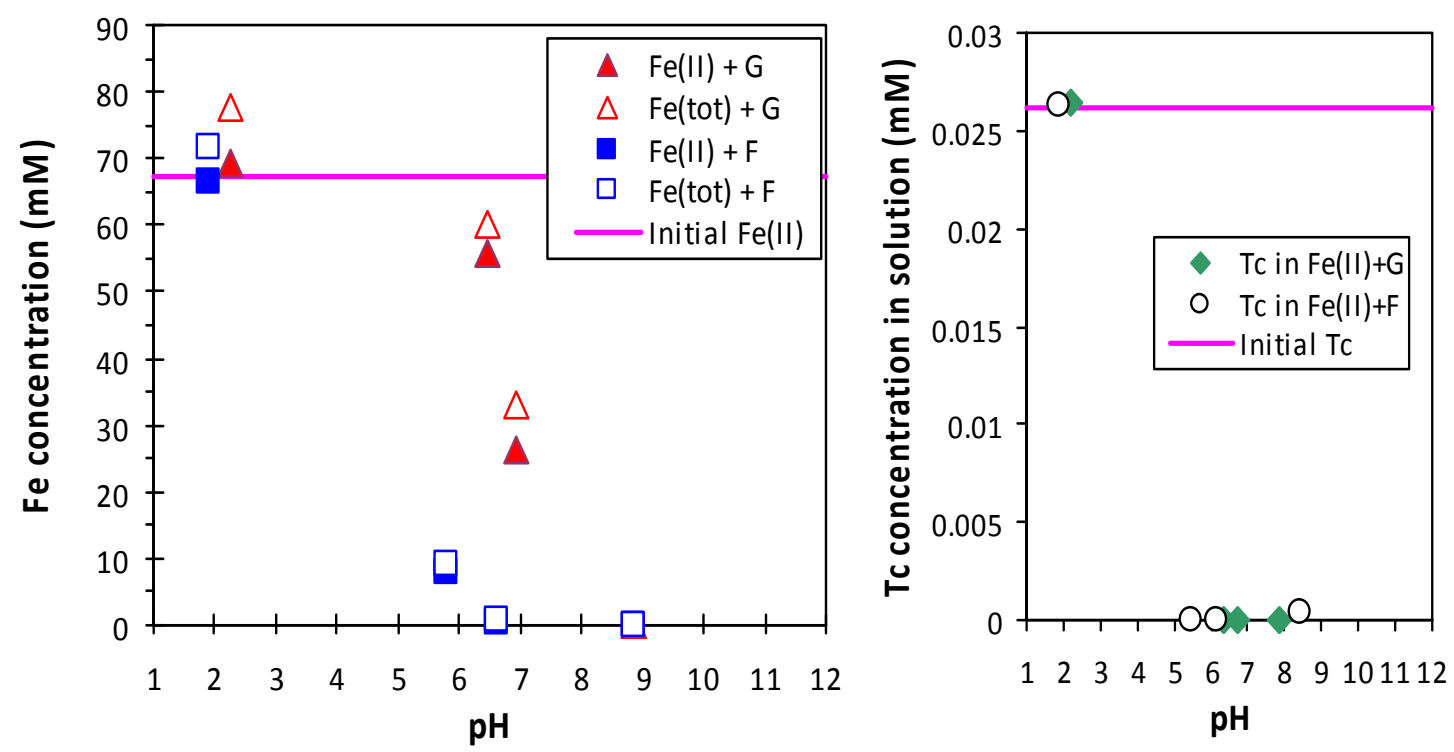

Figure 2.17. Dissolved Fe(II) and Fe(tot) Concentrations in Experiments Conducted at Different pHs with Fe Oxides Present ( $\mathrm{G}=$ goethite; $\mathrm{F}=$ ferrihydrite) (left) and Tc Removal in $\mathrm{Fe}(\mathrm{II})$ Solutions with Fe Oxides Present at Different pHs (right). The solids concentration in these batch experiments was $0.3 \mathrm{~g} / 50 \mathrm{~mL}$. 
In the presence of ferrihydrite, the tests showed about $90 \% \mathrm{Fe}(\mathrm{II})$ removal at $\mathrm{pH}=5.7$ by adsorption processes. Removal of $\mathrm{Fe}(\mathrm{II})$ in solution by adsorption on ferrihydrite was also much higher at a $\mathrm{pH}$ of 6.8 than in the systems without Fe oxide (Figure 2.16, left) and with goethite present in solution (Figure 2.17, left). The observed drop in both solution $\mathrm{Fe}($ tot) and $\mathrm{Fe}(\mathrm{II})$ in the ferrihydrite slurries at $\mathrm{pH}$ values lower than 7.5, the $\mathrm{pH}$ value where precipitation of $\mathrm{Fe}(\mathrm{OH})_{2}$ starts, confirms that the dominant mechanism of $\mathrm{Fe}$ (II) initial removal in the ferrihydrite slurries between $\mathrm{pH} \sim 5.5$ to 7.5 was $\mathrm{Fe}$ (II) adsorption, not precipitation of $\mathrm{Fe}(\mathrm{OH})_{2(\mathrm{~s})}$.

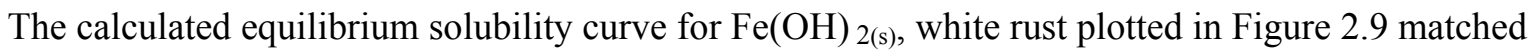
very well with the measured $\mathrm{Fe}$ (II) concentrations in the sample with goethite present at $\mathrm{pHs}$ higher than 7.5 (Figure 2.9). However, the measured Fe(II) solution concentrations in the presence of ferrihydrite fell to the left of the calculated equilibrium solubility curve line in the region of undersaturation, supporting our hypothesis that $\mathrm{Fe}$ (II) removal in these solutions resulted from adsorption of $\mathrm{Fe}$ (II) onto ferrihydrite and not precipitation of $\mathrm{Fe}(\mathrm{OH})_{2(\mathrm{~s})}$.

Removal of Tc from solution was also measured in the batch tests at different $\mathrm{pHs}$ containing either goethite or ferrihydrite. When $\mathrm{Tc}(\mathrm{VII})$ was spiked in $\mathrm{Fe}(\mathrm{II})$ solutions containing goethite or ferrihydrite solids at low $\mathrm{pH}(<3.0)$, the concentration of Tc was stable and similar to the initial Tc concentration (Figure 2.17, right) even after 7 days of reaction. Because Fe(II) adsorption onto goethite or ferrihydrite was insignificant and the solution was undersaturated with respect to $\mathrm{Fe}(\mathrm{OH})_{2(\mathrm{~s})}$ at these low $\mathrm{pH}$ values $(<3.0)$, no removal of Tc was observed. Also, even if all the initial Tc(VII) was reduced to Tc(IV) by $\mathrm{Fe}(\mathrm{II})$ in solution, $\mathrm{Tc}(\mathrm{IV})$ was undersaturated with respect to $\mathrm{TcO}_{2} \cdot \mathrm{xH}_{2} \mathrm{O}_{(\mathrm{s})}$ at these low $\mathrm{pH}$ values based on the solubility product of $\mathrm{TcO}_{2} 1.5 \mathrm{H}_{2} \mathrm{O}$ as shown below in Eq. (2.3) (Hess et al. 2008). However, $\mathrm{Tc}(\mathrm{VII})$ removal was fast and complete even after 1 day of reaction in solutions with ferrihydrite or goethite present at higher $\mathrm{pH}$ values (5.7 and 6.8), most likely resulting from Tc-reduction during reaction with either adsorbed $\mathrm{Fe}(\mathrm{II})$ on the ferrihydrite or the $\mathrm{Fe}(\mathrm{OH})_{2}$ precipitates that also formed in both systems.

$$
\mathrm{TcO}_{2} \cdot 1.5 \mathrm{H}_{2} \mathrm{O}(\mathrm{am})=\mathrm{TcO}(\mathrm{OH})_{2}(\mathrm{aq})+0.6 \mathrm{H}_{2} \mathrm{O}, \quad \mathrm{Ksp}=10^{-8.40}
$$

\subsubsection{Technetium Removal in Different Conditions by Fe(II)-Goethite or $\mathrm{Fe}(\mathrm{II})$-Ferrihydrite}

The objective of studies discussed in this section were to explore the impacts of varying different ratios of starting goethite, dosing amounts of the ferrous iron treatment reagent, different initial Tc(VII) concentrations, use of different waste stream compositions, and addition of two key waste stream anions on the removal of Tc. First, we will give a brief description of the batch test methodology again and then present results.

Preparation of the Fe(II)-goethite slurry used in this test was the same as previously described in Section 2.1.2, with the following exceptions: 1$)$ different initial goethite masses $(0.1$ or $2.0 \mathrm{~g}$ compared to 2.75 to $3.5 \mathrm{~g}$ used previously, 2) different Fe(II) concentrations $(0.01$ or $0.1 \mathrm{M}$ compared to $0.07 \mathrm{M}$ used previously), 3) different simulant types (see Table 2.2$)$, and 4) different initial Tc concentrations $\left(1.2 \times 10^{-6}\right.$ to $4.2 \times 10^{-4} \mathrm{M}$ compared to the previous $2.2 \times 10^{-5} \mathrm{M}$ ) were varied as a function of reaction time. In two tests, the type of ferric oxide used as the substrate was changed from the freshly prepared goethite to, in one case, a commercially available goethite, and in the other case freshly prepared ferrihydrite. Finally, the effects of anions in the waste stream on Tc removal by Fe(II)-goethite were also evaluated in both DI 
and simulant SSS-1 solution. The simulant SSS-1 represents the simplest mix of chemical components amongst all the simulants (Table 2.2). Simulant SSS-1, which contains high carbonate concentrations $(0.8 \mathrm{M})$, was fortified with $0.1 \mathrm{M}$ concentrations of two anions $\left(\mathrm{PO}_{4}{ }^{3-}\right.$ and $\left.\mathrm{SO}_{4}{ }^{3-}\right)$, the Tc, and then subjected to the $\mathrm{Fe}(\mathrm{II})$-goethite slurry interaction to evaluate whether phosphate and sulfate affect Tc removal.

The results of Tc removal in the simulant SSS-2 solution with different initial goethite masses and different amounts of Fe(II) concentrations are shown in Figure 2.18. Removal of Tc was fast and most of it (>90\%) was removed from the waste simulant SSS-2 within 1 day at all conditions studied. Slightly greater Tc removal was found as more Fe(II) was added to the slurry. Higher Fe(II) concentration, $0.1 \mathrm{M}$, was more effective for Tc removal in solution than $0.01 \mathrm{M}$, irrespective of initial goethite mass present in the slurry. This indicates that concentration of $\mathrm{Fe}(\mathrm{II})$ is more important than the mass of goethite present in removing Tc from solution. However, the least Tc removal was found in the lower initial goethite mass $(0.1 \mathrm{~g})$ and lowest Fe(II) concentration $(0.01 \mathrm{M})$ test condition. A slight decrease in Tc removal (percentage) in solution was found in most tests after 14 days in comparison to 1 day, which is likely caused by some dissolution of final Tc-goethite exposed for a long time in high caustic solution and reoxidation of the released Tc.

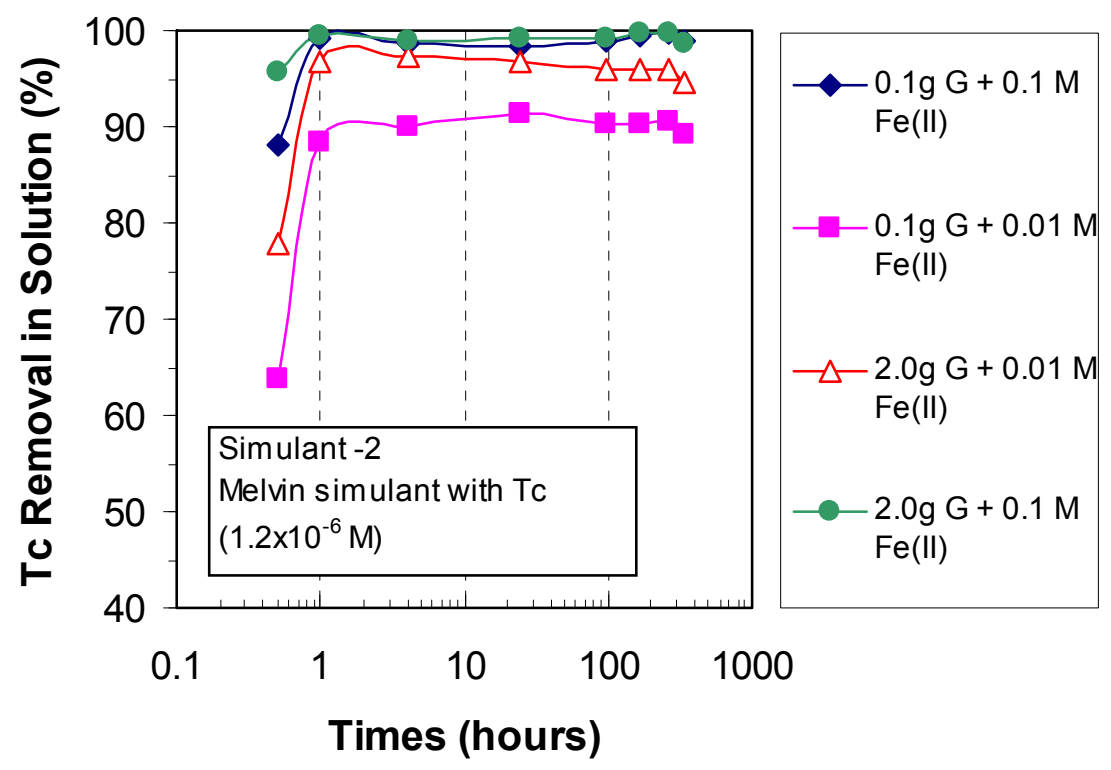

Figure 2.18. Tc(VII) Removal in Simulant SSS-2 Solution by Fe(II)- Goethite as a Function of Time

The results of Tc removal from simulant SSS-3 with varying goethite masses and Fe(II) concentrations are shown in Figure 2.19. Even though the initial Tc concentration in simulant-3 was about 200 times higher than the Tc concentration in simulant-2 (Figure 2.18), nearly complete Tc removal was also found in the presence of $0.1 \mathrm{M} \mathrm{Fe}(\mathrm{II})$ solutions within 1 hour of reaction no matter what the initial goethite mass was used (2 or $0.1 \mathrm{~g}$ ) (Figure 2.19).

Based on the total mass of final Tc-goethite after 7 days of reaction, the Tc concentration on the goethite solid was determined to be $1.02 \mathrm{mg}$ of Tc/g of goethite (Sample 2-3* in Table 2.1). A similar XRD pattern to those of Samples 2-2 and 2-3 was found in Sample 2-3* (see Figure 2.17), indicating a mixture of magnetite and goethite was present in Sample 2-3* prepared with high Tc concentration and 
simulant SSS-3 without additional armoring. Sample 2-3* also exhibited a reduced Tc(IV) oxidation state and molecular coordination environment similar to those of Tc-goethite Samples 2-2 and 2-3 (Figures 2.14 and 2.15). Because of the higher Tc concentration $\left(4.2 \times 10^{-4} \mathrm{M}\right)$ in simulant SSS-3 used to prepare Sample 2-3*, more definitive EXAFS spectra were obtained and the fit matched Model-1 again, which has Tc(IV) substituted for Fe(III) in the octahedral Fe(III) site of magnetite or goethite crystal structure without any neighboring Tc atoms (Figure 2.15). As discussed previously, it is not easy to distinguish Tc location between magnetite and goethite, because the octahedral Fe(III) site in magnetite is very similar to that of goethite. However, due to the high initial Tc concentration, a Tc SEM/EDX peak for Sample 2-3* was detected in a separated cubic-shaped mineral particle, which is typical shape of magnetite (Figure 2.20). The chemical composition of the selected region by SEM/EDX showed about $0.6 \mathrm{wt} \%$ Tc present. No detectable Tc EDX peaks were found in any acicular-shaped particle, which is typical of goethite, in Sample 2-3*. However, more quantitative analysis using TEM/SAED/EDX should be conducted to identify the exact Tc location in specific minerals in the Tc-goethite samples.

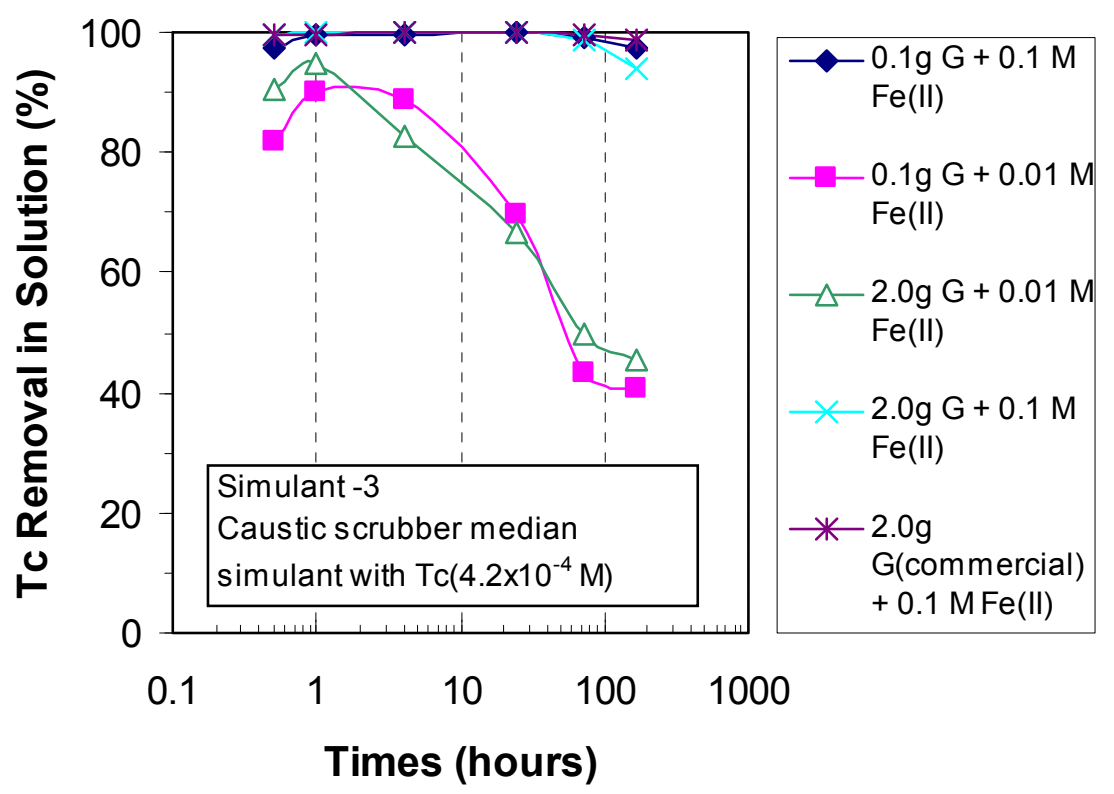

Figure 2.19. Tc(VII) Removal in Simulant SSS-3 Solution by Fe(II)- Goethite as a Function of Time

Commercially available goethite was also used along with our freshly prepared geothite and reacted with simulant SSS-3 and Fe(II) in the same way. The Tc removal results by both our freshly prepared (synthesized) and the commercial goethite were very similar through the first 7 days of reaction. The same trend of minor decreases in the Tc removal was also found when using simulant SSS-3 reacting with $0.1 \mathrm{M} \mathrm{Fe}(\mathrm{II})$ solutions after 7 days of reaction because of the dissolution of goethite exposed for more than 1 day at high $\mathrm{pH}$ conditions. The tests using simulant SSS-3 solutions with the lower Fe(II) concentration, $0.01 \mathrm{M} \mathrm{Fe}(\mathrm{II})$, showed noticeably less Tc removal as the reaction time increased beyond 1 hour. The Tc removal dropped from $90 \%$ to $40 \%$ as the contact time increased from 1 day to 7 days. This decreasing Tc removal was likely caused by the insufficient reduction capacity of the $0.01 \mathrm{M} \mathrm{Fe(II)}$ solution in comparison to the high total Tc concentration, $4.2 \times 10^{-4} \mathrm{M}$, especially at high $\mathrm{pH}$ conditions. Recall it takes 3 moles of Fe(II) to reduce each mole of Tc. 
The result of Tc removal in the simulant SSS-4 solution by the Fe(II)-goethite and Fe(II)-ferrihydrite showed very similar Tc removal behavior up through 1 day of reaction (Figure 2.21). Although the initial Tc concentration in the simulant SSS-4 solution $\left(3.2 \times 10^{-6} \mathrm{M}\right)$ was lower than the Tc concentration in simulant SSS-3 $\left(4.2 \times 10^{-4} \mathrm{M}\right)$, lower Tc removal (less than 90\%) was found even when $2.0 \mathrm{~g}$ goethite (or ferrihydrite) were present and reacted with $0.1 \mathrm{M} \mathrm{Fe}(\mathrm{II})$ solutions after 1 day of reaction (Figure 2.21). However, simulant SSS-4, submerged bed scrubber solution, has a relatively lower initial $\mathrm{pH}(9.2)$ compared to other simulants $(\mathrm{pH}=13.0)$, and the $\mathrm{pH}$ measured after mixing with Fe(II)-goethite(or ferrihydrite) slurry was lower than 6.0. At this low $\mathrm{pH}$ condition, even though higher Fe(II) concentration, $0.1 \mathrm{M}$, was used, some of the Fe(II) species could be present as dissolved Fe(II) that is considered to have lower reduction reactivity compared to surface-complexed or surface-precipitated Fe(II) species. Therefore, additional $\mathrm{NaOH}$ was added to the slurries prepared with ferrihydrite or goethite after 1 day complete mixing and additional samples were collected after 1 day reaction with the $\mathrm{NaOH}$ addition. Slightly increased Tc removal in both goethite and ferrihydrite slurries was also found after the addition of $\mathrm{NaOH}$ (Figure 2.21).

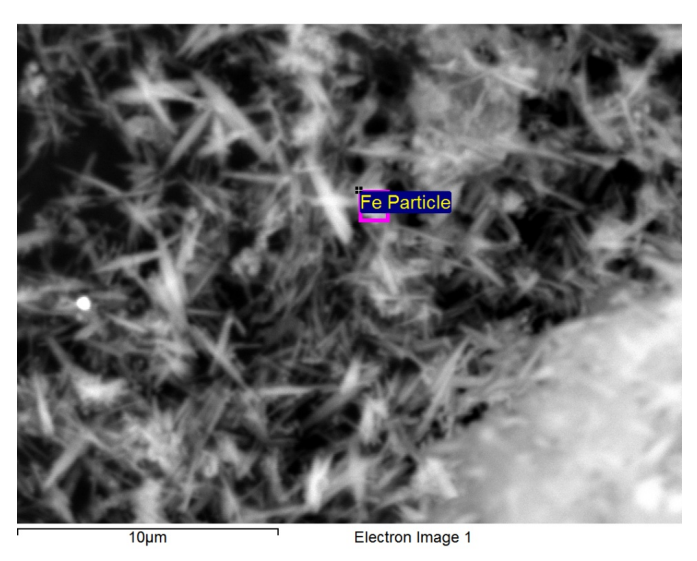

\begin{tabular}{l|llll}
\hline Element & $\begin{array}{l}\text { Intensity } \\
\text { Corrn. }\end{array}$ & Weight $\%$ & $\begin{array}{l}\text { Weight } \% \\
\text { Sigma }\end{array}$ & Atomic\% \\
O K & 1.2849 & 32.79 & 0.36 & 59.94 \\
$\mathrm{Na} \mathrm{K}$ & 0.3816 & 1.76 & 0.16 & 2.23 \\
$\mathrm{Al} \mathrm{K}$ & 0.5161 & 5.41 & 0.11 & 5.87 \\
$\mathrm{Si} \mathrm{K}$ & 0.6084 & 0.63 & 0.07 & 0.66 \\
$\mathrm{P} \mathrm{K}$ & 0.9982 & 0.43 & 0.07 & 0.40 \\
$\mathrm{~S} \mathrm{~K}$ & 0.8116 & 0.36 & 0.08 & 0.33 \\
$\mathrm{Cr} \mathrm{K}$ & 1.0852 & 0.16 & 0.05 & 0.09 \\
Fe K & 0.9167 & 57.43 & 0.37 & 30.08 \\
Co K & 0.8988 & 0.50 & 0.14 & 0.25 \\
Tc L & 0.7397 & 0.55 & 0.23 & 0.16 \\
& & & & \\
Totals & & 100.00 & & \\
\hline
\end{tabular}

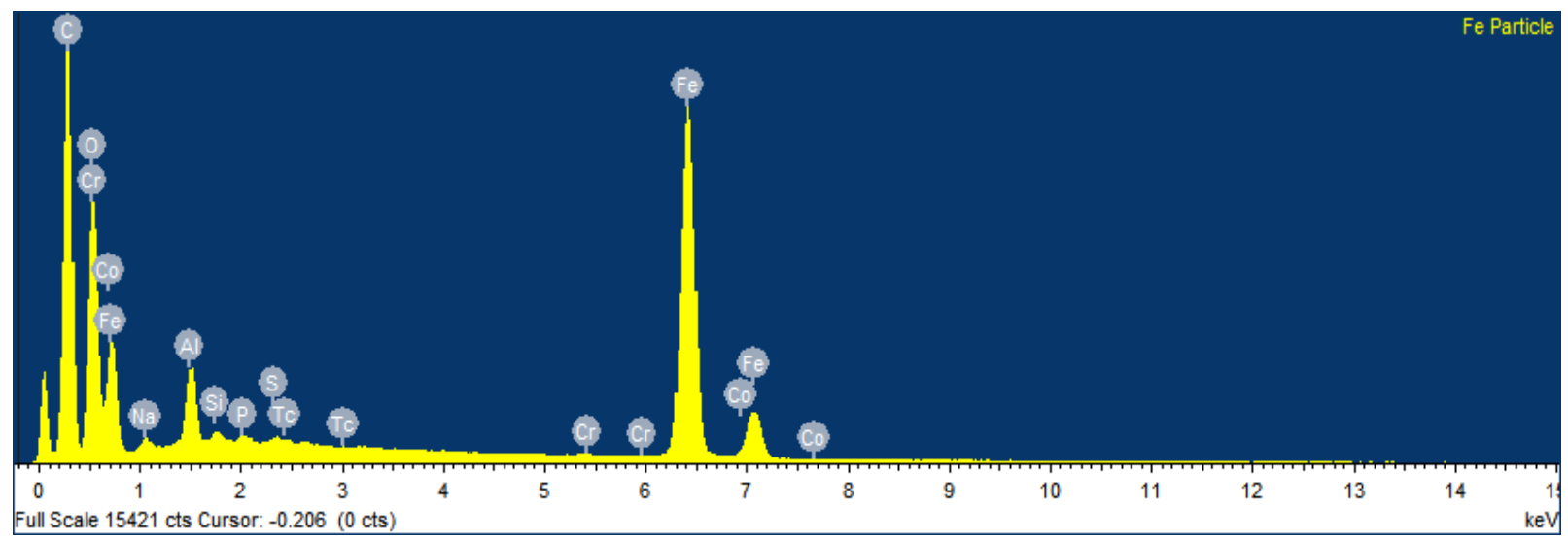

Figure 2.20. SEM/EDX for Tc-Goethite Samples Prepared Using Simulant-3 (caustic scrubber median) with $2.0 \mathrm{~g}$ of Initial Goethite and $0.1 \mathrm{M}$ of Fe(II) Without Additional Armoring Process, Sample 2-3*. A beam location is a cubic-shaped particle described as a pink rectangle denoted as "Fe particle."

The Tc removal behaviors by Fe(II)-goethite and -ferrihydrite were found to be similar when goethite or ferrihydrite was used as the initial solid substrate. This limited test suggests that ferrihydrite, a 
precursor mineral phase before being transformed to the more crystalline goethite, can be used to effectively remove Tc from waste streams using the Fe(II) treatment of the slurry under caustic conditions. Synthesis of ferrihydrite is also easier than goethite. However, more studies should be conducted using the $\mathrm{Fe}$ (II)-ferrihydrite substrate to evaluate the long-term stability of the resultant Tc-ferrihydrite mineral and the potential Tc release during mineral transformation from ferrihydrite. In the laboratory, we transform ferrihydrite to goethite using high $\mathrm{pH}$ and temperature $\left(80^{\circ} \mathrm{C}\right.$ in an oven); however, in nature over geologic time frames the transformation can occur at lower temperatures.

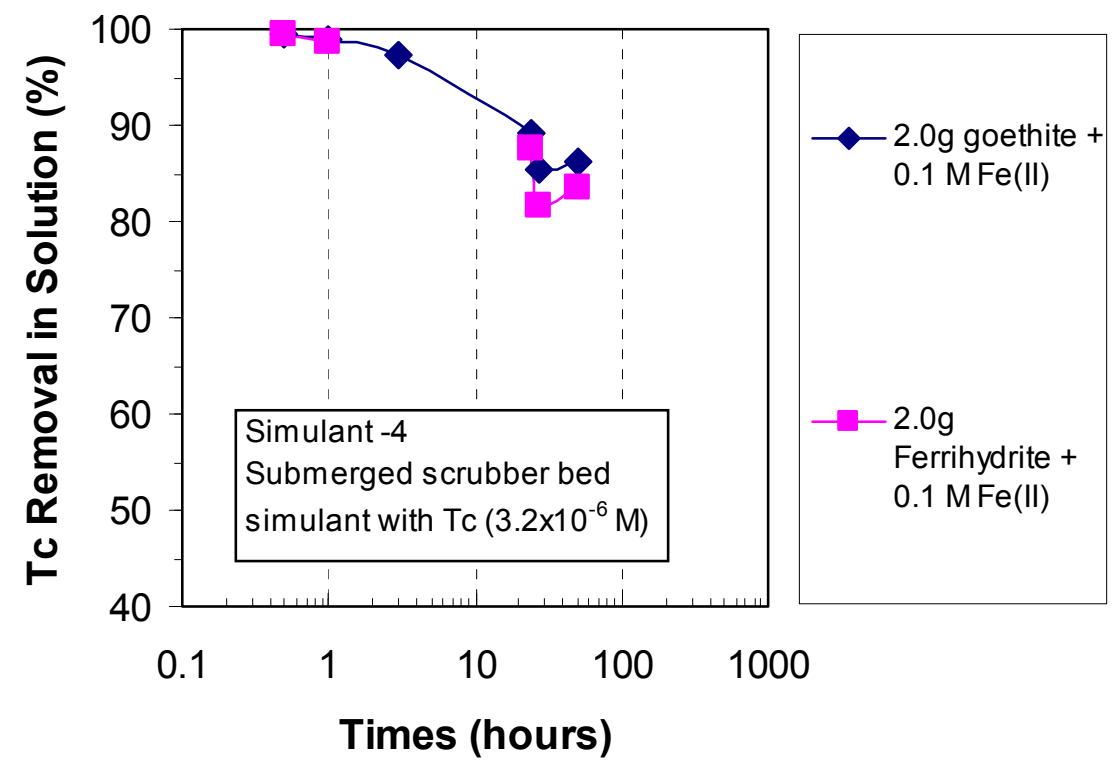

Figure 2.21. Tc(VII) Removal in Simulant SSS-4 Solution by Fe(II)- Goethite as a Function of Time. Additional $\mathrm{NaOH}$ was added after 1 day of mixing to increase the $\mathrm{pH}$ up to 12.0.

\subsubsection{Technetium Removal by Fe(II)-Goethite with Varying Anion Concentrations}

The effects of the anions, $\mathrm{SO}_{4}{ }^{2-}$ and $\mathrm{PO}_{4}{ }^{3-}$, on $\mathrm{Tc}$ removal by the $\mathrm{Fe}(\mathrm{II})$-goethite system were tested in simulant SSS-1 solution. An initial goethite mass of $2.0 \mathrm{~g}$ was reacted with $0.01 \mathrm{M} \mathrm{Fe}$ (II) to look for the impacts of these two anions at several concentrations of each anion. High Tc removal, $>90 \%$, was found after 1 hour of reaction in simulant SSS-1 solution without addition of $\mathrm{SO}_{4}{ }^{2-}$ and $\mathrm{PO}_{4}{ }^{3-}$ (Figure 2.22). Decreased Tc removal was observed at contact times longer than 1 hour of reaction as was found with other tests (results shown in Figures 2.18 and 2.19). The decreased Tc removal is attributed to having insufficient reduction capacity from the $0.01 \mathrm{M} \mathrm{Fe}(\mathrm{II})$ concentration to reduce all of the Tc, $4.2 \times 10^{-4} \mathrm{M}$ in simulant SSS-1 as found in the simulant SSS-3 tests (Figure 2.19). Decreased Tc removal was also found in the simulant SSS-1 solution when either $\mathrm{SO}_{4}{ }^{2-}$ or $\mathrm{PO}_{4}{ }^{3-}$, or both anions were added to the simulant

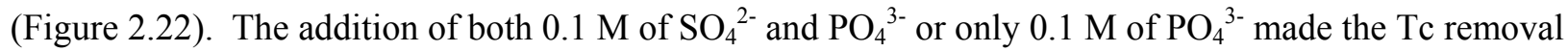
drop to $40 \%$ of the Tc in the simulant. The presence of $\mathrm{PO}_{4}{ }^{3-}$ has the most deleterious impact on Tc removal by the $\mathrm{Fe}(\mathrm{II})$-goethite substrate. The presence of $0.1 \mathrm{M}$ of $\mathrm{SO}_{4}{ }^{2-}$ anion also decreased Tc removal down to $70 \%$ compared to Tc removal when $\mathrm{SO}_{4}{ }^{2-}$ and $\mathrm{PO}_{4}{ }^{3-}$ were not present. However, the effect of $\mathrm{PO}_{4}{ }^{3-}$ in solution was greater than $\mathrm{SO}_{4}{ }^{2-}$ in hindering $\mathrm{Tc}$ removal. Because these anions are both dominant 
anions in scrubber off-gas simulants, more studies are needed to reveal the mechanism for why Tc removal is reduced by presence of $\mathrm{SO}_{4}{ }^{2-}$ and especially $\mathrm{PO}_{4}{ }^{3-}$.

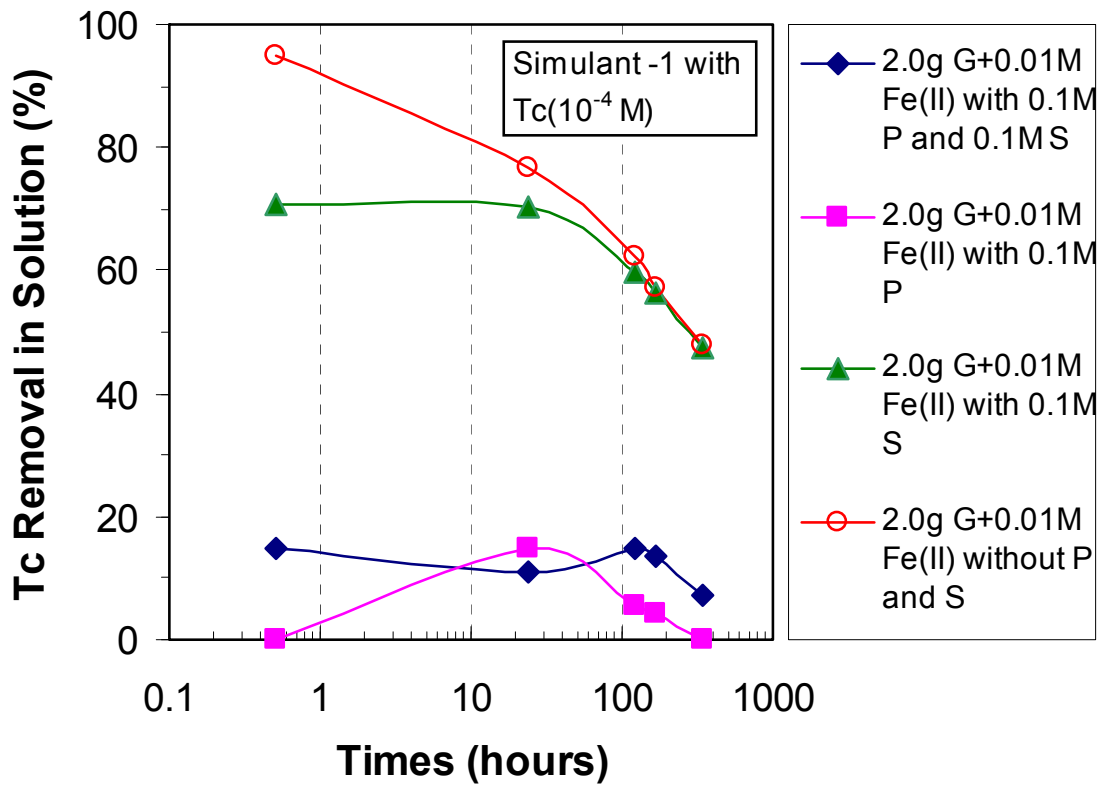

Figure 2.22. Anion Effects on Tc Removal in Simulant 1 Solution by Fe(II)- Goethite System (G= goethite; $\mathrm{P}=\mathrm{PO}_{4}{ }^{3-} ; \mathrm{S}=\mathrm{SO}_{4}{ }^{2-}$ )

\subsubsection{Limited Tc(VII) Release from Fe(II)-Goethite}

\subsubsection{Tc Release in Batch-Leaching Experiments}

Batch-leaching data for Tc and dissolved Fe(tot) as a function of time in different solutions are shown in Figure 2.23a and 2.23b. The leachates were analyzed in triplicate, and the average values were used in Figure 2.23. Measured $\mathrm{pH}$ values in the different types of leaching solutions showed no dramatic changes as a function of reaction time (Figure 2.23c), indicating that no significant $\mathrm{pH}$-altering geochemical reactions were occurring during the leach tests. Tc concentrations in the leachates even after 180 days of contact were less than $2 \mu \mathrm{g} / \mathrm{L}$ in the $\mathrm{pH}=4$ and 7 buffer solutions and the IDF pore water $(\mathrm{pH}=7.2)$ solutions. These solution concentrations equate to a Tc release of $\sim 2 \mu \mathrm{g} \mathrm{Tc} / \mathrm{g}$ of Tc-goethite solid. The release of Tc was higher when the Tc-geothite solids were immersed in the $\mathrm{pH}=10$ buffer (up to $7 \mu \mathrm{g}$ Tc/g of Tc-goethite solid) and GL solutions (up to $2.7 \mu \mathrm{g} \mathrm{Tc} / \mathrm{g}$ of Tc-goethite solid) (Figure 2.23a). The IDF pore water solution is germane to the expected disposal environment for solidified WTP secondary wastes. The leached Tc concentrations in the IDF pore water and $\mathrm{pH}=7$ buffer solution were very similar, and most of the measured Fe(tot) concentrations in these solutions were below the detection limit $(<50 \mu \mathrm{g} / \mathrm{L})$, suggesting that goethite (Tc-hosting material) dissolution was insignificant in circumneutral $\mathrm{pH}$ conditions. Because the GL solution has a relatively high $\mathrm{pH}(\sim 9.7)$ compared to the IDF pore water, more goethite dissolved such that the leached Tc concentrations in GL solution were higher than those in the IDF pore water solution.

The highest leachate concentrations of $\mathrm{Tc}$ and $\mathrm{Fe}(\mathrm{tot})$ were found in the $\mathrm{pH}=10$ buffer solution (Figure 2.23a and 2.23b). Because goethite dissolution increases at high $\mathrm{pH}$ near and above 10, the 
release of Tc appears to be associated with the innate stability of the goethite, which is least stable in the $\mathrm{pH}=10$ buffer solution. The two $\mathrm{pH}$ buffer solutions ( $\mathrm{pH}=10$ and $\mathrm{pH}=4$, respectively) showed the highest and the second highest, respectively, dissolved $\mathrm{Fe}($ tot) concentrations after 3 days of reaction time (Figure 2.23b). The GL showed the third highest solution concentration of Fe(tot). A progressively increasing dissolved $\mathrm{Fe}(\mathrm{tot})$ concentration after 180 days of reaction time was found only for the $\mathrm{pH}=10$ buffer solution and indicates that $\mathrm{Tc}$ release occurs mainly as the host goethite dissolves at $\mathrm{pH}=10$. A linear relation between dissolved total $\mathrm{Fe}$ and released total $\mathrm{Tc}$ concentrations was also observed in the $\mathrm{pH}=10$ solution (Figure 2.24).
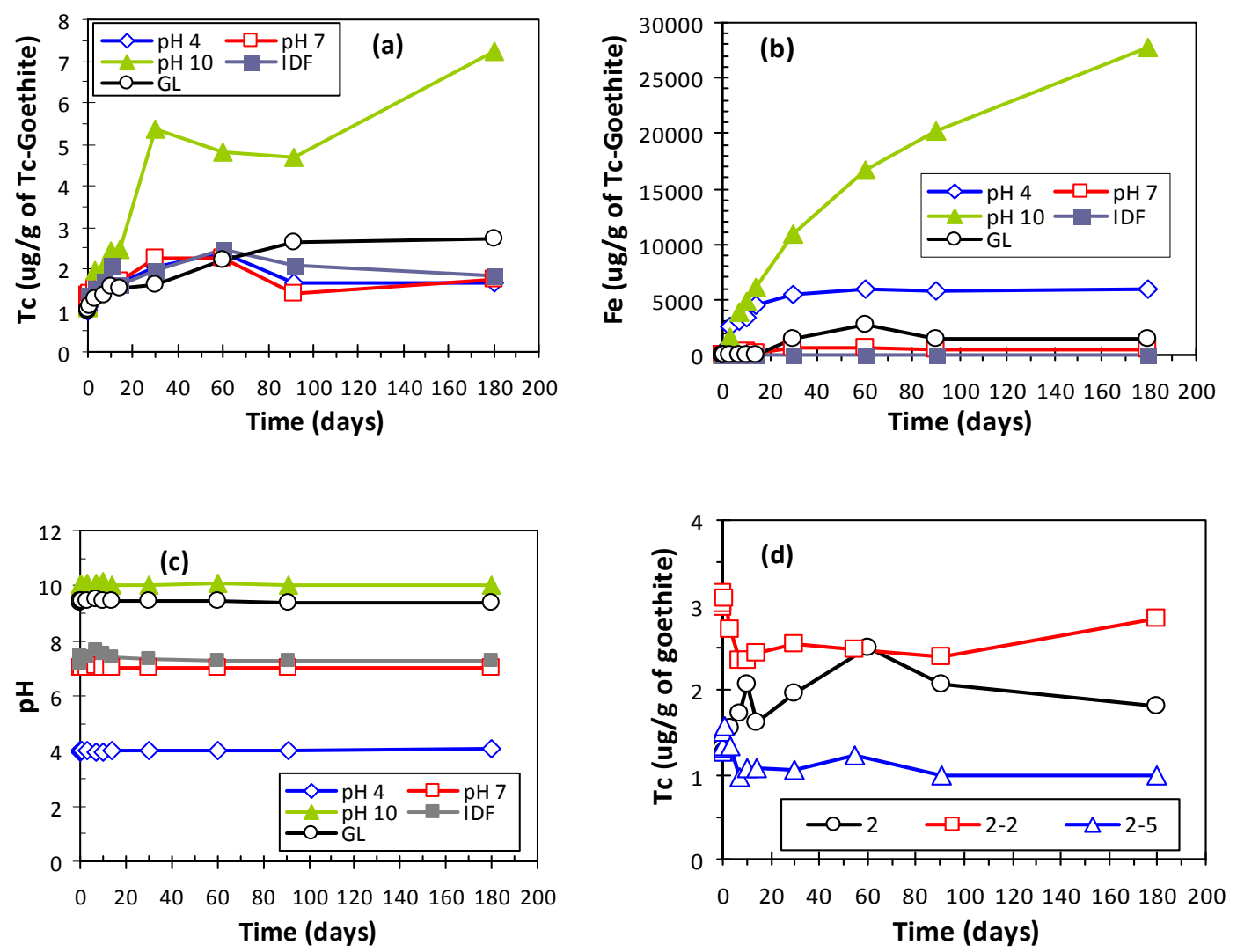

Figure 2.23. Batch-Leaching Results for Tc-Goethite Samples as a Function of Reaction Time with Different pH Buffer Solutions (4, 7, and 10), IDF Pore Water, and GL. (a) Tc leaching for Sample 2; (b) dissolved Fe(tot) for Sample 2; (c) measured pHs for Sample 2; and (d) Tc leaching for Tc-goethite Samples 2, 2-2, and 2-5 in IDF pore water.

Leached $\mathrm{Fe}($ tot $)$ in the other leachates, aside from the $\mathrm{pH}=10$ buffer solution, reached a constant concentration after 30 days of leaching. The comparable trend between the concentrations of dissolved $\mathrm{Tc}$ and $\mathrm{Fe}(\mathrm{tot})$ in different leaching solutions except $\mathrm{pH}=4$ buffer solution suggests that Tc leaching is closely related to goethite dissolution. Even though the $\mathrm{pH}=4$ buffer solution showed the second highest dissolved Fe(tot) concentration, the leached Tc concentration in the $\mathrm{pH}=4$ buffer solution was not the second highest (Figure 2.23a and 2.23b). The amount of $\mathrm{Tc}$ in the $\mathrm{pH}=4$ buffer leachate is slightly lower than Tc leached by the IDF pore water and GL solutions, indicating the possibility that released Tc is adsorbing onto the goethite surfaces at low $\mathrm{pH}$ (Liu and Fan 2005). Leached Tc, present as $\mathrm{TcO}_{4}{ }^{-}$, can adsorb onto the positively charged goethite surface at low $\mathrm{pH}$ because of goethite's higher point of zero 
net charge (PZNC) or point of zero charge (PZC) $(\mathrm{PZNC}=7.0-8.0$ [Sposito 1989] and $\mathrm{PZC}=7.28$ [Stumm 1992]). This also implies that any leached Tc reoxidizes back to pertechnetate as suggested by thermodynamic aqueous speciation calculations. Low detectable concentrations of dissolved $\mathrm{Fe}$ (tot) in the $\mathrm{pH}=7$ buffer and IDF pore water leachates are related to the goethite solubility, which is quite low at circumneutral $\mathrm{pH}$ values.

Additional Tc leaching tests using powdered Tc-goethite Samples 2-2 and 2-5 in IDF pore-water solution were conducted to investigate the effect of the additional goethite armoring process. Recall that after sequestering Tc from the waste simulants via the $\mathrm{Fe}(\mathrm{II})$ treatment at high $\mathrm{pH}$ that an additional treatment with $\mathrm{Fe}(\mathrm{III})$ and $\mathrm{NaOH}$ solution was performed to promote further ferric oxide precipitation and coating of the Tc-Fe(II)-treated goethite. The results of these additional leach tests on powdered armored (Samples 2 and 2-5) and unarmored (Sample 2-2) samples showed no detectable Fe(tot) in the IDF porewater leachates for all three Tc-goethite samples even after 180 days of leaching. Especially at early leaching times of less than 10 days (Figure 2.23d), noticeably more Tc was leached from Sample 2-2, which was prepared without additional goethite armoring and showed a more dominant magnetite mineral content, compared to Samples 2 and 2-5 that were prepared with two different armoring processes and in which only goethite mineral was observed in the final product. Although Samples 2 and 2-5 were both prepared with additional goethite armoring, Sample 2-5 showed complete Tc removal from solution when adding $\mathrm{NaOH}$ solution first before adding the $\mathrm{Fe}\left(\mathrm{NO}_{3}\right)_{3} \cdot 9 \mathrm{H}_{2} \mathrm{O}$ to the Tc-Fe(II) goethite slurry (Table 2-1). For Sample 2, the additional goethite armoring was performed by mixing the $\mathrm{NaOH}$ with $\mathrm{Fe}\left(\mathrm{NO}_{3}\right)_{3} \cdot 9 \mathrm{H}_{2} \mathrm{O}$ solution and then contacting the Tc-Fe(II) goethite slurry. Sample 2-5 was the most resistant to Tc leaching (less than $2.0 \mathrm{wt} \%$ of Tc removed after 180 days in IDF pore water) and also showed the highest Tc sequestration during the Fe(II)-goethite treatment step (100\% Tc uptake in Table 2-1).

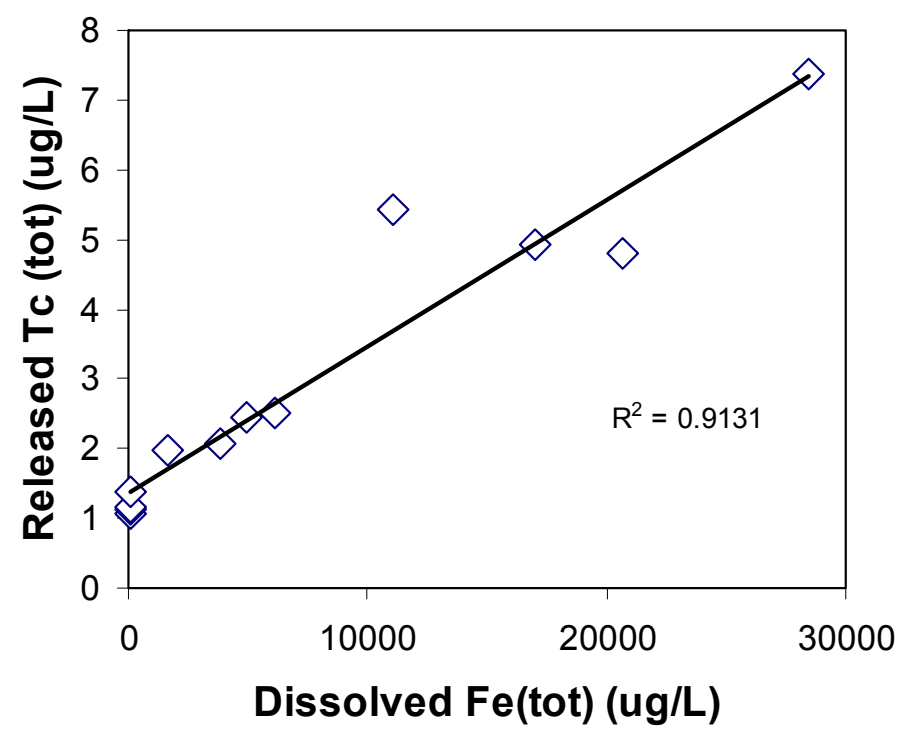

Figure 2.24. A Linear Relation Between Total Dissolved Fe and Released Total Tc Concentrations in $\mathrm{pH}=10$ Solution. The measured data (symbol) and a regression fit (line) are provided with correlation coefficient, $\mathrm{R}^{2}$. 


\subsubsection{Diffusion Coefficient and Leachability Index for Tc}

Despite the fact that no detectable Fe(tot) was found in IDF pore water leachates, indicating that little dissolution occurred even when powdered goethite was used, monolithic, cylindrical pellets of the Tc-goethite waste form were used to determine an effective diffusion coefficient (or leachability index) for Tc immersed in IDF pore water. A small aliquot of leachate was removed from the leaching container at time intervals from 30 minutes to 120 days throughout the leaching period. The small aliquot was analyzed for Tc concentration and $\mathrm{pH}$. The $\mathrm{pH}$ remained constant at a value close to the initial $\mathrm{pH}(\sim 7.2)$ of the IDF pore water. The diffusivity of Tc for all three Tc-goethite pellets made with Samples 2, 2-2, and 2-5 Tc-goethite solids was calculated with Eq. (2.1), and the results are displayed in Figure 2.25a. The first values of Tc diffusivity for Samples 2-2 and 2-5 after 30 min of contact were low, likely because of the oleic acid used on the final monolithic pellet surfaces to keep the pellets intact. However, the Sample 2 pellet broke into several pieces when the leaching IDF pore water was introduced (Figure 2.26) and resulted in the highest calculated Tc diffusivity at 30 minutes because we could not adjust the equation for the unknown increase in pellet surface area. Although Samples 2 and 2-5 were prepared with additional goethite armoring, Sample 2 showed the highest Tc diffusivity during the 120-day leaching period because of the instability of the Sample 2 pellet. The Sample 2-5 pellet was stable even after 120 days of leaching in IDF pore water, and showed a lower Tc diffusivity than Sample 2-2, which was not prepared with additional goethite armoring (Figure 2.23). A small peak in the calculated Tc diffusivity values for Samples 2 and 2-2 pellets was observed after 3 days leaching because additional small pieces spalled off both Sample 2 and Sample 2-2 pellets (Figure 2.26). Because the cylindrical, monolithic Tc-goethite pellets for Samples 2 and 2-2 broke apart during the diffusion experiments, a credible Tc diffusivity coefficient could only be determined for Sample 2-5, for which the pellet remained stable for the entire 120 days of reaction. The effective diffusion coefficients for all three test samples (ignoring the fact that two of the pellets broke apart) are plotted in Figure 2.25a.
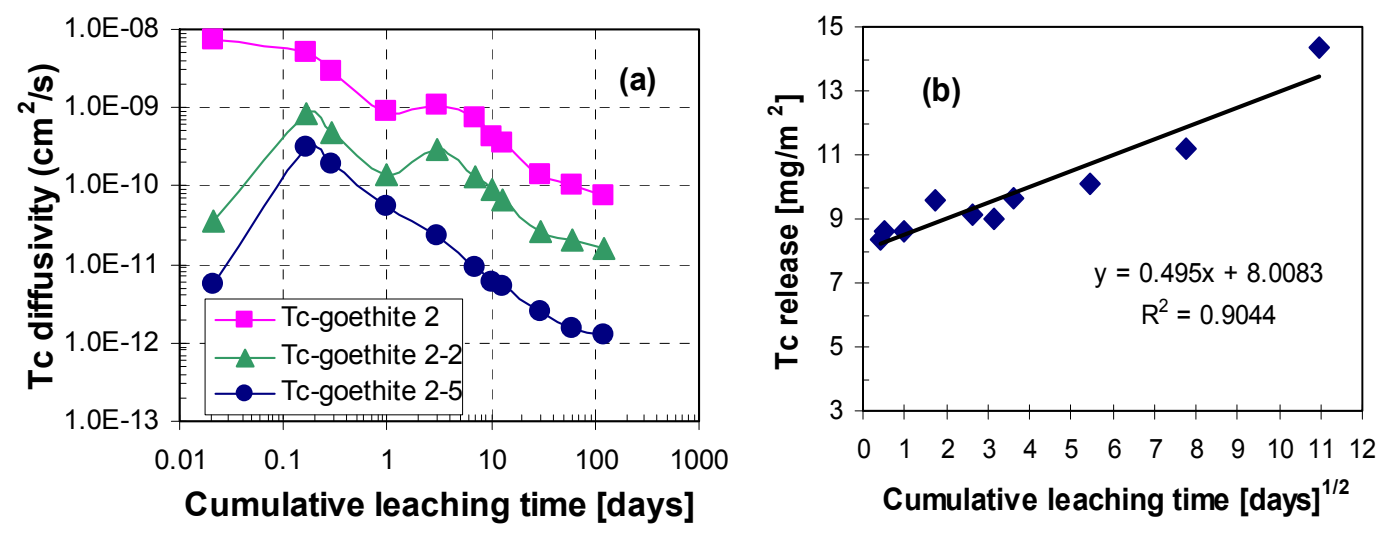

Figure 2.25. Calculated Tc Effective Diffusivities for Samples 2, 2-2, and 2-5 as a Function of Cumulative Leaching Time (a) and the Linear Dependence Between Cumulative Tc Release and Cumulative Leaching Time, $\mathrm{t}^{1 / 2}$ for Sample 2-5 (b) 

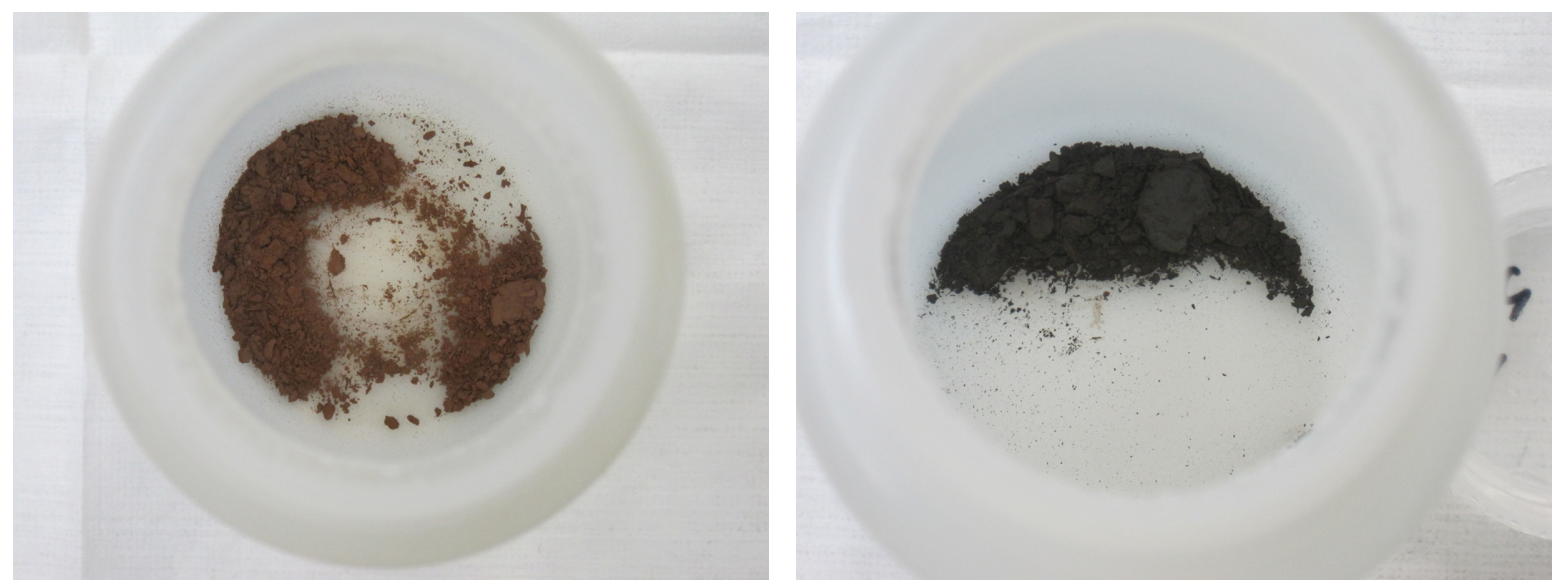

Figure 2.26. Cylindrical Monolithic Pellets of Tc-Goethite Samples. (Left) Sample 2 after leaching in IDF pore water, and (right) Sample 2-2 after leaching in IDF pore water. Also see Figure 2.1 for Sample 2-5 before and after leaching.

The calculated individual interval diffusivity values for the Sample 2-5 pellet showed a gradually decreasing trend as the contact time increased, except one value that was determined at 30 minutes of contact (Figure 2.25). Based on the assumptions and boundary conditions for simple radial diffusion from a cylinder into an infinite bath presented by Crank (1980), the mass release of Tc should follow a linear dependence on the square root of time, $\mathrm{t}^{1 / 2}$. Excluding the first data point collected at 30 minutes, Sample 2-5 showed a mass release proportional to $\sqrt{\mathrm{t}}$ with a linear correlation coefficient $\left(\mathrm{R}^{2}=0.90\right)$ in Figure 2.25b. Because the Samples 2 and 2-2 pellets broke apart during the leaching experiment, the linear correlation coefficients for those samples Tc mass released versus $\sqrt{\text { time }}$ were poor $\left(\mathrm{R}^{2}<0.80\right)$. The calculated average Tc diffusivity for Sample 2-5 is $6.15 \times 10^{-11} \mathrm{~cm}^{2} / \mathrm{s}$, and the leachability index (LI) is 10.2. The low value for Tc diffusivity and the high LI value are comparable to those found in several different Hanford grouts that ranged from $10^{-12}$ to $10^{-9} \mathrm{~cm}^{2} / \mathrm{s}$ with LIs from 9 to 12 (Serne et al. 1992). The LI is used as a performance criterion for use and disposal of treated waste, and in most cases, treatment is considered effective in for solid waste forms when the LI value is equal to or greater than nine (Mann et al. 2003). The value of LI for the Tc-Fe(II) goethite Sample 2-5 pellet is similar to or slightly higher (better performance) than those of Cast Stone ( $\mathrm{LI}=9.4$ to 10.3 for $\mathrm{Tc}$ ) prepared with a lowactivity waste simulant (Lockrem 2005).

\subsubsection{Solid-Phase Characterization}

Although Tc-Fe(II) goethite Samples 2, 2-2, and 2-5 were reacted with various leaching solutions in both powder and pellet form, the final Tc-Fe(II) goethite powder samples after 180 days of leaching showed identical XRD patterns to the initial Tc-Fe(II) goethite sample (Figure 2.27). No mineralogical changes were observed using XRD analysis, even for the final Tc-goethite Sample 2, which had been leached by a $\mathrm{pH}=10$ buffer solution for 180 days and showed the highest dissolved Fe(tot) concentration (Figure 2.23). Both Samples 2-2 and 2-5 leached in an IDF pore water solution also showed no changes in mineralogy after 180 days of leaching (Figure 2.27), suggesting that goethite is very stable at circumneutral $\mathrm{pH}$ conditions, which is germane to the potential low-level waste repository at the Hanford Site. 

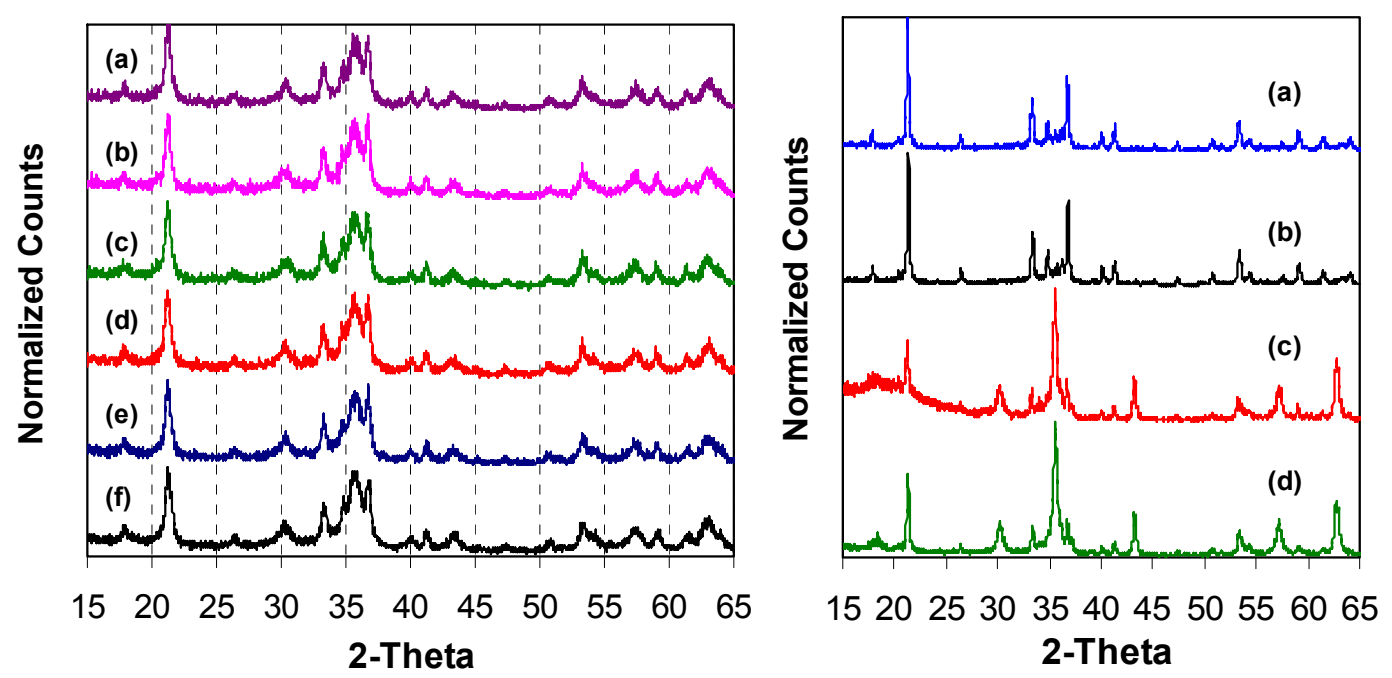

Figure 2.27. XRD Patterns of the Tc-Fe(II) Goethite Sample 2 (left) and Tc-Fe(II) Goethite Samples 2-2 and 2-5 (right). (Left-a) reacted Tc-Fe(II) goethite Sample 2 with $\mathrm{pH}=4$ solution after 180 days; (left-b) reacted Tc-Fe(II) goethite Sample 2 with $\mathrm{pH}=7$ solution after 180 days; (left-c) reacted Tc-Fe(II) goethite Sample 2 with $\mathrm{pH}=10$ solution after 180 days; (left-d) reacted Tc-Fe(II) goethite Sample 2 with IDF pore water after 180 days; (left-e) reacted Tc-Fe(II) goethite Sample 2 with glass leachate after 180 days; (left-f) unleached initial Tc-Fe(II) goethite Sample 2; (right-a) reacted Tc-Fe(II) goethite Sample 2-5 with synthetic IDF pore water after 180 days; (right-b) unleached initial Tc-Fe(II) goethite Sample 2-5; (right-c) reacted Tc-goethite Sample 2-2 with IDF pore water after 180 days; and (right-d) unleached initial Tc-goethite Sample 2-2.

\subsubsection{The XANES Analysis for Tc Oxidation State on the Leached Tc-Goethite}

The XANES spectra for the Tc standards $\left(\mathrm{KTcO}_{4}, \mathrm{NaTcO}_{4}, \mathrm{TcO}_{4}{ }^{-}\right.$adsorbed on Reillex-HPQ resin, and $\mathrm{TcO}_{2} \cdot 2 \mathrm{H}_{2} \mathrm{O}$ ) and the Tc-Fe(II) goethite Samples 2, 2-2, and 2-5 after leaching in IDF pore water solution for 180 days are shown in Figure 2.28 (left). The XANES spectrum of the aliquot of Sample 2 contacted with atmospheric oxygen for 180 days is also shown along with the linear combination fit in Figure 2.28 (left). Because the XANES spectra for the $\mathrm{Tc}(\mathrm{VII})$ standards $\left(\mathrm{NaTcO}_{4}, \mathrm{KTcO}_{4}\right.$, and $\mathrm{TcO}_{4}{ }^{-}$ adsorbed on ion exchange resin) are very similar and are characterized by a strong pre-edge feature because of the $1 \mathrm{~s}$ to $4 \mathrm{~d}$ transition for the tetrahedral $\mathrm{TcO}_{4}{ }^{-}$anion, only one XANES spectrum for $\mathrm{TcO}_{4}{ }^{-}$is provided in Figure 2.28 (left). The XANES spectrum of $\mathrm{TcO}_{2} \cdot 2 \mathrm{H}_{2} \mathrm{O}$ is very different and characteristic for $\mathrm{Tc}(\mathrm{IV})$ coordinated by six oxygen atoms in an octahedral geometry.

The oxidation state of $\mathrm{Tc}$ in the leached $\mathrm{Tc}-\mathrm{Fe}$ (II) goethite samples was determined by fitting their XANES spectra using the spectra for the $\mathrm{TcO}_{4}{ }^{-}$adsorbed on Reillex-HPQ resin and the spectra for the $\mathrm{TcO}_{2} \cdot 2 \mathrm{H}_{2} \mathrm{O}$ standards. In all cases, the fitting results indicated that only $\mathrm{Tc}(\mathrm{IV})$ was present in both unleached and leached Tc-Fe(II) goethite Samples 2, 2-2, and 2-5 after they were leached in IDF pore water solution for 180 days. In addition, the unleached Tc-Fe(II) goethite Sample 2 aliquot that was exposed to atmospheric oxygen for 180 days also showed only the Tc(IV) oxidation state was present. The other Tc-Fe(II) goethite samples that were leached in the different $\mathrm{pH}$ buffer and simulated glass leachants also showed no reoxidized Tc(VII) in the XANES spectra. The best fit modeling results are shown in Figure 2.28 (right). The fraction of Tc present in the Tc-Fe(II) goethite samples as $\mathrm{TcO}_{4}{ }^{-}$in all 
the leached or exposed to air after between 120 and 180 days was less than $1 \%$, suggesting that the reoxidation of the Tc(IV) initially incorporated within the Fe(II)-treated goethite mineral lattice was limited.
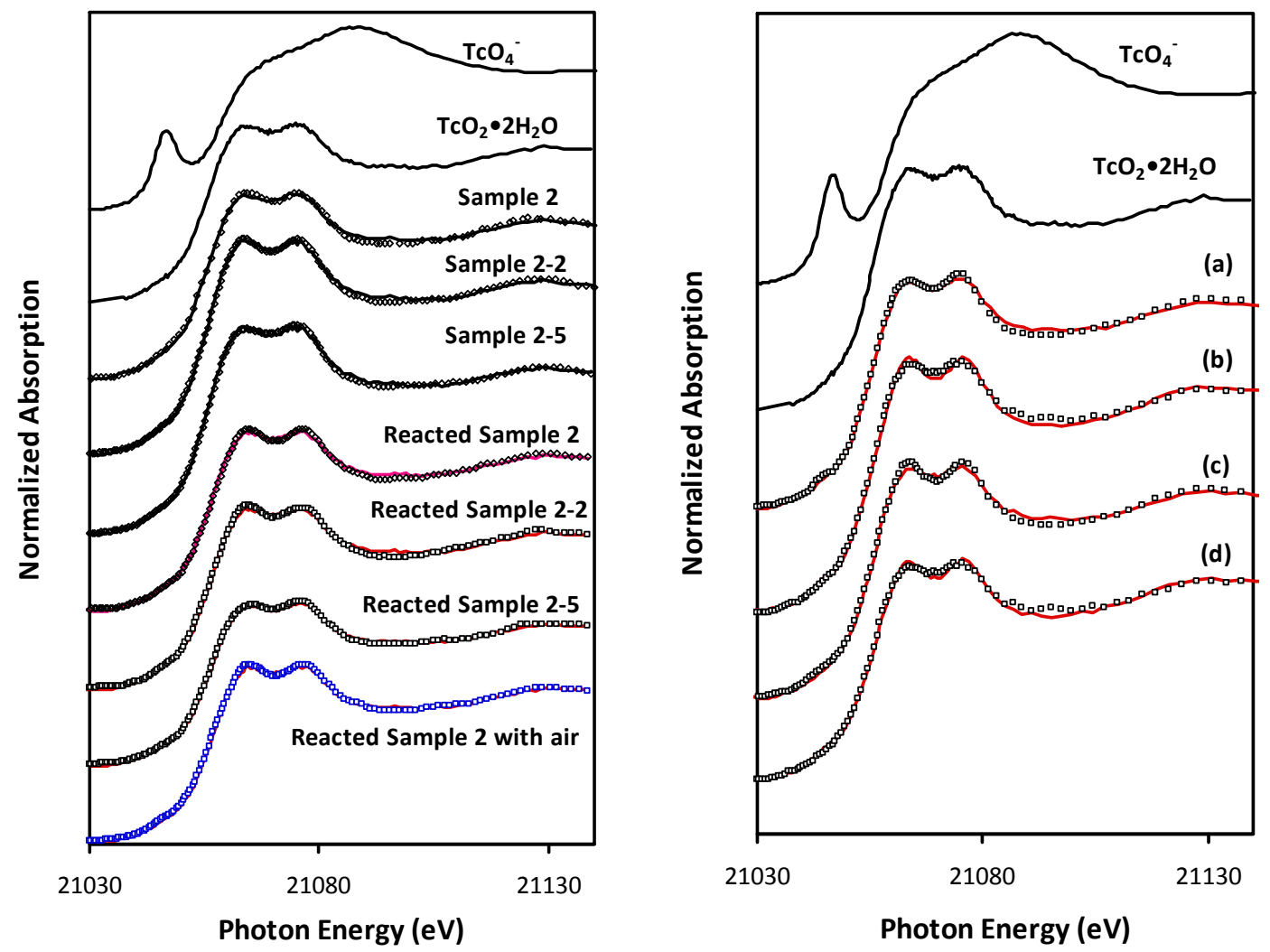

Figure 2.28. Normalized XANES Spectra for Tc(VII) and Tc(IV) Standards as Well as Tc-Fe(II) Goethite Samples. (Left) Samples 2, 2-2, and 2-5 are the Tc-Fe(II) goethite samples before leaching in IDF pore water. The Reacted Samples 2, 2-2, and 2-5 indicate the Tc-Fe(II) goethite samples after leaching in IDF pore water for 180 days. The Reacted Sample 2 in air was contacted for 180 days with atmospheric air. The rectangular symbol (black or blue) and line (black or red) in Tc-goethite spectra indicate the measured data and a linear combination fit, respectively. (Right) Normalized XANES spectra for Tc(VII) and Tc(IV) standards, and the reacted Tc-Fe(II) goethite samples of (a) Tc-Fe(II) goethite pellet Sample 2-5 leached in IDF pore water solution after 120 days; (b) Tc-Fe(II) goethite powder Sample 2 leached in $\mathrm{pH}=10$ solution after 180 days; (c) Tc-Fe(II) goethite powder Sample 2 leached in $\mathrm{pH}=4$ solution after 180 days; and (d) Tc-Fe(II) goethite powder Sample 2 leached in simulated glass leachate after 180 days. The rectangular black symbols and red lines indicate the measured data and a linear combination fit, respectively. 


\section{0 $\operatorname{Re}(\mathrm{VII})$ Sequestration by Fe(II)-Goethite}

Because in laboratory-scale experiments, Re is often used as a nonradioactive surrogate for Tc to avoid the radioactive contamination problems caused by Tc compounds, the objective of this study was to estimate potential differences in Re and Tc behavior in systems of goethite and in the presence of $\mathrm{Fe}$ (II) or other reductants. Specifically, the objectives were to 1) determine the extent and rate of aqueous $\mathrm{Re}(\mathrm{VII})$ attenuation under acidic conditions in the presence of goethite and $\mathrm{Fe}(\mathrm{II})$ (or other reductants); 2) determine the extent and rate of aqueous $\operatorname{Re}(\mathrm{VII})$ attenuation under alkaline conditions in the presence of goethite, $\mathrm{Fe}$ (II) (or other reductants) and additional Fe(III); and 3) elucidate mechanism(s) of Re(VII) attenuation [reduction and precipitation as discrete $\mathrm{Re}(\mathrm{IV})$ oxide particles] vs. incorporation as either $\mathrm{Re}(\mathrm{VII})$ and/or Re(IV) inside the structure of the minerals that are formed in these systems. Results demonstrated that $\operatorname{Re}(\mathrm{VII})$ was resistant to reduction, and, apparently, it was much more resistant to reduction and incorporation into goethite and other iron oxides than $\mathrm{Tc}(\mathrm{VII})$. The apparent reduction of $\mathrm{Re}(\mathrm{VII})$ under both acidic and basic conditions was slow and incomplete. Much smaller amounts of aqueous Re interacted with goethite compared to its chemical analog, Tc. The data generated during these experiments provided scientific insights into whether Re can be used as a surrogate for the Tc under conditions where their interaction, reduction, and incorporation in potential waste forms, such as goethite, is promoted. Testing is currently underway to demonstrate the capture of Tc in goethite under simple and more complex waste solutions (see Section 2.0 above). In addition, Re is being evaluated as a surrogate for $\mathrm{Tc}$ in the goethite incorporation process, leading to a bench-scale demonstration of the preparation of $\mathrm{Re}$ and/or Tc goethite.

Based on the Tc and Re analogy and mainly because under some circumstances it is not possible to conduct research work with radionuclides, Re has been commonly used as a substitute for Tc in experiments of different kinds and their behaviors are compared in many studies (Brookins 1986; Zhang et al. 2000; Volkovich et al. 2002; Kim and Boulegue 2003; Kim et al. 2004; Poineau et al. 2006; Anderson et al. 2007). Additional details about the similarities and differences in their behavior are described by Icenhower et al. (2010) and are presented below.

\subsection{Re Versus Tc: Similarities}

Some similarities (mostly elemental and ionic) between these two chemical elements are listed below and presented in Table 3.1:

- Both Re and Tc may occur as heptavalent cations (7+) of similar size.

- They both combine with oxygen to form water soluble oxyanionic species, i.e., the pertechnetate $\left(\mathrm{TcO}_{4}{ }^{-}\right)$and perrhenate $\left(\mathrm{ReO}_{4}{ }^{-}\right)$species.

- The aqueous species $\left[\mathrm{Re}(\mathrm{IV}) \mathrm{O}(\mathrm{OH})_{3}\right]^{-}$forms under alkaline conditions (i.e., $\mathrm{pH}>9$ ) and low concentrations ( $\operatorname{Re}<10^{-6} \mathrm{~mol} / \mathrm{L}$ ) (Kim and Boulegue 2003). This aqueous species is analogous to $\left[\mathrm{Tc}(\mathrm{IV}) \mathrm{O}(\mathrm{OH})_{3}\right]^{-}$that is formed under similar conditions (Eriksen et al. 1992).

- Dissolution in neutral $\mathrm{pH}$ regimes releases neutral species of Re, just as in the case of technetium (Lieser et al. 1987):

$$
\mathrm{ReO}_{2}(\mathrm{cr})+\mathrm{H}_{2} \mathrm{O} \leftrightarrow \mathrm{ReO}(\mathrm{OH})_{2}{ }^{\circ}(\mathrm{aq})
$$


- The solubility of Re oxides under various oxidation states was studied in a series of experiments conducted under oxidizing and anoxic conditions, with the objective to verify the validity of the available thermodynamic data concerning Re (Kim and Boulegue 2003). These researchers found that the predicted solubility of $\mathrm{Re}$, under the conditions found in radioactive wastes storage, is very high when $\mathrm{Re}$ occurs in the form of $\mathrm{ReO}_{4}{ }^{-}$, which is an analogue of $\mathrm{TcO}_{4}{ }^{-}$.

- The most comprehensive review paper about the chemistry of radioactive Tc species and their nonradioactive Re surrogates in the context of Hanford Site low-level radioactive waste processing and vitrification, was written by Darab and Smith (1996). In this review, detailed information extracted from different publications, was presented on the hydrolysis, precipitation, phase transformation, volatilization and redox chemistries of these species during the drying, calcining, and vitrification of aqueous waste slurries. The similarities between the chemistry of Tc and Re chemical species were highlighted in this review paper, to evaluate the performance of $\mathrm{Re}$ as a surrogate for $\mathrm{Tc}$ in laboratory and engineering-scale low-level radioactive waste vitrification experiments.

Table 3.1. Chemical Properties of Re and Tc (from Icenhower et al. 2010)

\begin{tabular}{lcc}
\hline \multicolumn{1}{c}{$M=\mathrm{Tc}$ or Re } & $\mathrm{Tc}$ & $\mathrm{Re}$ \\
\hline Principal oxidation states: & $\mathrm{IV}, \mathrm{VII}$ & $\mathrm{III}, \mathrm{IV}, \mathrm{VII}$ \\
Cation (VII) size (nm) & $51^{(\mathrm{a})}$ & $52^{(\mathrm{a})}$ \\
Cation (IV) size (nm) & $78.5^{(\mathrm{a})}$ & $77^{(\mathrm{a})}$ \\
$M(\mathrm{VII})-\mathrm{O} \AA$ & $1.73^{(\mathrm{b})}$ & $1.74^{(\mathrm{c})}$ \\
$M(\mathrm{IV})$-O $\AA$ & $2.00^{(\mathrm{d})}$ & $1.98^{(\mathrm{c})}$ \\
$M(\mathrm{IV})$ - $\mathrm{S} \AA$ & $2.33^{(\mathrm{e})}$ & $2.36^{(\mathrm{f})}$ \\
$\mathrm{E}_{\mathrm{hyd}}(\mathrm{eV})$ & $-2.4^{(\mathrm{g})}$ & $-2.5^{(\mathrm{g})}$ \\
$\mathrm{Binding}$ energy $(\mathrm{eV})$ & $-388.7^{(\mathrm{g})}$ & $-371.1^{(\mathrm{g})}$ \\
$M \mathrm{O}_{2} / M \mathrm{O}_{4}^{-}(\mathrm{V})$ & $-0.747^{(\mathrm{h})}$ & $-0.510^{(\mathrm{i})}$ \\
\hline
\end{tabular}
(a) Shannon (1976).
(b) Faggiani et al. 1980).
(c) Colton (1965).
(d) Almahamid et al. (1995).
(e) Lamfers et al. (1996).
(f) Murray et al. (1994).
(g) Anderson et al. (2007b).
(h) Meyer and Arnold (1991).
(i) Kotegov et al. (1968).

\subsection{Re Versus Tc: Differences}

There are differences in the behavior of Re and Tc and some researchers believe that in some cases and under some specific conditions the use of Re as an analog of Tc might yield incorrect conclusions. Some differences are listed below:

- Differences in complexation energies between the chloride species of Re and Tc may render the usefulness of the chemical analogy void (Icenhower et al. 2010). Complexation of Tc with chloride results in a higher solubility (Hess et al. 2004), whereas the chloride complexes of Re results in 
virtually no difference in solubility, as confirmed experimentally by Xiong and Wood (1999).

Therefore, in cases where solutions are chloride-rich, such as certain tank waste chemistries, the use of Re as a Tc analog should be avoided.

- Complexation of Tc and Re by organic ligands appears to be quite different (Jurisson and Murmann 1999), and experiments aimed at understanding Tc speciation in organic-bearing waste, for example, should use Tc rather than Re, as demonstrated by Xia et al. (2006).

- Dissolution of $\mathrm{ReO}_{2}$ showed little dependence on $\mathrm{pH}$, and the presence of oxygen did not appear to affect its solubility. The lack of dependence of dissolution on oxygen partial pressure makes the behavior of $\mathrm{ReO}_{2}$ different from that of $\mathrm{TcO}_{2}$; Lieser et al. (1987) reported that $\mathrm{TcO}_{2}$ solubility is strongly dependent upon the presence of oxygen.

- Other studies have demonstrated that substantial differences between Tc and Re behavior exist for conditions in which electron transfers become important. This topic will be treated in more details in the following section.

\subsubsection{Re Reduction}

Only in recent years has the scientific community paid particular attention to issues (some listed below) related to the differential behavior of Tc and Re in terms of pertechnetate and perrhenate reduction.

- A modeling investigation contrasting Tc and Re sorption and reduction onto iron- and sulfur-bearing minerals was carried out (Anderson et al. 2007). The modeling exercise was based on a quantum mechanical program, and calculations predicted that $\mathrm{TcO}_{4}{ }^{-}$and $\mathrm{ReO}_{4}{ }^{-}$sorption was similar on galena terrace surfaces. On the other hand, $\mathrm{TcO}_{4}{ }^{-}$was predicted to be reduced on galena near-step edges, but $\mathrm{ReO}_{4}{ }^{-}$was not. Part of the difference between the two elements may be a reflection of their chemical properties, such as their binding energies. The binding energies of $\mathrm{TcO}_{4}{ }^{-}$and $\mathrm{ReO}_{4}{ }^{-}$are -388.7 and $-371.1 \mathrm{eV}$, respectively.

- Krupka and collaborators (Krupka et al. 2006) report that Re(VII) sorbed onto or co-precipitated with corrosion products, such as goethite, lepidocrocite, and maghemite. This behavior contrasts with that of Tc, which sorbs as $\mathrm{Tc}(\mathrm{IV})$ rather than $\mathrm{Tc}(\mathrm{VII})$ onto these corrosion products. Their results also suggest that Tc precipitates or forms co-precipitates with Fe(III) minerals. Krupka et al. (2006) suggest that this is due to the difference in the standard potential of the $\operatorname{Re}(\mathrm{VII}) / \operatorname{Re}(\mathrm{IV})$ and $\mathrm{Tc}(\mathrm{VII}) / \mathrm{Tc}(\mathrm{IV})$ couples. The oxidation potential of the former is $-0.510 \mathrm{~V}$, whereas the latter has a value of $-0.738 \mathrm{~V}$ (Kotegov et al. 1968).

- In another study, researchers used x-ray absorption spectroscopy (XAS) to define the local chemical environments of Tc and its chemical analogue Re in precipitates of mackinawite (tetragonal FeS) and its oxidation products (Wharton et al. 2000). Dissolved Tc(VII) as pertechnetate was reduced to $\mathrm{Tc}(\mathrm{IV})$ upon co-precipitation with FeS, while coprecipitated Tc(IV) underwent no redox change while being incorporated into $\mathrm{FeS}$ precipitates. Upon oxidation of the host lattice, Tc remains in oxidation state IV and forms a phase similar to $\mathrm{TcO}_{2}$. Perrhenate behaves in a similar way to pertechnetate upon co-precipitation, but there is evidence that mixed Re-S-Fe phases form as opposed to discrete Tc-S and Fe-S phases co-precipitating and physically mixing. Importantly, upon reoxidation, the host FeS forms goethite and the Re may occupy channels in the goethite structure. $\operatorname{Re}(\mathrm{IV})$ is anomalous in 
that it forms a $\mathrm{ReO}_{2}$-like phase upon co-precipitation with FeS. These authors claim that the $\mathrm{Tc} / \mathrm{Re}$ analogy is only partially sound and that they behave differently during incorporation into the FeS solid phase.

- Other researchers have found that the lack of perrhenate reduction by dissimilatory sulfate-reducing bacteria and Fe-reducing bacteria contrast with published reports of pertechnetate behavior (Dolor et al. 2009). They conclude that despite many qualitative similarities between Re and Tc, these two elements are quantitatively dissimilar, with Re fixation requiring more intensely reducing conditions.

- In yet another study (Maset et al. 2006), it was found that $\mathrm{ReO}_{4}{ }^{-}$did not undergo reduction, as shown by the constant pore water concentration and the chromatographic data, and thus, these authors concluded that Re does not function as an analogue for Tc under nitrate- and iron-reducing conditions in the environment.

- Another group of researchers has noticed that although Tc receives attention largely because of its high environmental mobility, it also causes problems during its incorporation into nuclear waste glass because of the volatility of Tc(VII) compounds (Lukens et al. 2007). According to them, this volatility decreases the amount of ${ }^{99} \mathrm{Tc}$ stabilized in the waste glass and causes contamination of the waste glass melter and off-gas system. The approach to decreasing the volatility of ${ }^{99} \mathrm{Tc}$ that has received the most attention is the reduction of the volatile Tc(VII) species to less volatile $\mathrm{Tc}(\mathrm{IV})$ species in the glass melt. They think that although on engineering-scale experiments Re is often used as a nonradioactive surrogate for Tc to avoid the radioactive contamination problems caused by volatile Tc compounds, $\operatorname{Re}(\mathrm{VII})$ is more stable toward reduction than $\mathrm{Tc}(\mathrm{VII})$, so more reducing conditions would be required in the glass melt to produce Re(IV). To better understand the redox behavior of Tc and Re in nuclear waste glass, they prepared a series of glasses under different redox conditions. The speciation of Tc and Re in the resulting glasses was determined by XFAS spectroscopy. Surprisingly, Re and Tc do not behave similarly in the glass melt. Although Tc(0), $\mathrm{Tc}(\mathrm{IV})$, and $\mathrm{Tc}(\mathrm{VII})$ were observed in these glass samples, only $\operatorname{Re}(0)$ and $\operatorname{Re}(\mathrm{VII})$ are found. In no case is $\mathrm{Re}(\mathrm{IV})$ [or $\mathrm{Re}(\mathrm{VI})$ ] observed in the glass.

- In another study submitted recently for publication, batch-reaction experiments and solid-phase characterization analyses were performed to examine the uptake of dissolved perrhenate [Re(VII)] or pertechnetate [Tc(VII)] by A-516 steel coupons that corroded in simulated groundwater solutions or dilute water (Brown and Krupka, manuscript in preparation). The goal of these researchers was to identify the mechanism(s) that control the uptake of ${ }^{99} \mathrm{Tc}$ by corrosion products on carbon steel in the presence of dilute solutions. XAFS was used to study the oxidation states of Re and Tc incorporated into the corroded steel coupon surfaces. X-ray fluorescence maps showed that the corroded coupons contain localized regions enriched in Re or Tc. The XAS results were consistent with sorbed Re as perrhenate and reduced $\operatorname{Re}(\mathrm{IV})$ was not present in significant amounts (a maximum of $5 \%$ and $10 \%$ $\mathrm{Re}(\mathrm{IV})$. In contrast to the Re results, the XAFS results indicated that most of the sorbed Tc had been reduced to Tc(IV) during incorporation into the corroded steel coupon. The shape of the near edge and extended fine structure is similar to the Tc(IV)-hydrous ferric oxide (HFO) adsorbate and not the $\mathrm{TcO}_{2} \bullet \mathrm{nH}_{2} \mathrm{O}$ standard. 


\subsubsection{Re Incorporation in Solids}

Studies of the incorporation of oxidized and/or reduced Re in different Fe oxides or other minerals are scarce in the literature, although this is an important subject because the manner in which Tc and/or Re are incorporated into the glass matrix is still uncertain (Darab and Smith 1996).

In a recent study, a group of researchers were able to synthesize sodalite $\left[\mathrm{Na}_{8}\left(\mathrm{AlSiO}_{4}\right)_{6}\left(\mathrm{ReO}_{4}\right)_{2}\right]$ that contained $\mathrm{Re}(\mathrm{VII})$, using a hydrothermal method; its crystal structure was determined from Rietveld refinement of experimental X-ray powder diffraction data (Mattigod et al. 2006) (Figure 3.1). This study showed that $\operatorname{Re}(\mathrm{VII})$ can be incorporated into sodalite solids, and the authors claimed that similar results may be obtained for Tc(VII) as well.
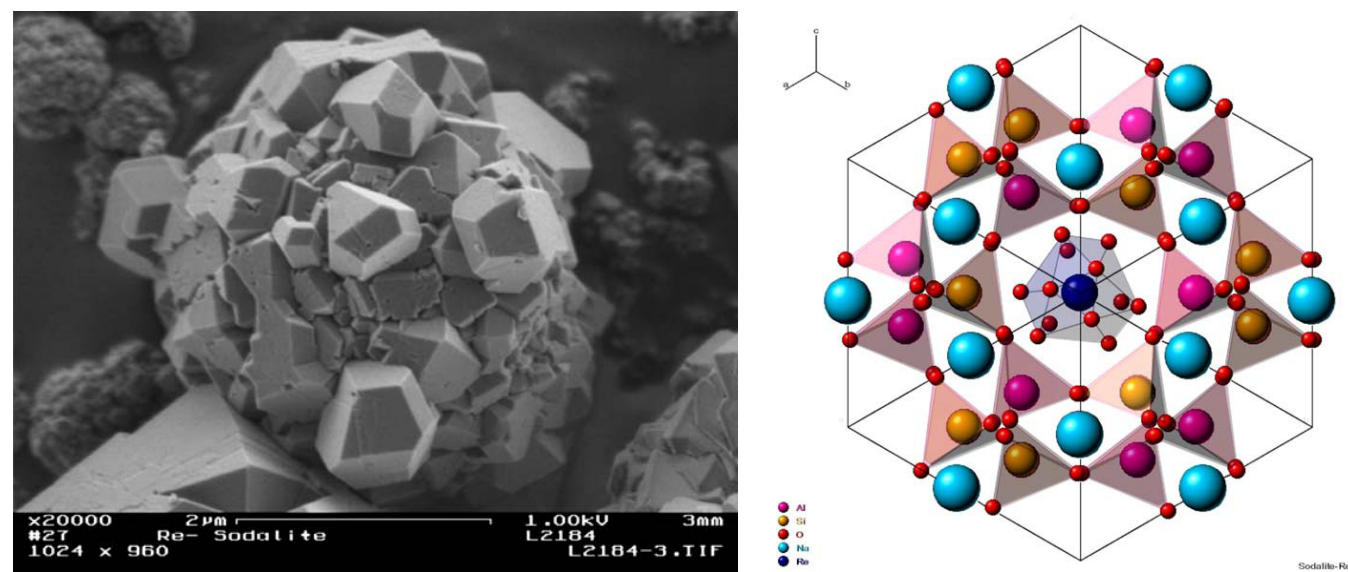

Figure 3.1. A Cluster of Doubly Terminated Trapezohedral Crystals of Synthetic Perrhenate Sodalite (left) and a Model of the Crystal Structure of Perrhenate Sodalite (right) (Mattigod et al. 2006)

\subsubsection{Scientific Objectives}

Based on the current findings in the literature, we designed and conducted a series of laboratory experiments to study Re behavior during interaction with goethite in the presence or absence of Fe(II) (or other reductants) to induce reducing conditions. The results of the experiments should allow us to evaluate potential differences in Re and Tc behavior in such systems.

Experiments were designed to address the following specific scientific objectives:

1. Determine the extent and rate of aqueous Re(VII) attenuation under acidic conditions in the presence of goethite and reductants.

2. Determine the extent and rate of aqueous $\operatorname{Re}(\mathrm{VII})$ attenuation under alkaline conditions in the presence of goethite and reductants.

3. Elucidate mechanism(s) of $\operatorname{Re}(\mathrm{VII})$ attenuation (reduction and precipitation as discrete Re solids vs. Re incorporation) into the goethite structure vs. Re adsorption onto goethite surface sites. 


\subsection{Materials and Methods}

Laboratory experiments were focused on synthesizing goethite and studying Re interactions with goethite in the presence of a reductant (such as $\mathrm{Fe}(\mathrm{II})$ ), and under acidic and basic conditions.

\subsubsection{Laboratory Procedure to Synthesize Goethite}

This laboratory procedure is the same as the one used to synthesize goethite in studies conducted with Tc (see Section 2.0). Approximately $5 \mathrm{~g}$ of goethite $(\alpha-\mathrm{FeOOH})$ was prepared from dissolved ferric nitrate with the addition of $\mathrm{NaOH}$ at elevated temperature $\left(80^{\circ} \mathrm{C}\right)$ in an oven for 7 to 10 days. The $\mathrm{FeOOH}$ was separated from the suspension by filtration and the excess $\mathrm{NaOH}$ was rinsed off using DI water.

The procedure involved the following steps:

1. Dissolve $11.4 \mathrm{~g}$ of $\mathrm{Fe}\left(\mathrm{NO}_{3}\right)_{3} \bullet 9 \mathrm{H}_{2} \mathrm{O}$ in $100 \mathrm{~mL}$ of DI water (the solution had a $\mathrm{pH} \sim 2.3$ ).

2. Add $150 \mathrm{~mL}$ of $2 \mathrm{M} \mathrm{NaOH}$. Mix well, and place the suspension in an oven at $80^{\circ} \mathrm{C}$ for 7 to 10 days. The resulting solid will be $\alpha$-FeOOH (goethite).

3. Separate the FeOOH from the liquid phase using vacuum filtration. Rinse the solids using DI water (filtrate $\mathrm{pH}$ was 12.3).

\subsubsection{Laboratory Procedure to Study Re Interaction with Goethite in the Presence of a Reductant [Fe(II)]]}

The Re interactions with goethite solids in the presence of Fe(II) were studied similarly to the Tc interactions discussed in Section 2.1.2. This procedure involved the following steps:

1. Re-suspend solid goethite $(\alpha-\mathrm{FeOOH})$ in $250 \mathrm{~mL}$ of degassed water. (The degassed water was prepared by boiling water under vacuum).

2. Adjust the $\mathrm{pH}$ of the suspension to 2 to 3 using nitric acid. Typically, $\sim 100-200 \mu \mathrm{L}$ of $8 \mathrm{M}$ $\mathrm{HNO}_{3}$ was added to bring the $\mathrm{pH}$ down to 2.4.

3. Add $3.47 \mathrm{~g}$ of ferrous chloride hexahydrate while slowly bubbling $\mathrm{N}_{2}$ gas into the slurry. Cover the reaction vessel to avoid air/oxygen diffusion in or slowly exchange the head space with $\mathrm{N}_{2}$ gas. Wait 1 hour (or longer).

4. Add $500 \mu \mathrm{g}$ Re as sodium perrhenate $(1.0 \mathrm{~mL}$ of $500 \mu \mathrm{g} / \mathrm{mL}$ Re as sodium perrhenate was added).

5. Wait 1 day to allow for heterogeneous reduction of $\operatorname{Re}(\mathrm{VII})$. (Suspension $\mathrm{pH}$ after 1 day equilibration was 1.7.)

6. Add $150 \mathrm{~mL} 2 \mathrm{M} \mathrm{NaOH}$ to precipitate additional Fe(II/III) oxides, which may incorporate $\mathrm{Re}(\mathrm{IV})$ and/or armor Re(IV) solids that potentially formed on the original goethite surfaces.

7. Dissolve $11.4 \mathrm{~g}$ of $\mathrm{Fe}\left(\mathrm{NO}_{3}\right)_{3} \cdot 9 \mathrm{H}_{2} \mathrm{O}$ in a separate $100 \mathrm{~mL}$ quantity of deionized water, and add it to the FeOOH-Re-ferrous suspension. 
8. Place the suspension in a moisture-tight container in oven at $80^{\circ} \mathrm{C}$. (Small volume aliquot (usually $1 \mathrm{~mL}$ ) subsamples of the slurry were taken, filtered, and the solids and supernates were stored in separate plastic vials at $4^{\circ} \mathrm{C}$.)

9. Determine the partitioning of Re between liquid and solid phases using the separated slurry subsamples.

10. At the end of the oven curing time, cool the slurry to room temperature and separate the solid phase from the liquid using filtration. The solid material was thoroughly rinsed with deionized water while on filter. The solid material was subsequently air-dried, crushed to powder, stored inside glass vials, and used for further post-experimental solid-phase characterization, including microwave digestion, XRD, SEM/EDS, and others.

\subsubsection{Experiments Conducted During This Investigation}

The resultant solid material from Section 3.3.2 was used in all experiments described below unless otherwise specified. A statement of the objectives and other details pertaining to each of the experiments conducted during this investigation are provided below.

Experiment 1. The objective was to determine Re attenuation by the Fe(II)-treated goethite under conditions similar to those that showed nearly $100 \%$ Tc attenuation (see Sections 2.1.2 and 2.2.1). The procedure described in the section 3.3.2 was followed during this experiment. The Re-geothite solid sample for this experiment was collected, filtered, and analyzed for Re and Fe after 240 hours of reaction and heating at $80^{\circ} \mathrm{C}$.

Experiment 2. This experiment was conducted with a different source of Re than sodium perrhenate; the latter was used in Experiment 1 and all other experiments that follow. For experiment 2, rhenium pentachloride $\left[\mathrm{Re}(\mathrm{V}) \mathrm{Cl}_{5}\right]$ solid was used to prepare the Re stock solution by dissolving an appropriate amount of this solid to yield a measured final Re concentration in the systems that was equal to $19326 \pm$ $304 \mu \mathrm{g} \mathrm{L}^{-1}$ (approximately $104 \mu \mathrm{mol} \mathrm{L}^{-1}$ or $10^{-4} \mathrm{~mol} \mathrm{~L}^{-1}$ ). The objective was to study the behavior of pentavalent $\operatorname{Re}[\operatorname{Re}(\mathrm{V})]$ (a lower valence state of Re than perrhenate) in this system. The only difference in Experiment 2 was the source of the Re added in Step 4 above in Section 3.3.2. Various slurry samples from Experiment 2 were collected, syringe-filtered using a $0.22-\mu \mathrm{m}$ filter (this procedure was used in all experiments), and analyzed for total $\mathrm{Re}$ and $\mathrm{Fe}$. Initial $\mathrm{pH}$ before the $2 \mathrm{M} \mathrm{NaOH}$ solution was added into the batch reactors was 1.89. The first sample was collected at this time, i.e., before the addition of base. Additional Fe(III) was added after 24 hours of equilibrating time with the basic solution and the bottles were placed in the oven. Additional samples were collected 24, 48, 72, 168, and 336 hours after the slurry was placed in the oven, and the corresponding measured $\mathrm{pH}$ values were 13.4, 13.21, 13.21, 13.20, and 13.22 , respectively.

Experiment 3. The objectives of this experiment were to 1) determine the extent and rate of aqueous $\mathrm{Re}(\mathrm{VII})$ attenuation under acidic conditions in the presence of goethite and $\mathrm{Fe}(\mathrm{II}) ; 2$ ) determine the extent and rate of aqueous $\mathrm{Re}(\mathrm{VII})$ attenuation under alkaline conditions in the presence of goethite, $\mathrm{Fe}(\mathrm{II})$ and additional $\mathrm{Fe}(\mathrm{III})$; and 3) elucidate, if possible, mechanism(s) of Re(VII) attenuation (such as, for example, reduction and precipitation vs. incorporation). All operations were performed inside a glove box with an $\mathrm{O}_{2}$ level less than $1 \mathrm{ppm}$. 
Details of the laboratory procedure are provided below. Three $500-\mathrm{mL}$ bottles labeled 1, 2, and 3 were prepared for this experiment. Two grams of synthetic goethite in $250 \mathrm{~mL}$ of de-aerated DI water were added to each bottle and were mixed well by swirling and inverting the bottles 5 to 10 times. The resulting mixture was a muddy and orange-colored slurry. The $\mathrm{pH}$ measurements indicated that $\mathrm{pH}$ ranged from 10.22 to 10.28 in the three bottles. The $\mathrm{pH}$ in each bottle was adjusted to a range of 2 to 3 by adding $200 \mu \mathrm{L}$ of $8 \mathrm{M} \mathrm{HNO}_{3}$ (final $\mathrm{pH}$ of each mixture was $~ 2.5$ ). Subsequently, 4.1 grams of ferrous chloride hexahydrate was added and again the bottles were mixed well and set aside for 5 days to allow sufficient time for the contents to reach equilibrium. The bottles were kept inside the glove box and were shaken by hand periodically. The first 1-mL sample suspension was taken from each bottle after 5 days after measuring the $\mathrm{pH}$ ( $\mathrm{pH}$ was measured in all bottles: $\mathrm{pH}_{1}=2.53 ; \mathrm{pH}_{2}=2.51 ; \mathrm{pH}_{3}=2.50$ ). The samples were filtered through a $0.22-\mu \mathrm{m}$ filter using a 3-mL syringe and both the supernate and solids from the aliquot were stored inside the chamber at room temperature. This first supernate sample was later analyzed to determine total Fe and Fe(II) concentrations in the system.

Then $500 \mu \mathrm{g} \mathrm{mL}^{-1} \mathrm{Re}$ as sodium perrhenate was prepared, by dissolving $0.0146 \mathrm{~g}$ of $\mathrm{NaReO}_{4}$ into $20 \mathrm{~mL}$ of de-aerated DI water, and mixed well. This stock solution was used to spike the Fe(II)-goethite mixture after the 5-day equilibration time period. One milliliter of the Re stock solution was added to each of the bottles, which contained $249 \mathrm{~mL}$ of suspension, and they were allowed to equilibrate for 3 days. After the three days of reaction aliquots of the slurry were filtered and both the solids and supernate saved for further analysis.

Concentrations of Re, total Fe, and Fe(II) in the supernate solutions were measured using ICP-MS, ICP-OES, and the ferrozine method, respectively. The procedure to determine $\mathrm{Fe}(\mathrm{II})$ concentration is described below.

Experiment 4. The objective of this experiment was to study the effect of initial Re concentration on Re overall attenuation in the Fe(II)-treated goethite system. Two bottles were prepared for this experiment using $\sim 2.0 \mathrm{~g}$ of synthetic goethite prepared in our laboratory, which was resuspended in $250 \mathrm{~mL}$ DI-water. Measured $\mathrm{pHs}$ for the initial goethite slurry both bottles were 9.48 and 9.60. The $\mathrm{pH}$ was adjusted to 2.41 and 2.19 using $200 \mu \mathrm{L}$ of $8 \mathrm{M}$ nitric acid. Ferrous chloride hexahydrate $(\sim 4.1 \mathrm{~g})$ was added to each bottle in an anaerobic chamber. After 1 hour, $2 \mathrm{~mL}$ of the Re stock solution was added in each of them and they were mixed well by hand. After 15 minutes, $1 \mathrm{~mL}$ samples were taken to measure initial Re concentration in the system, and the bottles were left on the bench top to equilibrate for about 24 hours, and resampled again. The $2 \mathrm{M} \mathrm{NaOH}$ solution was added increasing the $\mathrm{pH}$ to 13.32 and 13.34. The bottles were placed afterwards in the $80^{\circ} \mathrm{C}$ oven. No additional Fe(III) was added in this experiment. Periodic sampling occurred during those days in the oven. This experiment was run in two replicates. The aqueous phase was sampled after the Re inoculation to the Fe(II)-geothite slurry at $0,24,48,71,138$, $168,191,216,312$, and 368 hours.

Experiment 5. This experiment was conducted using the SBS simulant (Table 3.2; same as SSS-4 in Table 2.2), which was spiked with Re. Four bottles were prepared for these experiments. Two bottles (bottles 3 and 4) were run as control bottles; they initially contained $250 \mathrm{~mL}$ of the slurry consisting of $2.75 \mathrm{~g}$ of goethite in $250-\mathrm{mL}$ of deionized water mixed with an additional $250-\mathrm{mL}$ SBS solution. The SBS solution was prepared using de-aerated DI water, i.e., boiled under vacuum. Ten milliliters of the $500 \mu \mathrm{g} \mathrm{mL} \mathrm{me}^{-1} \mathrm{Re}$ as sodium perrhenate stock solution was added to each of these control bottles. 
The other two bottles (bottles 1 and 2) initially contained $250 \mathrm{~mL}$ of the goethite slurry (2.75 $\mathrm{g}$ of goethite added to 250 de-aerated distilled water; the $\mathrm{pH}$ of the slurry was adjusted to 1.5 to 2 using $8 \mathrm{M} \mathrm{HNO}_{3}$ by addition of $500 \mu \mathrm{L}$ of acid to bring the $\mathrm{pH}$ down to 2.01 [bottle 1] and 1.99 [bottle 2]). Powder $\mathrm{FeCl}_{2} \times 4 \mathrm{H}_{2} \mathrm{O}$ (3.49 $\mathrm{g}$ in bottle 1 and $3.48 \mathrm{~g}$ in bottle 2$)$ was added to the goethite slurry. In addition, $260 \mathrm{~mL}\left(10 \mathrm{~mL}\right.$ of the $500 \mu \mathrm{g} \mathrm{mL}^{-1} \mathrm{Re}$ as sodium perrhenate stock solution and $250 \mathrm{~mL}$ of SBS solution) were also added to bottles 1 and 2 . The $\mathrm{pH}$ was adjusted after mixing to around 10 using $2 \mathrm{M} \mathrm{NaOH}$. Thirty-five milliliters of the base were used to adjust pHs to 10.5 (bottle 1) and 10.59 (bottle 2). After addition of the base, the suspension turned a yellow-green-brown color.

All bottles were left to react. Bottles 1 and 3 were left on the bench top for 2 hours. Bottles 2 and 4 were placed in an $80^{\circ} \mathrm{C}$ oven for 2 hours. After 2 hours of reaction, $\mathrm{Fe}\left(\mathrm{NO}_{3}\right)_{3} \bullet 9 \mathrm{H}_{2} \mathrm{O}$ solution was added to bottles 1 and $2(11.4 \mathrm{~g} / 100 \mathrm{~mL})$ and mixed well. The $\mathrm{pH}$ was adjusted back up to $\sim 10 \mathrm{using}$ $2 \mathrm{M} \mathrm{NaOH}$. Bottle 1 used $45 \mathrm{~mL}$ of the base and raised the $\mathrm{pH}$ up to 11.87 , after which $1 \mathrm{~mL}$ of $8 \mathrm{M} \mathrm{HNO}_{3}$ was added to decrease the $\mathrm{pH}$ to 10.62 . Bottle 2 received $42 \mathrm{~mL}$ of the base to increase the $\mathrm{pH}$ to 10.50. One-milliliter slurry samples were taken from bottles 1 and 2 and syringe filtered using a $0.22-\mu \mathrm{m}$ syringe filter. Both experimental bottles with their controls were left to react another hour. Bottles 1 and 3 were left on the bench top and Bottles 2 and 4 were placed in an $80^{\circ} \mathrm{C}$ oven. After one more hour of reaction, the slurries were filtered. Twenty milliliters of filtrate $(0.45-\mu \mathrm{m}$ filters $)$ were saved from each of the four bottles and the solids were rinsed well with $\mathrm{DI}_{2} \mathrm{O}$. One-milliliter samples of the filtrates were submitted for Re and Fe analysis by ICP-MS and ICP-OES, respectively.

Table 3.2. Chemical Constituents for SBS Simulants Used in the Re-Goethite Experiment

\begin{tabular}{|c|c|c|}
\hline Constituents & Moles/L & Target (M) \\
\hline $\mathrm{Na}$ & $2.00 \mathrm{E}+00$ & 2 \\
\hline $\mathrm{Al}$ & $9.88 \mathrm{E}-03$ & $9.88 \mathrm{E}-03$ \\
\hline $\mathrm{Si}$ & $4.52 \mathrm{E}-02$ & $4.52 \mathrm{E}-02$ \\
\hline K & $9.82 \mathrm{E}-02$ & $9.82 \mathrm{E}-02$ \\
\hline NH4+ & $2.72 \mathrm{E}-01$ & $2.08 \mathrm{E}+00$ \\
\hline $\mathrm{Cr}$ & $3.46 \mathrm{E}-03$ & $3.46 \mathrm{E}-03$ \\
\hline $\mathrm{Ag}$ & $7.18 \mathrm{E}-05$ & $7.20 \mathrm{E}-05$ \\
\hline $\mathrm{Cd}$ & 7.23E-05 & 7.24E-05 \\
\hline As & $7.04 \mathrm{E}-04$ & $0.00 \mathrm{E}+00$ \\
\hline $\mathrm{Re}$ & & $1.0 \mathrm{E}-04$ \\
\hline I & $2.10 \mathrm{E}-04$ & $2.10 \mathrm{E}-04$ \\
\hline $\mathrm{Hg}$ & $1.79 \mathrm{E}-06$ & $1.84 \mathrm{E}-06$ \\
\hline $\mathrm{Pb}$ & $1.54 \mathrm{E}-05$ & $1.55 \mathrm{E}-05$ \\
\hline $\mathrm{CO}_{3}^{-2}$ & $3.32 \mathrm{E}-03$ & $3.32 \mathrm{E}-03$ \\
\hline $\mathrm{NO}_{3}^{-}$ & $1.49 \mathrm{E}+00$ & $3.44 \mathrm{E}+00$ \\
\hline $\mathrm{OH}^{-}$ & $6.63 \mathrm{E}-08$ & $6.66 \mathrm{E}-08$ \\
\hline $\mathrm{Cl}-$ & $1.41 \mathrm{E}-01$ & $3.28 \mathrm{E}-03$ \\
\hline $\mathrm{NO}_{2}^{-}$ & $1.31 \mathrm{E}-01$ & $1.31 \mathrm{E}-01$ \\
\hline $\mathrm{PO}_{4}{ }^{3-}$ & 7.62E-03 & 7.62E-03 \\
\hline $\mathrm{SO}_{4}{ }^{2-}$ & $1.45 \mathrm{E}-01$ & $1.44 \mathrm{E}-01$ \\
\hline $\mathrm{F}^{-}$ & $1.63 \mathrm{E}-01$ & $1.63 \mathrm{E}-01$ \\
\hline TOC (as oxalate) & $9.88 \mathrm{E}-03$ & $9.88 \mathrm{E}-03$ \\
\hline
\end{tabular}




\subsubsection{Laboratory Methods and Instruments Employed During This Investigation}

\subsubsection{Aqueous Phase Analyses}

$\mathrm{Re}$ and Fe concentrations were the main aqueous phase variables determined in the filtrates from the slurries. Changes in aqueous $\mathrm{Re}$ and $\mathrm{Fe}$ concentrations with time during these experiments were followed. These analyses were performed in the Environmental Sciences Laboratory (Applied Geology and Geochemistry Group) and the filtered aqueous samples were analyzed for total Fe and Re using ICP-OES or ICP-MS, respectively. The results were compared with those obtained in similar experiments conducted with Tc as described in Section 2.2.1.

\subsubsection{Ferrozine Method for Fe(II) Analysis}

Ferrozine solution: Prepare the ferrozine solution by adding $1 \mathrm{~g}$ of ferrozine and $11.915 \mathrm{~g}$ of 4-(2-hydroxyethyl)-1-piperazineethanesulfonic acid (HEPES) buffer to a 1-L volumetric flask. The concentration of HEPES buffer will be $50 \mathrm{mM}$. Adjust the $\mathrm{pH}$ of the solution to 7.0 using $5 \mathrm{M} \mathrm{NaOH}$. Make sure the $\mathrm{pH}$ electrode is clean of any Fe(II) impurities. (The standard method for cleaning the $\mathrm{pH}$ electrode is to immerse it for 5 minutes in $0.1 \mathrm{M} \mathrm{NaOH}$ followed by placing it for 5 minutes in $0.1 \mathrm{M} \mathrm{HCl})$.

Fe(II) stock standard: Prepare a $1000-\mathrm{mg} / \mathrm{L} \mathrm{Fe}(\mathrm{II})$ standard using pure $\mathrm{FeCl}_{2}$. Dissolve the salt $\left(0.57 \mathrm{~g} \mathrm{FeCl}_{2}\right.$ with $\left.250 \mathrm{~mL} \mathrm{HCl} 0.5 \mathrm{M}\right)$ to prepare the $1000-\mathrm{mg} / \mathrm{L} \mathrm{Fe}(\mathrm{II})$ standard.

Fe(II) standards: Using the stock standard, prepare 5 standards for $\mathrm{Fe}(\mathrm{II})$ calibration curve. The standards $10 \mathrm{mg} / \mathrm{L}, 5 \mathrm{mg} / \mathrm{L}, 1 \mathrm{mg} / \mathrm{L}, 0.5 \mathrm{mg} / \mathrm{L}$ and $0.1 \mathrm{mg} / \mathrm{L}$ will be prepared by dilution in DI water of the stock standard. Prepare two blank samples for background correction.

Preparation of samples and standards for Fe(II) analysis should be done inside the environmental chamber. Mix the $0.2-\mathrm{mL}$ blank or standard or sample with $1.8 \mathrm{~mL}$ of the ferrozine solution. Always start by adding $1.8 \mathrm{~mL}$ of ferrozine in all falcon tubes (falcon tubes or any plastic container that will be in contact with samples or standards are required to be degassed inside the environmental chamber for 24 hours). Add the sample to every tube containing ferrozine starting with blanks-standards-samples. It is safe to remove the samples from the chamber for analysis. The UV-vis spectrometer should have been turned on and should be ready for analysis at this point. The measurement of Fe(II) absorbance will be conducted at the 562-nm wavelength. Start with background correction by placing the blanks into cuvettes and zeroing the reading. Continue transferring standards into cuvettes and measuring the absorbance. It is a good idea to measure a background sample (ferrozine + sample matrix) to check interference due to the matrix. Continue with transferring and measuring the samples.

Note: After mixing with ferrozine, all the readings were completed within one-half hour.

\subsubsection{Microwave Digestion Method}

This method was used to determine the total amount of Re in the final goethite product. Microwave digests were performed in a MARS 5 Microwave Accelerated Reaction System following procedure EPA SW-846 Method 3052, Microwave Assisted Acid Digestion of Siliceous and Organically Based Matrices. The digests were then analyzed for total Fe and Re using ICP-OES and ICP-MS, respectively. 


\subsubsection{XRD Analyses}

At the end of the experiments, the solid materials were separated from the liquid using vacuum filtration with $0.45-\mu \mathrm{m}$ Nalgene filter units and were subsequently rinsed with DI water. The solid materials were air dried overnight, crushed to a powder using a mortar and pestle, and subsequently characterized by XRD to identify the potential presence of any Fe and possible Re phases. Each sample was analyzed on a Scintag XRD unit operating at $45 \mathrm{kV}$ and $40 \mathrm{~mA}$ with a range of 2 to 652 -theta degrees and a scan rate of 1 degree per second. The scans were retrieved electronically and were examined using the JADE XRD software.

\subsubsection{SEM/EDS Analyses and Measurements}

Samples of the solid materials (goethite) were analyzed by SEM and EDS at the Environmental Molecular Sciences Laboratory (EMSL). The sample mounts consisted of carbon-coated, metallographic polished cross sections. A Zeiss LEO-982 FE-SEM was used for high-resolution imaging. The SEM system was equipped with an Oxford INCA EDS for semi-quantitative elemental analysis and mapping. Operating conditions consisted of $20 \mathrm{keV}$ for SEM imaging and $20 \mathrm{keV}, 100$ live seconds and 20 to $30 \%$ dead time for the EDS analyses. Photomicrographs of high-resolution secondary electron (SE) images and backscattered electron (BSE) images were obtained as digital images and stored in electronic format. The specific surface area of final goethite containing Tc(VII) or Re solids was measured using a Micromeritics ASAP 2020 gas-sorption system with a multipoint (5 points) $\mathrm{N}_{2}$-BET method (Brunauer et al. 1938).

\subsection{Results}

\subsubsection{Experiment 1}

A summary of the results from this experiment is presented in Table 3.3. In this table, data collected from other experiments conducted with Tc are also presented for comparison. The total amount of Tc or Re that was present in the final solid was determined by either microwave digestion for the Re-goethite and Tc (Sample 2) or strong acid extractions at high temperature (Samples 2-1 to 2-5 of Tc-goethite). For a detailed description and data interpretation of the Tc experiments, refer to Sections 2.1.2 and 2.2.1 of this report.

Clearly, much less Re than Tc was sequestered by the final goethite product formed in Experiment 1. While the total Tc amount removed from the aqueous phase varied between $93 \%$ to $100 \%$, the total amount of Re removed was significantly smaller ( 17\%). Approximately $2.4 \mu \mathrm{g} \mathrm{Re} / \mathrm{g}$ of goethite was sequestered in Re-goethite Experiment 1. Again, this was significantly smaller than the amount of Tc sequestered in goethite, which varied from 79 to $149 \mu \mathrm{g} / \mathrm{g}$ of solid depending on the experimental method employed to create the reacted goethite. 
Table 3.3. Data from Experiments Conducted with Tc and Re

\begin{tabular}{lcccccccc}
\hline & \multicolumn{7}{c}{ Sample Approach IDs for Laboratory Scale Test } \\
\cline { 2 - 8 } \multicolumn{1}{c}{ Results } & 2 & $2-1$ & $2-2$ & $2-3$ & $2-3^{*}$ & $2-4$ & $2-5$ & $\operatorname{Re}$ \\
\hline $\begin{array}{l}\text { Specific surface area } \\
\left(\mathrm{m}^{2} / \mathrm{g}\right)\end{array}$ & 142.5 & & & & & & 76.8 & 14.2 \\
$\begin{array}{l}\text { Final Tc/Re removal } \\
\text { on solid }(\mu \mathrm{g} / \mathrm{g})^{*}\end{array}$ & 85.7 & 84.4 & 149.1 & 143.1 & 1020 & 78.9 & 96.0 & 2.38 \\
$\begin{array}{l}\text { Contaminant (Tc or } \\
\mathrm{Re}) \text { uptake (\%) }\end{array}$ & 93.7 & 92.6 & 96.5 & 96.3 & 93.8 & 92.9 & 100.0 & 17.2 \\
\hline
\end{tabular}

* Final concentration of $\mathrm{Tc} / \mathrm{Re}$ on solid was determined by either microwave digestion ( $\# 2$ and $\mathrm{Re}$ ) or acid extract with a heat (\#2-1 to 2-5).

The XRD analysis of a powder sample of the final goethite material from Experiment 1 indicated that only goethite was present in this solid sample (Figure 3.2.). However, one noticeable observation made during this experiment was that the color of the suspension immediately changed to a dark green-gray color after the addition of the $2 \mathrm{M} \mathrm{NaOH}$ solution to the suspension. Upon daily mixing of the suspension, it was observed there were two distinct mineral phases present in the reaction bottle. One mineral was a bright orange color and settled relatively slowly (most likely goethite). The other mineral (as of yet unidentified) had a dark green-gray color and settled more rapidly. They both resuspended when the suspension was hand-mixed daily. Over the course of the 10 -day incubation at $80^{\circ} \mathrm{C}$, the material that was dark green-gray color slowly changed to the bright orange color that is characteristic of goethite. By 8 days of heating the slurry, all of the solid material appeared to be the same color. This suggests that more than one solid phase might have been present in the reaction bottles at the beginning of the experiment. This will be discussed further later in this section.

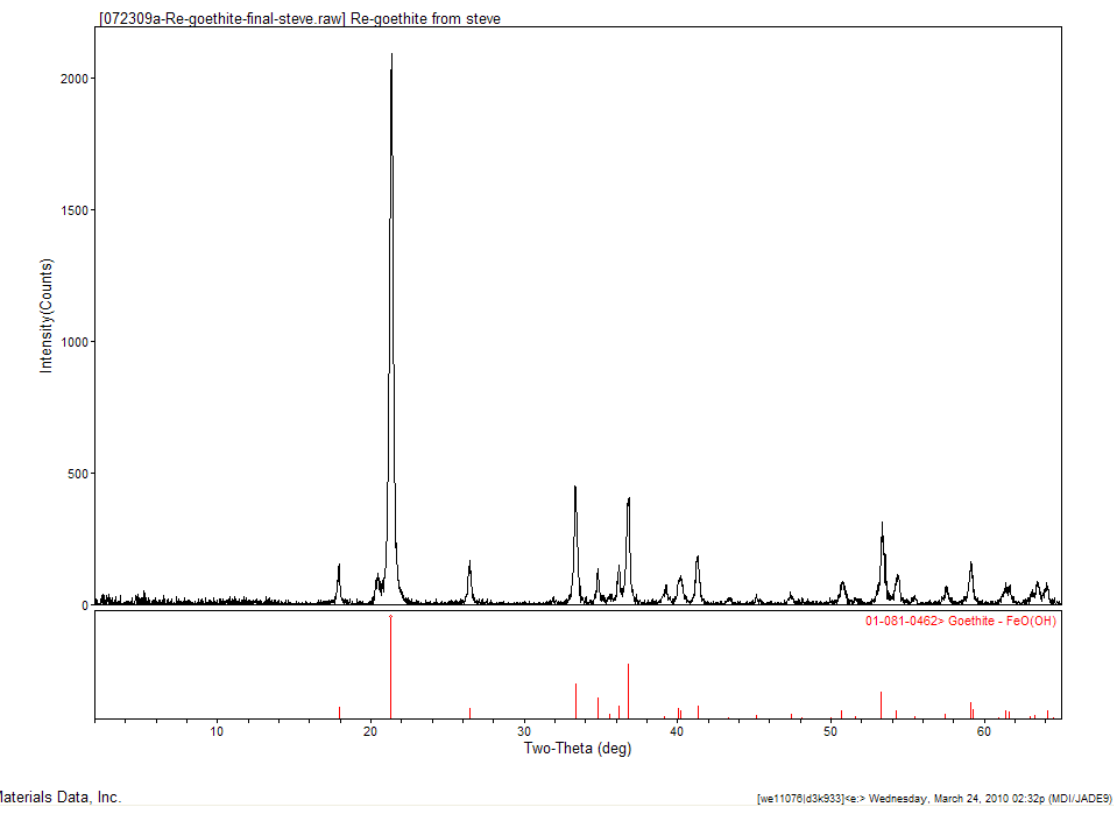

Figure 3.2. XRD Analysis Pattern for the Final Powder Goethite (Experiment 1) 
The morphological features of the goethite particles at the end of Experiment 1 and their chemical compositions were studied using SEM and EDS, respectively (Figures 3.3, 3.4, and 3.5). SEM micrographs showed that goethite particles occurred as micron-sized rods with irregular shapes and lengths. Similar to Tc-goethite, acicular-shaped goethite particles were observed in the final Re-goethite. However, the morphology of the final Tc- and Re-bearing solid products also showed some differences.

EDS measurements confirmed that the final solid in Experiment 1 had a chemical composition similar to that of goethite (Figure 3.5). Similar to the goethite, which reacted with Tc, Re was not detected in the EDS elemental analyses because of the low Re concentration relative to Fe in the solid.
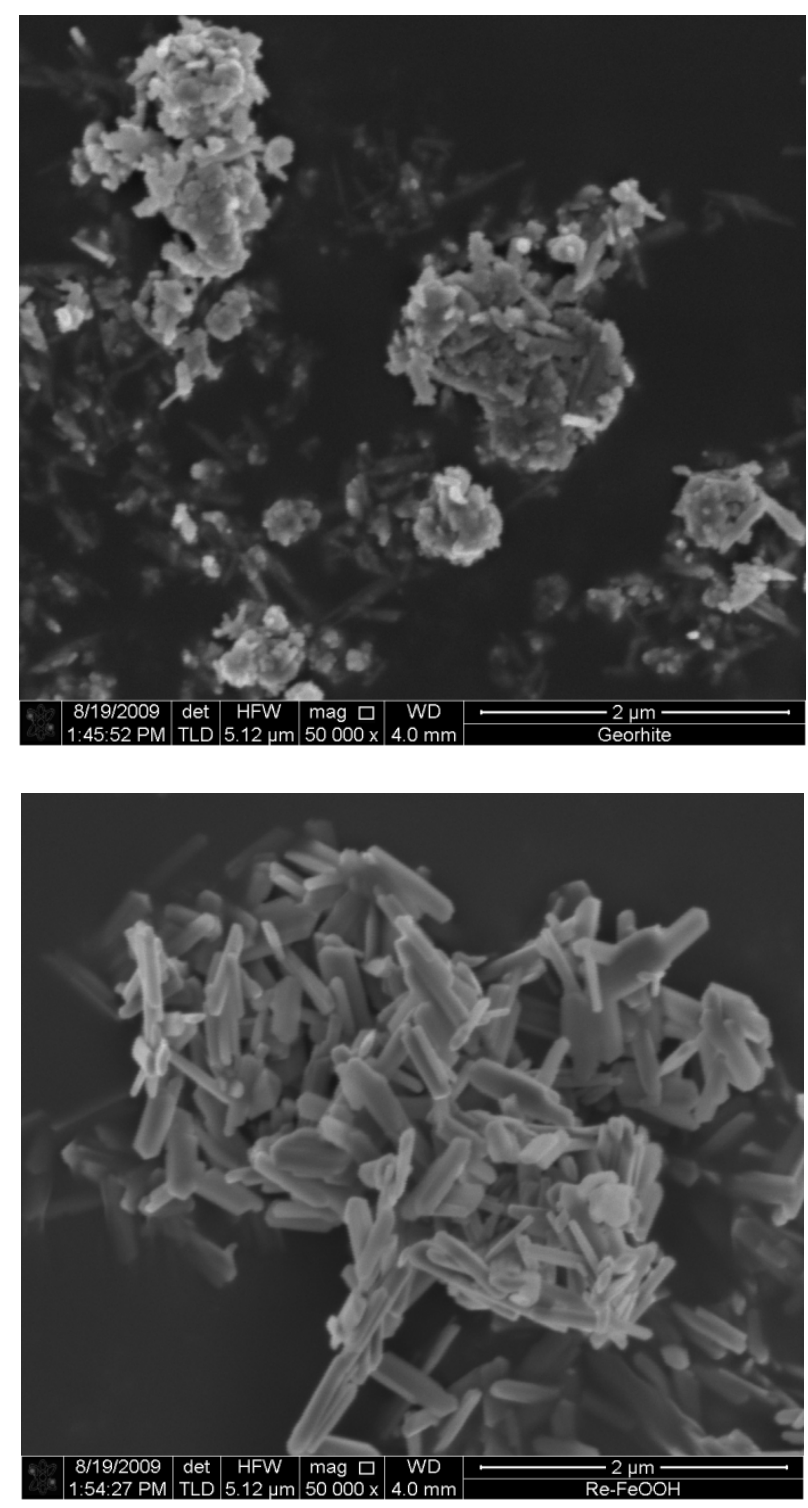

Figure 3.3. SEM Micrographs of Initial (above) and Final Goethite Product (below) (Experiment 1) 

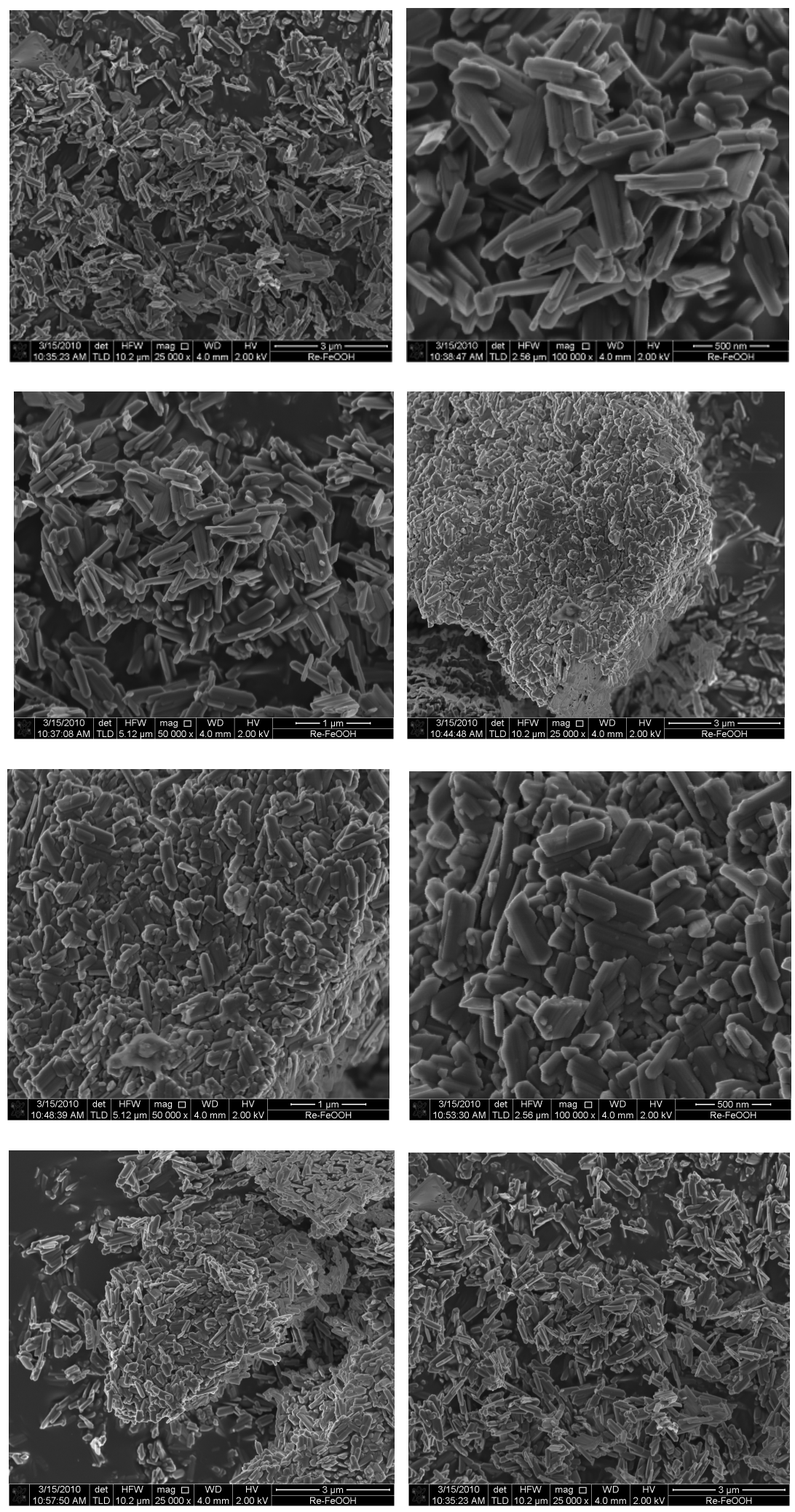

Figure 3.4. Additional SEM Micrographs Taken in the Final Goethite Product (Experiment 1) 

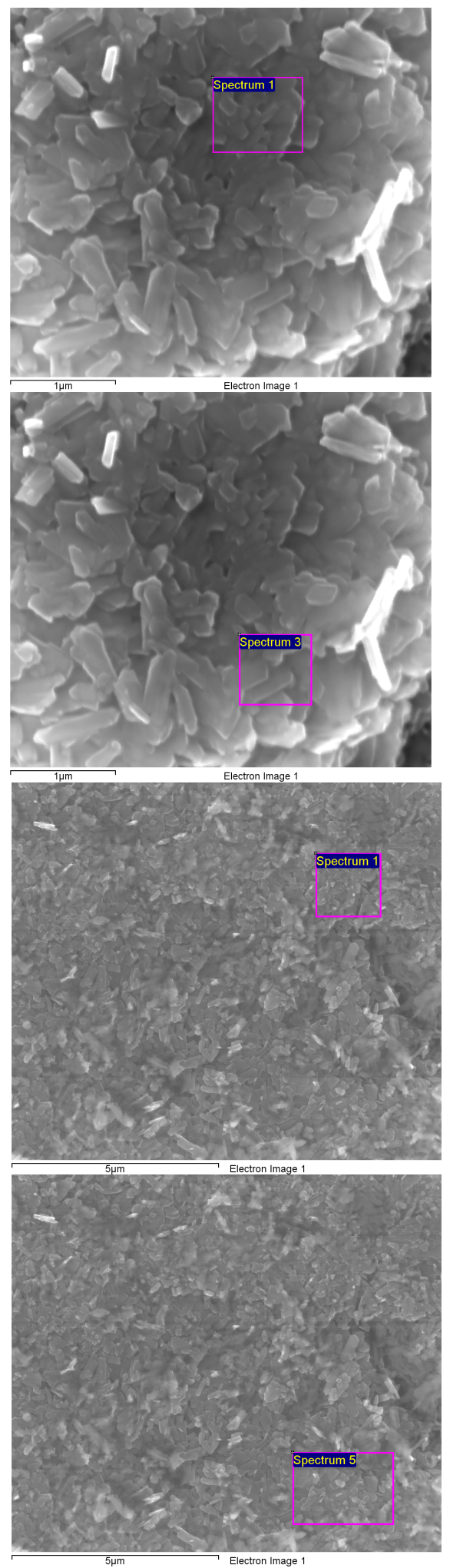

Figure 3.5. EDS Spectrum Taken in the Same Goethite Powder as the One Presented in the Previous Figure (Experiment 3). Re was not detected in this or any other EDS spectra measured in the final goethite sample.
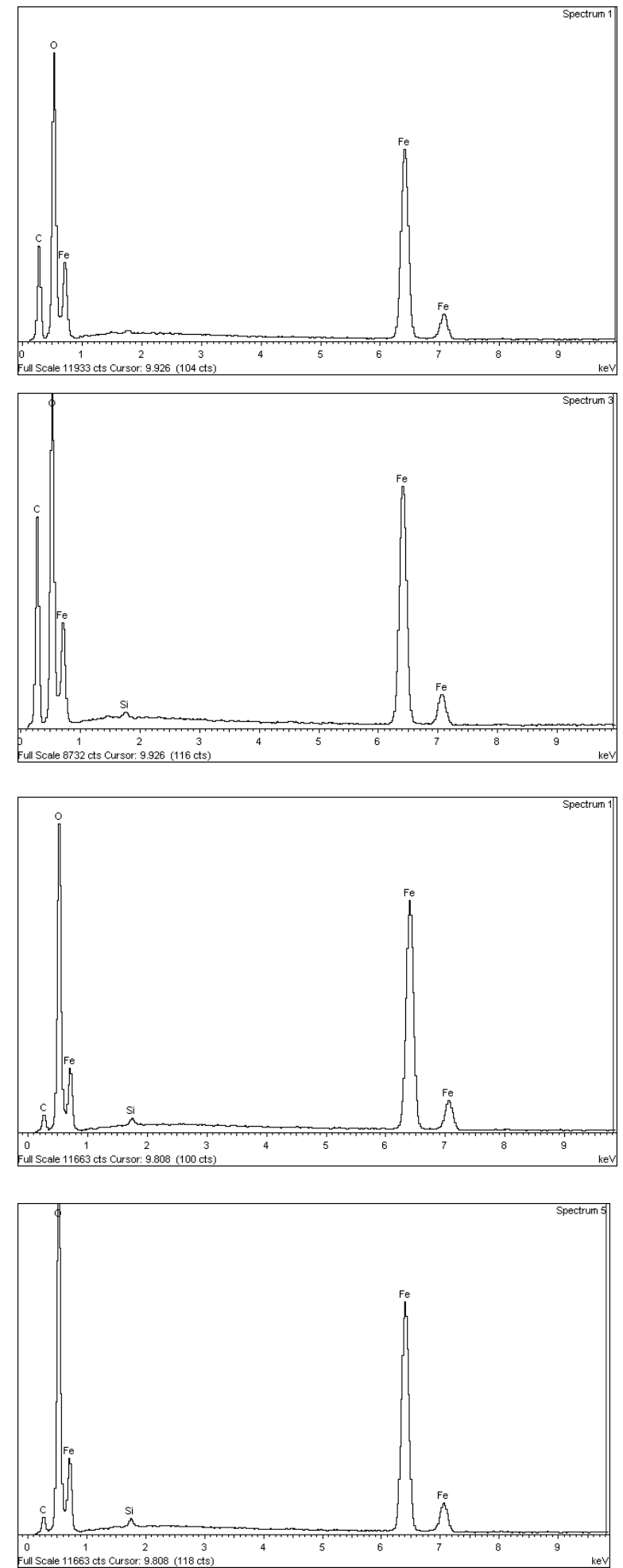
Results from the surface area measurements for two of the Tc- and the Re-goethite final solids were $142.5,76.8$, and $14.2 \mathrm{~m}^{2} \mathrm{~g}^{-1}$, respectively (Table 3.3). The specific surface area of for Sample 2 Tc-goethite of $142.5 \mathrm{~m}^{2} \mathrm{~g}^{-1}$ was greater than typical values found in samples of synthesized goethite $\left(10-90 \mathrm{~m}^{2} / \mathrm{g}\right.$ ) (Schwertmann and Cornell 2000) but the value of $76.8 \mathrm{~m}^{2} \mathrm{~g}^{-1}$ found for Tc Sample 2-5 was near the high end of surface areas reported by Schwertmann and Cornell. The higher surface area for the Tc-goethite Sample 2 may be attributed to the presence of small (most likely nanosized) magnetite particles that were present in this Tc-goethite sample, as confirmed by the XRD results. In addition, the presence of small goethite particles was also demonstrated in the SEM/TEM images of the Tc-goethite samples. As discussed in Section 2.2.1, the Tc-goethite Sample 2-5 did not contain magnetite, which has a larger specific surface area than goethite.

The lower surface area value $\left(14.2 \mathrm{~m}^{2} \mathrm{~g}^{-1}\right)$ measured in the final Re-goethite sample was within the surface area range of goethite, albeit on the low end. The lower value for the Re-goethite was attributed to the relatively more abundant crystalline individual goethite crystals with larger size that were present in this sample. In addition, smaller particles of goethite or other Fe oxides (such as magnetite) were not found in this sample.

\subsubsection{Experiment 2}

This experiment was conducted with rhenium pentachloride used as the source of Re instead of sodium perrhenate, which was used in all the other experiments. About $37 \%$ of the initial Re mass present in solution was removed from the aqueous phase during the first 24 hours of experimental time (Figure 3.6). In addition the percentage of Re that was sequestered dropped to $\sim 17 \%$ after 14 days of reaction. The total amount of Re sequestered in the Re-goethite solid was still smaller than the total amount sequestered in the Tc-goethite solids (93\% to 100\%), but it was greater than the amount of Re sequestered when sodium perrhenate was used as a Re source. Rhenium pentachloride contains $\operatorname{Re}(\mathrm{V})$, while sodium perrhenate contains $\operatorname{Re}(\mathrm{VII})$. About $17 \%$ of the initial $\operatorname{Re}(\mathrm{VII})$ amount was sequestered in Experiment 1 in comparison to the 37\% initially sequestered in Experiment 2 but after 14 days or reaction the Re sequestered in Experiment 2 was only slightly higher 17 vs. 13\% than in Experiment 1 after 10 days of reaction. The initial increase in Re sequestration could be attributed to the fact that rhenium pentachloride is a pentavalent Re solid and the extent of Re reduction to $\mathrm{Re}$ (IV) in the Fe(II)-treatment of the initial and neoformed goethite could be greater.

As noted, the aqueous Re concentration increased with time. This could be due to the oxidative dissolution of $\operatorname{Re}(\mathrm{IV})$ solids, which is a two-step reaction involving reoxidation of $\operatorname{Re}(\mathrm{IV})$ to $\operatorname{Re}(\mathrm{V})$ and/or $\operatorname{Re}(\mathrm{VII})$ followed by the Re mobilization (i.e., release into the aqueous phase). However, this could be also due to the time-dependent dissolution of the Re(IV) compounds, including Re-goethite, that may have formed in this system, which remained at high $\mathrm{pH}$.

Because the amount of Re sequestered by goethite in Experiment 2 was also small by the end of the experiment, it was not possible to use spectroscopic surface and bulk techniques to determine the Re valence state in the final goethite solid. Therefore, it was difficult to determine whether Re attenuation occurred as a result of $\operatorname{Re}(\mathrm{V})$ reduction to $\operatorname{Re}(\mathrm{IV})$, or whether other attenuation mechanisms were operational under these conditions; for example, $\operatorname{Re}(\mathrm{V})$ incorporation into the freshly precipitated $\mathrm{Fe}$ oxides (goethite and/or others) after the addition of the Fe(III) and the $2 \mathrm{M} \mathrm{NaOH}$ solution in the batch reactors, conditions under which the Fe(III) precipitation is greatly promoted. 


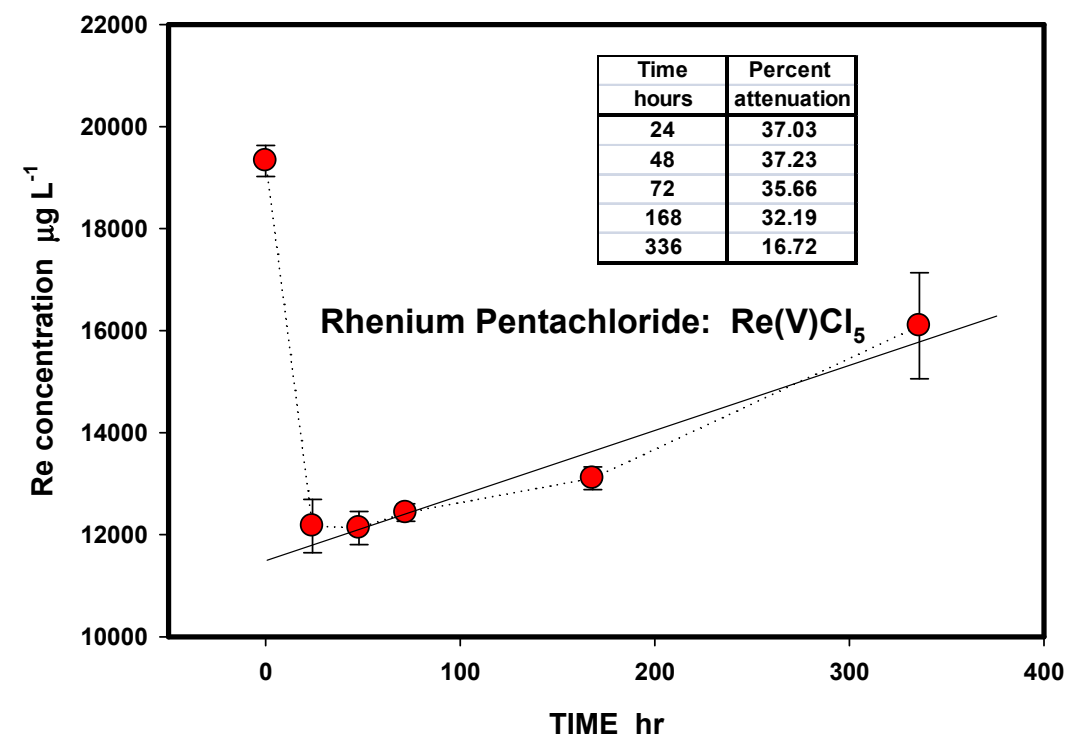

Figure 3.6. Changes in Re Concentration with Time in the Experiment Conducted with Rhenium Pentachloride (Experiment 2)

The XRD analysis performed in a powder solid sample in Experiment 2, collected after 24 hours of base addition indicated that both goethite and magnetite were present (Figure 3.7). The observed presence of magnetite likely explains the change in color from orange to a more dark color observed in all experiments immediately after the addition of the $2 \mathrm{M} \mathrm{NaOH}$ solution, although the presence of other minor but important Fe phases should not be ruled out. These minor phases are usually difficult to identify with XRD.

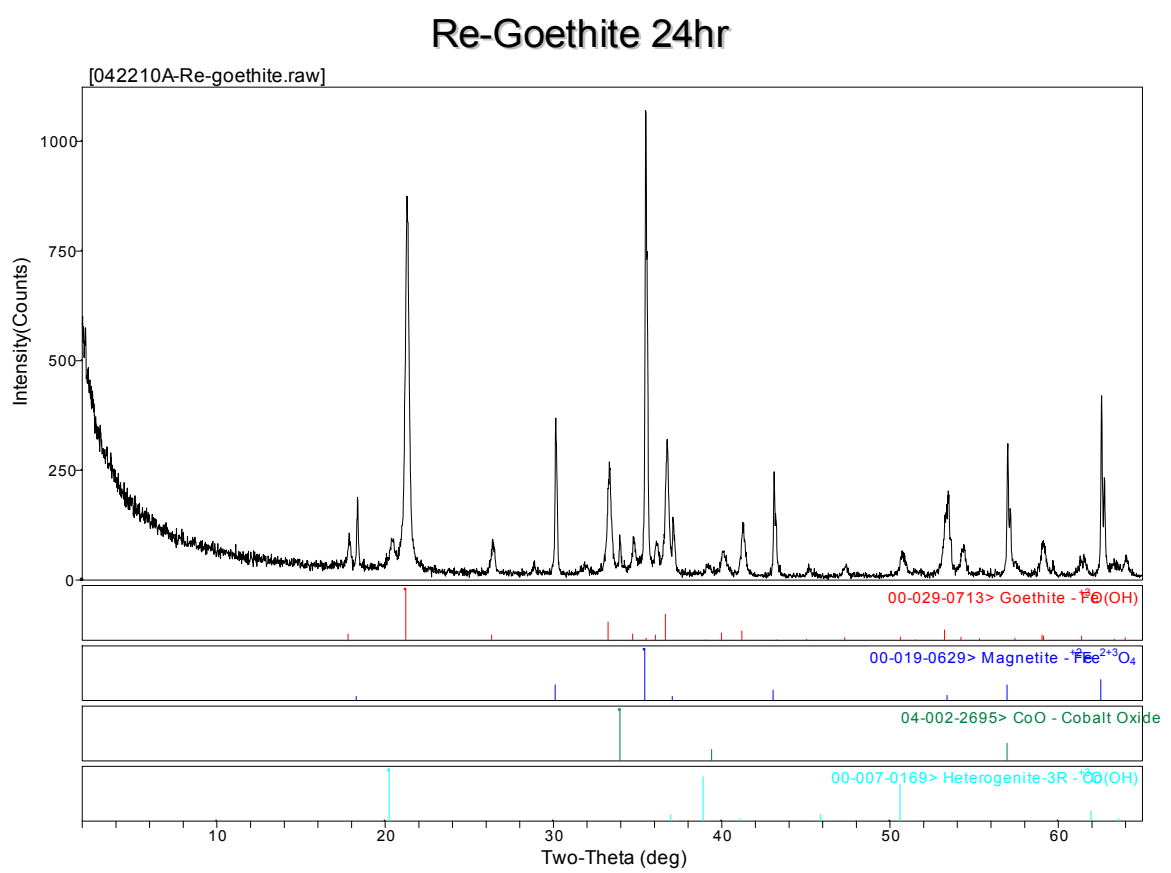

Figure 3.7. XRD Analysis Pattern Taken in Powder Goethite (Experiment 2). After 1 day of reaction. 


\subsubsection{Experiment 3}

The first phase of this experiment, which was used three replicates, was conducted under acidic conditions ( $\mathrm{pH}$ was adjusted with a $8 \mathrm{M} \mathrm{HNO}_{3}$ solution to about 2.5) and in the presence of goethite, $\mathrm{Re}(\mathrm{VII})$ and Fe(II). During this phase, which lasted for about 200 hours, there were no significant changes in the aqueous total $\mathrm{Fe}$, total $\mathrm{Re}$, and $\mathrm{Fe}(\mathrm{II})$ concentrations at seven different experimental times when aqueous samples were collected and analyzed for these analytes (Figure 3.8).

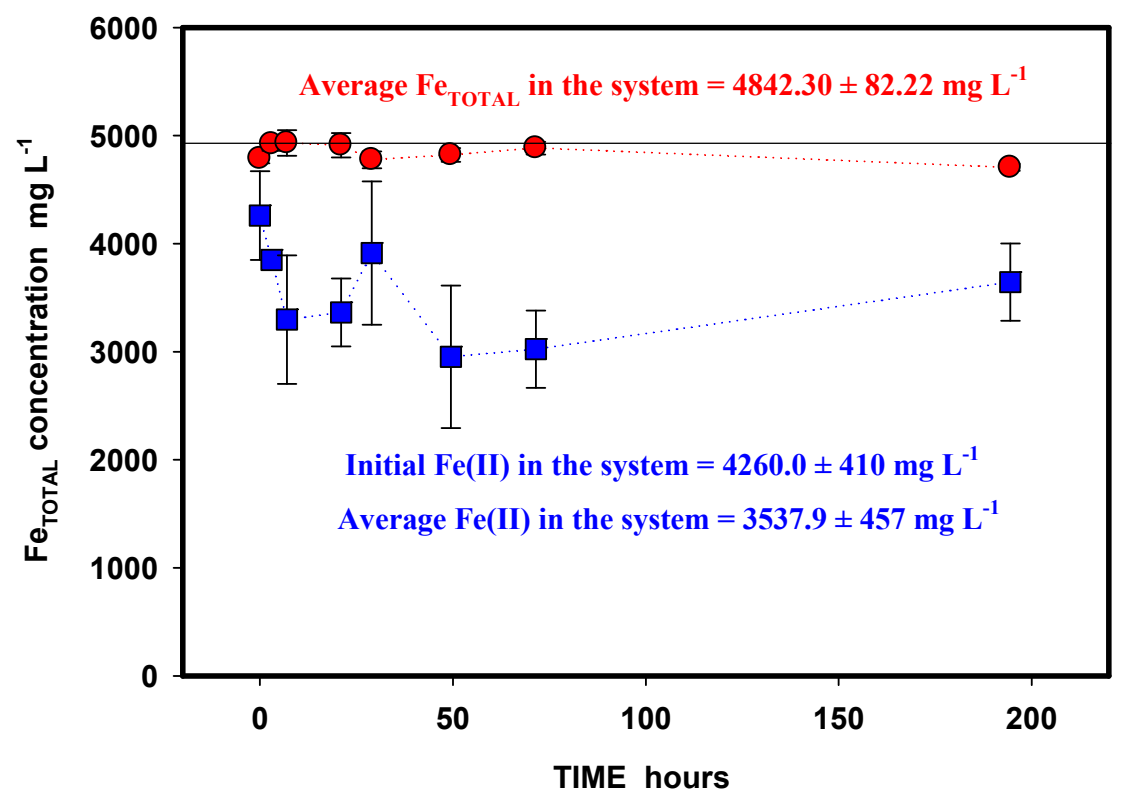

Figure 3.8. Changes in Total $\mathrm{Fe}$ (red) and $\mathrm{Fe}(\mathrm{II})$ (blue) Concentration with Time in Experiment 3 While Slurry was Kept Acidic

The fact that the total Fe concentration was higher than the Fe(II) concentration was most likely the result of the dissolution of goethite and/or other minor Fe oxides present in the initial goethite sample. The total Fe concentration did not change during this experiment as long as the $\mathrm{pH}$ remained acidic. One may compare the initial value of $\mathrm{Fe}_{\text {TOTAL INITIAL }}=4787 \pm 43 \mathrm{mg} \mathrm{L}^{-1}$ (which was the average of three measurements performed in liquid samples collected in each of the three reaction bottles before the experiment was started) with the average value calculated based on the results from the seven aqueous samples collected in each of the three reaction bottles at different times during the experiment (a total of 21 samples), which was $\mathrm{Fe}_{\mathrm{TOTAL}}=4842 \pm 82 \mathrm{mg} \mathrm{L}^{-1}$ (Figure 3.9).

Total Re concentration in the initial solution (which is the average of three independent measurements; i.e., different instruments and technicians) was $\operatorname{Re}_{\text {TOTAL INITIAL }}=1.93 \pm 0.04 \mathrm{mg} \mathrm{L}^{-1}$, while the average Re concentration measured during these experiments (a total of 21 measurements), was $\operatorname{Re}_{\mathrm{TOTAL}}=$ $1.92 \pm 0.05 \mathrm{mg} \mathrm{L}^{-1}$, clearly demonstrating that total Re concentration did not change during the first phase (the acidic portion) of these experiments.

In addition, $\mathrm{Fe}$ (II) concentration did not change significantly during these experiments if one compares the initial value (which is again the average of three measurements performed on samples collected in each of the three reaction bottles at time zero), Fe(II) $)_{\text {INITIAL }}=4260 \pm 410 \mathrm{mg} \mathrm{L}^{-1}$, with the average value measured during these experiments (again a total of 21 samples), $\mathrm{Fe}(\mathrm{II})=3538 \pm 457 \mathrm{mg} \mathrm{L}^{-1}$ (Figure 3.8). 
The small changes in the $\mathrm{Fe}(\mathrm{II})$ concentration observed during the experiments may be attributed to the sensitivity of the measurement method (which varied between $5 \%$ to $10 \%$ ), and possibly, to the reaction of $\mathrm{Fe}(\mathrm{II})$ with small amounts of either Re(VII) or residual oxygen that may have been present in these systems.

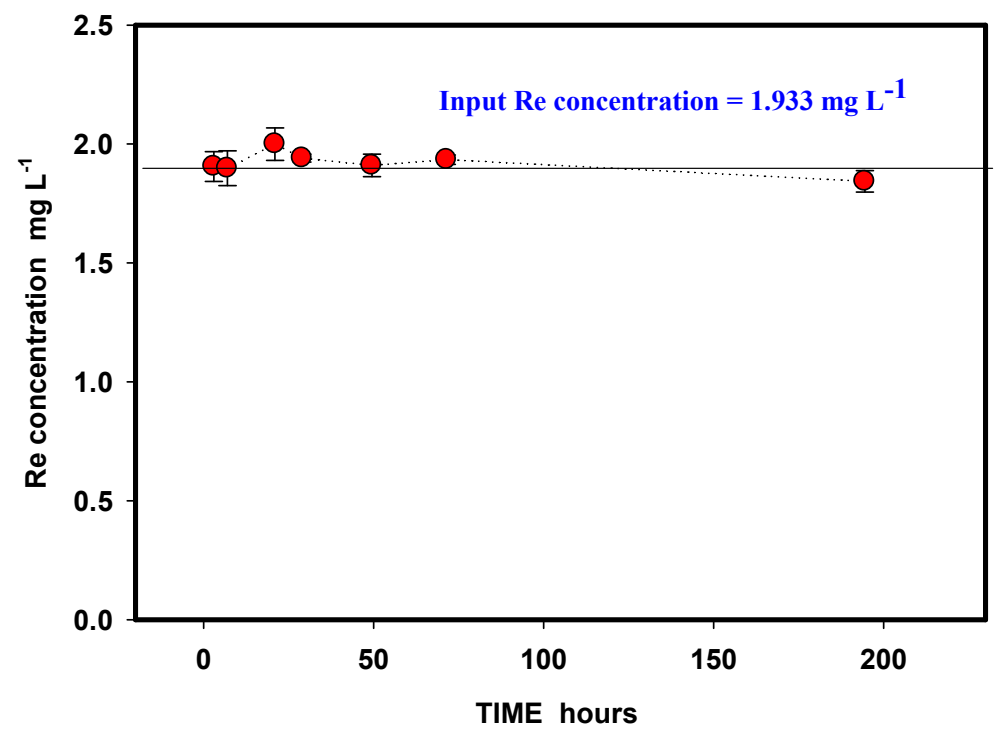

Figure 3.9. Changes in Re Concentration with Time in Experiment 3 While Slurry was Kept Acidic

Some significant changes occurred during the second phase of this experiment (Figure 3.10) after the addition of the $2 \mathrm{M} \mathrm{NaOH}$ and ferric nitrate solutions in the reaction bottles 2 and 3 (bottle 1 was run as a control, which occurred at 365 hours of experimental time.

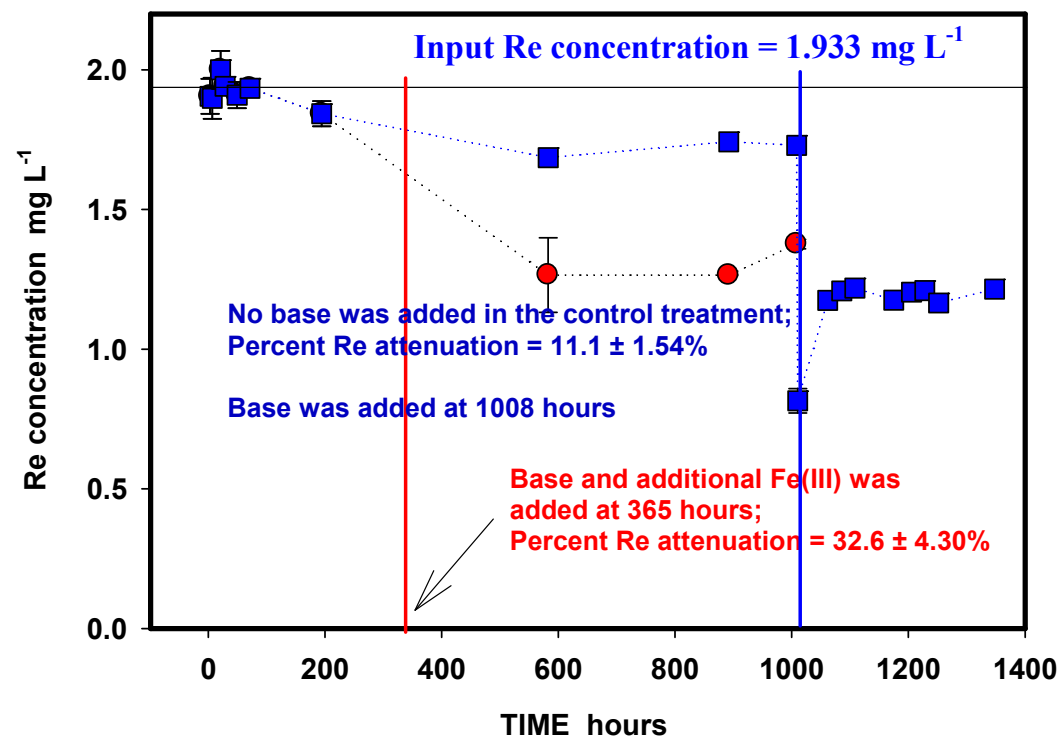

Figure 3.10. Changes in Re Concentration with Time in Experiment 3. The blue symbols are Re in the control bottle (no base or Fe(III) added until $1008 \mathrm{hrs}$ ) and the red symbols are the average of Re concentrations in the two bottles to which caustic and Fe(III) were added at $365 \mathrm{hrs}$. 
The total Fe aqueous concentration decreased dramatically during the second phase of the experiment. The measured concentrations varied from about 3 to $25 \mathrm{mg} \mathrm{L}^{-1}$, which is a dramatic decrease from the measured concentration of $4,842 \mathrm{mg} \mathrm{L}^{-1}$ that was present in the acidic slurry. Clearly, Fe precipitated and most likely formed stable Fe oxides under the basic conditions ( $\mathrm{pH}$ over 13). Assuming that all $\mathrm{Fe}(\mathrm{III})$ added in each reaction bottle as ferric nitrate also precipitated to form goethite, an additional $3.87 \mathrm{~g}$ of $\mathrm{FeOOH}$ (goethite) was formed in each reaction bottle.

The aqueous Re concentration decreased after the sequential addition of $2 \mathrm{M} \mathrm{NaOH}$ and the $\mathrm{Fe}(\mathrm{III})$ solutions, decreasing to $1.26 \pm 0.13 \mathrm{mg} \mathrm{L}^{-1}$ by 582.5 hours, $1.26 \pm 0.00 \mathrm{mg} \mathrm{L}^{-1}$ by 892 hours, and $1.38 \pm$ $0.02 \mathrm{mg} \mathrm{L}^{-1}$ by 1,008 hours (Figure 3.10). The average percent attenuation was $32.6 \pm 4.3 \%$ in the bottles under basic conditions, while this percentage was $11.1 \pm 1.5 \mathrm{mg} \mathrm{L}^{-1}$ in the control bottle (under acidic conditions). After the sequential addition of the $\mathrm{NaOH}$ base and $\mathrm{Fe}(\mathrm{III})$ solution to the control bottle at 1008 hours of experimental time, further decreases in Re concentration was observed.

The average total amount of Re sequestered in the final solid product of these experiments determined with the microwave digestion method was $74 \pm 11 \mu \mathrm{g} \mathrm{g}^{-1}$.

\subsubsection{Experiment 4}

This experiment was conducted at a higher Re concentration $\left(\mathrm{Re}_{\mathrm{TOTAL} \mathrm{INITIAL}}=3.89 \pm 0.08 \mathrm{mg} \mathrm{L}^{-1}\right)$ than the one used in Experiment $3\left(\operatorname{Re}_{\text {TOTAL INITIAL }}=1.93 \pm 0.04 \mathrm{mg} \mathrm{L}^{-1}\right)$. Aqueous samples were taken at time zero to determine the initial Re concentration ( $\operatorname{Re}_{\text {TOTAL INITIAL }}=3.89 \pm 0.08 \mathrm{mg} \mathrm{L}^{-1}$ ), and 24 hours after addition of $\mathrm{Fe}(\mathrm{II})$ but before the addition of the $2 \mathrm{M} \mathrm{NaOH}$ solution ( $\mathrm{Re}_{\text {TOTAL } 24 \text { HOURS }}=3.78 \pm$ $\left.0.06 \mathrm{mg} \mathrm{L}^{-1}\right)$. These two values were not significantly different, re-confirming that no significant changes in Re concentration occurred as a function of time ( 24 hours) in the presence of $\mathrm{Fe}(\mathrm{II})$ under acidic condition. However, the Re concentration decreased significantly after the base addition $\left(\operatorname{Re}_{\text {TOTAL }} 48\right.$ HOURS $=$ $\left.1.93 \pm 0.22 \mathrm{mg} \mathrm{L}^{-1}\right)$. The Re concentration changed little in the course of this experiment after 48 hours of experimental time ( $\operatorname{Re}_{\text {TOTAL AVERAGE } 48-312 \text { HOURS }}=1.44 \pm 0.12 \mathrm{mg} \mathrm{L}^{-1}$ ) (Figure 3.11). The average total amount of Re sequestered in the final solid product of these experiments determined with the microwave digestion method was $153 \pm 39 \mu \mathrm{g} \mathrm{g}^{-1}$. Additional Fe(III) (armoring step) was not added in this experiment.

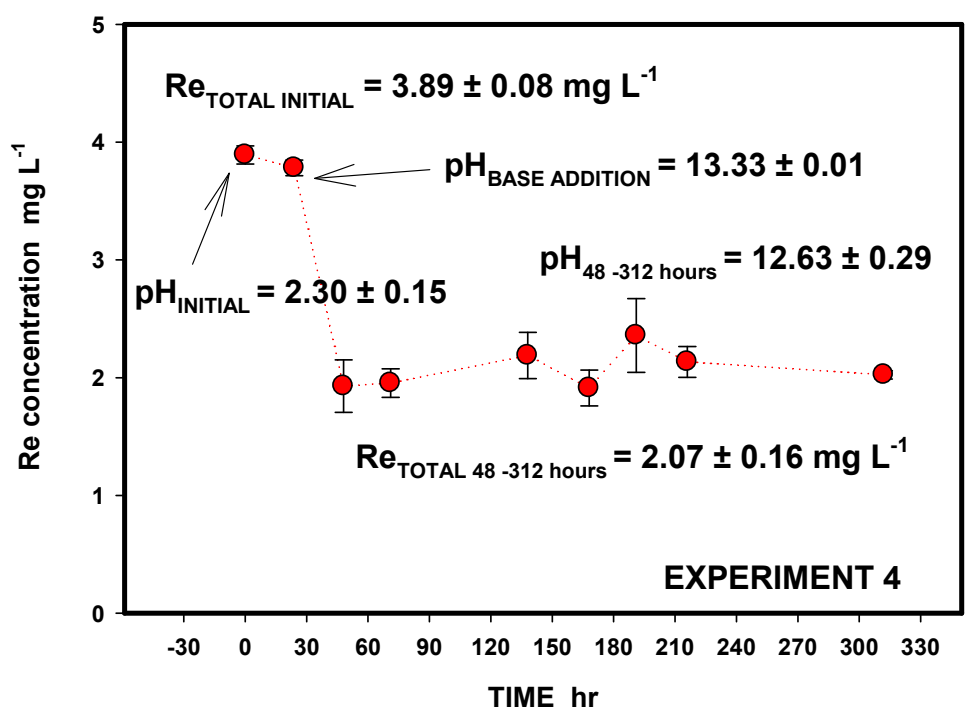

Figure 3.11. Changes in Re Concentration with Time (Experiment 4) 


\subsubsection{Experiment 5}

This experiment was conducted to study the effect of the SBS simulant (Table 3.2), which is twice as concentrated as the SBS simulant (SSS-4) described in Table 2.2, in the Re attenuation in systems containing goethite and $\mathrm{Fe}(\mathrm{II})$ as a reductant.

The results from the analyses performed for the aqueous samples collected in the control experiments (Re spiked SBS solution), and those of the experiments conducted with goethite slurry mixed with the Re-spiked SBS solution and in the presence of Fe(II) and additional base and Fe(III), indicated that similar Re concentrations were observed in the supernate solutions from these experiments.

The average Re concentration in the control test was $\operatorname{Re}_{\mathrm{TOTAL} C O N T R O L}=17617 \pm 311 \mu \mathrm{g} \mathrm{L}^{-1}$. The average concentration in the other tests, where the Re-spiked SBS waste solution and goethite slurry were treated with $\mathrm{Fe}(\mathrm{II})$, caustic, and additional Fe(III) that promoted significant precipitation of additional iron oxides, was $\mathrm{Re}_{\text {TотAL }}=19055 \pm 682 \mu \mathrm{g} \mathrm{L}{ }^{-1}$. Thus, there was no removal of the Re from the SBS waste solution by the goethite and the additional iron oxides that precipitated in the slurry.

\subsection{Summary of the Findings}

The following conclusive statements are based on the results collected during this research effort:

1. On laboratory- and engineering-scale experiments, $\mathrm{Re}$ is often used as a nonradioactive surrogate for Tc to avoid the radioactive contamination problems caused by Tc compounds.

2. These two chemical elements and analogs may behave similarly under certain chemical conditions.

3. However, when electron transfer reactions are involved, their behavior may be significantly different. $\operatorname{Re}(\mathrm{VII})$ appears to be more resistant to reduction than $\mathrm{Tc}(\mathrm{VII})$.

4. Aqueous $\operatorname{Re}(\mathrm{VII})$ concentrations are attenuated in a system composed of goethite and in the presence of aqueous and/or sorbed Fe(II). The magnitude of the attenuation, however, was smaller compared to Tc under similar conditions and the Re(VII) attenuation was slow to occur and not complete over time periods up to a few tens of days. In fact, $\operatorname{Re}(\mathrm{VII})$ spiked into a concentrated simulant SBS waste stream was not removed from solution at all by the process of treating seed goethite with $\mathrm{Fe}$ (II) and adjusting the slurry $\mathrm{pH}$ to high values and attempting to precipitate additional ferric oxides with addition of Fe(III) solution to the caustic slurry. In a similar experiment using Tc(VII)-spiked SBS simulant the Tc removal percentage was $\sim 90 \%$ (see Figure 2.21)

5. The Re attenuation mechanisms were difficult to determine using solid-phase characterization because of the small amounts of Re associated with the final solid products.

6. The possible Re attenuation mechanisms in this system include the following:

a. Aqueous $\operatorname{Re}(\mathrm{VII})$ may undergo reduction to $\operatorname{Re}(\mathrm{IV})$; reduced $\operatorname{Re}(\mathrm{IV})$ may form stable solids under final basic conditions imposed on the system; its precipitation may follow a different pathway than that of $\mathrm{Fe}(\mathrm{III})$.

b. Reduced Re(IV) may be incorporated into Fe oxides' crystal structures [co-precipitation with $\mathrm{Fe}(\mathrm{III}) / \mathrm{Fe}(\mathrm{II})]$ during Fe oxide precipitation under basic conditions. 
c. Aqueous Re(VII) may be incorporated into Fe oxides' crystal structures during their precipitation under basic conditions.

7. It is important to determine the identity of the Fe compounds that may be formed when conditions transition from strongly acidic (i.e., $\mathrm{pH} \sim 2$ ) to strongly basic (i.e., $\mathrm{pH} \sim 12.5$ ), and in the presence of $\mathrm{Fe}(\mathrm{III})$ and $\mathrm{Fe}(\mathrm{II})$. Magnetite was formed in the first 24 hours of reaction time and it was detected by XRD in addition to goethite. The Fe(II)- bearing phases that potentially formed in the beginning when Fe(II) geothite slurries were made caustic may play an important role in the $\mathrm{Re}(\mathrm{VII})$ attenuation in this systems.

8. Other stronger reductants, such as sulfides, may be more efficient, compared to Fe(II), in reducing Re(VII) in these chemical systems. However, they may also significantly change the composition of the initial solid phase (i.e., goethite) in the systems. For this reason, they were not tested during this investigation. 


\subsection{Conclusions and Summary Statements}

The observed high-percentage Tc incorporation within the Fe(II)-treated Fe-oxide mineral (magnetite or goethite) structure provides a viable option for treating waste streams containing $\mathrm{Tc}(\mathrm{VII})$ and forming stable Tc-bearing solid waste forms. With Fe(II) acting as a catalyst on the surfaces of initially prepared goethite for reduction of $\mathrm{Tc}(\mathrm{VII})$, the final product of goethite can remove Tc from off-gas secondary waste solutions quickly and efficiently. Because goethite is very stable with respect to other iron oxides or (oxy)hydroxides in both dry and wet environments over a range of particle sizes (Navrotsky et al. 2008), Tc reduced and incorporated within the goethite is unlikely to be released, even when the final Tc-goethite product is exposed to oxidizing conditions. We also found that the sequestered Tc was slower to reoxidize and exhibited lower leachability compared to the literature data on the leachability/ dissolution or release of Tc adsorbed onto ferric oxides or from discrete $\mathrm{TcO}_{2} \cdot 2 \mathrm{H}_{2} \mathrm{O}_{(\mathrm{s})}$ crystals present in mixed solids. The sequestration of Tc within the Fe(II)-treated goethite can be enhanced by using a secondary armoring process where additional goethite coatings or goethite mineral formation from mineral transformation of preexisting magnetite are produced by contacting the $\mathrm{Fe}(\mathrm{II})$-treated goethite with ferric solution at high $\mathrm{pH}$, such as the method used for Sample 2-5. Even though high concentrations of Tc were found in the cubic shaped magnetite particles in Sample 2-3* using SEM/EDX, more solid-phase characterization using TEM is needed to quantitatively identify the Tc location within or on specific minerals.

The removal of $\mathrm{Tc}(\mathrm{VII})$ by goethite from various waste simulants using the Fe(II) treatment process was tested by varying the synthesis conditions. These variations in synthesis protocol show that the concentration of $\mathrm{Fe}$ (II) reductant is the most important factor controlling the removal of Tc(VII) from the simulant solutions, especially when the waste simulants contain relatively high concentrations of Tc. The presence of anions other than hydroxide and carbonate in the waste streams, especially $\mathrm{PO}_{4}{ }^{3-}$ and to lesser extents $\mathrm{SO}_{4}{ }^{2-}$, decreases the Tc-removal efficiency slightly. It was also discovered that the mixing time between the waste simulant, the goethite, and Fe(II) reductant should be less than 1 day to minimize Tc re-release from the solid via $\mathrm{Fe}$ oxide dissolution at the high $\mathrm{pH}$ condition. The Tc re-release from the $\mathrm{Fe}(\mathrm{II})$-treated solid appears to be caused by dissolution of the Tc-hosting Fe(II)-treated goethite or magnetite in the high-pH slurry. Although more studies are needed, ferrihydrite can be also used as an initial mineral substrate instead of goethite to remove Tc from waste solutions when the slurry is treated with $\mathrm{Fe}(\mathrm{II})$.

Reoxidation reactions for Tc(IV) were found to be fast when past waste forms came in contact with atmospheric oxygen, even when different reductants were added as Tc getters to reduce Tc(VII) to Tc(IV) as $\mathrm{TcO}_{2} \cdot 2 \mathrm{H}_{2} \mathrm{O}$ in solidified waste forms (Lukens et al. 2005; Burke et al. 2006). Previous studies of the evolution of Tc oxidation states in cement waste forms containing Tc reductants show that the fraction of $\mathrm{Tc}(\mathrm{VII})$ present in the cement rapidly increases from about $10 \%$ to $40-50 \%$ after exposure to atmospheric oxygen within 4 months (Lukens et al. 2005). Even though $\mathrm{Tc}(\mathrm{VII})$ is initially reduced to $\mathrm{TcO}_{2} \cdot 2 \mathrm{H}_{2} \mathrm{O}$ in the reducing cement waste forms containing sulfide as a reductant, reoxidation of $\mathrm{Tc}(\mathrm{IV})$ from $\mathrm{TcO}_{2} \cdot 2 \mathrm{H}_{2} \mathrm{O}$ occurs rapidly upon being exposed to air, because $\mathrm{Tc}(\mathrm{IV})$ as $\mathrm{TcO}_{2} \cdot 2 \mathrm{H}_{2} \mathrm{O}$ is not stable towards oxidation by oxygen.

However, reduced $\mathrm{Tc}(\mathrm{IV})$ that is co-precipitated within $\mathrm{Fe}(\mathrm{II})$-treated goethite lattices with the subsequently added $\mathrm{Fe}(\mathrm{III})$ and $\mathrm{NaOH}$ process, as discussed for Sample 2-5 in this study, remains quite 
stable. The combination of ferric oxide armoring and the innate stability of the goethite in all subsurface environmental conditions protects Tc(IV) from future oxygen contact and reduces the rate of Tc reoxidation from $\mathrm{Tc}(\mathrm{IV})$ to $\mathrm{Tc}(\mathrm{VII})$.

Although Re and Tc behave similarly under certain chemical conditions and Re is used as a surrogate for Tc, their reduction behaviors are significantly different in the Fe(II)-geothite treatment protocol discussed in this report. Reduction of $\operatorname{Re}(\mathrm{VII})$ is much slower, and ultimately less efficient over practical time periods than $\mathrm{Tc}(\mathrm{VII})$, and the magnitude of Re removal from solution is also smaller compared to those of Tc under similar Fe(II)-goethite conditions. Because of this dissimilarity and the lower removal capacity for Re by the Fe(II)-goethite system, more attention and care are needed to prepare solid samples when Re is scheduled to be used as a surrogate for Tc. 


\subsection{References}

Amstaetter, K., Borch, T., Larese-Casanova, P., and Kappler, A. 2010. Redox transformation of arsenic by Fe(II)-activated goethite (alpha-FeOOH). Environ. Sci. Technol. 44, 102-108.

Anderson, B.E., U. Becker, K.B. Helean, and R.C. Ewing. 2007. Perrhenate and pertechnetate Behavioron iron and sulfur-bearing compounds, p. 425-430, In D. Dunn, et al., eds. Scientific Basis for Nuclear Waste Management XXX, Vol. 985. Materials Research Society, Warrendale.

Bacon, D. H. and McGrail, B. P. 2001. Waste form release calculations for the 2001 immobilized lowactivity waste performance assessment. Pacific Northwest National Laboratory, Richland, WA, PNNL-13369.

Bao, Y., Grutzeck, M. W., and Jantzen, C. M. 2005. Preparation and properties of hydroceramic waste forms made with simulated Hanford Low-Activity Waste. J. Am. Ceram. Soc. 88(12), 3287-3302.

Bondietti, E. A. and Francis, C. W. 1979 . Geologic migration potential of Tc-99 and Np-237. Science 203, 1337-1340.

Brookins, D.G. 1986. Rhenium as analog for fissiogenic technetium: Eh-pH diagram $\left(25^{\circ} \mathrm{C}, 1 \mathrm{bar}\right)$ constraints. Applied Geochemistry 1:513-517.

Brunauer, S.; Emmett, P. H.; Teller, E. Adsorption of gases in multimolecular layers. Journal of the American Chemical Society 1938, 60, 309-319.

Burke, I. T., Boothman, C., Lloyd, J. R., Livens, F. R., Charnock, J. M., Mcbeth, J. M., Mortimer, R. J. G., and Morris, K. 2006. Reoxidation behavior of Technetium, iron, and sulfur in estuarine sediments. Environ. Sci. Technol. 40, 3529-3535.

Crank, J. 1980. Mathematics of diffusion. Oxford University Press, London.

Darab, J. G. and Smith, P. A. 1996. Chemistry of technetium and rhenium species during low-level radioactive waste vitrification. Chem. Mat. 9, 1004-1021.

Dolor, M.K., C.C. Gilmour, and G.R. Helz. 2009. Distinct Microbial Behavior of Re Compared to Tc: Evidence Against Microbial Re Fixation in Aquatic Sediments. Geomicrobiology Journal 26:470-483.

Downward, L., Booth, C. H., Lukens, W. W., and Bridges, F. 2006. A variation of the F-test for determining statistical relevance of particular parameters in EXAFS fits 13th International Conference on X-ray Absorption Fine Structure, Stanford, CA, USA, July 9-14.

Elsner, M., Schwarzenbach, R. P., and Haderlein, S. B. 2004. Reactivity of Fe(II)-bearing minerals toward reductive transformation of organic contaminants. Environ. Sci. Technol. 38, 799-807.

Eriksen, T.E., P. Ndalamba, J. Bruno, and M. Caceci. 1992. The solubility of $\mathrm{TcO}_{2} * 2 \mathrm{H}_{2} \mathrm{O}$ in neutral to alkaline solutions under constant $\mathrm{pCO}_{2}$. Radiochim. Acta 58:67-70. 
Fredrickson, J. K., Zachara, J. M., Kennedy, D. W., Kukkadapu, R. K., McKinley, J. P., Heald, S. C., Liu, C., and Plymale, A. E. 2004. Reduction of $\mathrm{TcO}_{4}{ }^{-}$by sediment associated biogenic $\mathrm{Fe}(\mathrm{II})$. Geochemica Costmochimica Acta 68, 3171-3187.

Gibbs, C. R. 1976. Characterization and application of ferrozine iron reagent as a ferrous indicator. Anal. Chem. 48(8), 1197-1201.

Gilliam, T. M., Spence, R. D., Bostick, W. D., and Shoemaker, J. L. 1990. Solidification/stabilization of technetium in cement-based grouts. J. Hazard. Mater., 189-197.

Gu, B., Brown, G. M., Bonnesen, P. V., Liang, L., Moyer, B. A., Ober, R., and Alexandratos, S. D. 2000. Development of novel bifunctional anion-exchange resins with improved selectivity for pertechnetate sorption from contaminated groundwater. Environmental Science and Technology 34, 1075-1080.

He, Y. T. and Traina, S. J. 2007. Transformation of magnetite to goethite under alkaline $\mathrm{pH}$ conditions. Clay Minerals 42(1), 13-19.

Hess, N. J., Qafoku, O., Xia, Y., Moore, D. A., and Felmy, A. R. 2008. Thermodynamic model for the solubility of $\mathrm{TcO}_{2} \mathrm{xH}_{2} \mathrm{O}$. j. Solution Chem. 37, 1471-1487.

Josephson, G., Piepel, G., and Westsik, J. H. 2010. Selection of secondary waste test compositions. Pacific Northwest National Laboratory, Unpublished.

Kaplan, D. I., Parker, K. E., and Kutnyakov, I. V. 1998a. Radionuclide distribution coefficients for sediments collected from borehole 299-E17-21: Final report for subtask 1a. Pacific Northwest National Laboratory, Richland, PNNL-11966.

Kaplan, D. I.and Serne, R. J. Pertechnetate Exclusion from Sediments. Radiochimica Acta 1998b, 81, 117-124.

Keith-Roach, M. J., Morris, K., and Dahlgaard, H. 2003. An investigation into technetium binding in sediments. Mar. Chem. 81, 149-162.

Kim, E., and J. Boulegue. 2003 . Chemistry of rhenium as an analogue of technetium: Experimental studies of the dissolution of rhenium oxides in aqueous solutions. Radiochimica Acta 91:211-216.

Kim, E., M.F. Benedetti, and J. Boulegue. 2004. Removal of dissolved rhenium by sorption onto organic polymers: study of rhenium as an analogue of radioactive technetium. Water Research 38:448-454.

Kotegov, K. V., Pavlov, O. N., and Shvedov, V. P. 1968. Technetium. Academic Press, New York.

Krupka, K.M., C.F. Brown, T. Schaef, S.M. Heald, M.M. Valenta, and B.W. Arey. 2006. Rhenium uptake as analogue for 99Tc by steel corrosion products. B. Sagar (ed.), 11th International HighLevel Radioactive Waste Management Conference (IHLRWM), Las Vegas, Nevada. American Nuclear Society.

Lee, S. Y. and Bondietti, E. A. 1983. Technetium behavior in sulfide and ferrous iron solutions. Proc. Mat. Res. Soc. Symp. 
Liang, L., Gu, B., and Yin, X. 1996. Removal of technetium-99 from contaminated groundwater with sorbents and reductive materials. Separations Technology 6, 111-122.

Lieser, K.H., C. Bauscher, and T. Nakashima. 1987. Dissolution of $\mathrm{TcO}_{2}$ in aqueous solutions under various conditions. Radiochimica Acta 42:191-200.

Liu, D. J. and Fan, X. H. 2005. Adsorption behavior of ${ }^{99}$ Tc on $\mathrm{Fe}, \mathrm{Fe}_{2} \mathrm{O}_{3}$ and $\mathrm{Fe}_{2} \mathrm{O}_{4}$. J. Radio. Nuclear Chem. 264 (3), 691-698.

Livens, F. R., Jones, M. J., Hynes, A., Charnock, J. M., Mosselmans, F. W., Hennig, C., Steele, H., Collison, D., Vaughn, D. J., Pattrick, R. A. D., Reed, W. A., and Moyes, L. N. 2004. X-ray absorption spectroscopy studies of reactions of technetium, uranium and neptunium with mackinawite. Journal of Environmental Radioactivity 74, 211-219.

Lockrem, L. L. 2005. Hanford contaminated cast stone facility tank 1-process testing and development final test report. CH2M Hill, Richland, WA, RPP-RPT-26472, Rev. 0.

Lukens, W. W., Bucher, J. J., Edelstein, N. M., and Shuh, D. K. 2002. Products of pertechnetate radiolysis in highly alkaline solution: Structure of $\mathrm{TcO}_{2} \mathrm{xH}_{2} \mathrm{O}$. Environ. Sci. Technol. 36, 1124-1129.

Lukens, W. W., Bucher, J. J., Shuh, D. K., and Edelstein, N. M. 2005. Evolution of Technetium speciation in reducing grout. Environ. Sci. Technol. 39, 8064-8070.

Lukens, W.W., D.A. McKeown, A.C. Buechele, I.S. Muller, D.K. Shun, and I.L. Pegg. 2007. Dissimilar behavior of technetium and rhenium in borosilicate waste glass as determined by X-ray absorption spectroscopy. Chemistry of Materials 19:559-566.

Luykx, F. 1986. Technetium Discharges in the Environment. In: Desmet, G. and Myttenaere, C. (Eds.), Technetium in the Environment. Elsevier, Essex, UK.

Mahoney, L. A. and Russell, R. L. 2004. Vitrification offgas caustic scrubber secondary waste simulant formulation. Pacific Northwest National Laboratory, Richland, PNNL-14582 Rev. 1.

Mann, F. M., Puigh, R. J., Khaleel, R., Finfrock, S., McGrail, B. P., Bacon, D. H., and Serne, R. J. 2003. Risk assessment supporting the decision on the initial selection of supplemental ILAW technologies. CH2M HILL Hanford Group Inc., Richland, WA, RPP-17675, Rev. 0.

Maset, E.R., S.H. Sidhu, A. Fisher, A. Heydon, P.J. Worsfold, A.J. Cartwright, and M.J. Keith-Roach. 2006. Effect of organic co-contaminants on technetium and rhenium speciation and solubility under reducing conditions. Environmental Science \& Technology 40:5472-5477.

Mattigod, S. V., Serne, R. J., and Fryxell, G. E. 2003. Selection and Testing of "Getters" for Adsorption of Iodine-129 and Technetium-99: A Review. Pacific Northwest National Laboratory, Richland, WA, PNNL-14208.

Mattigod, S.V., B. Peter McGrail, D.E. McCready, L.-Q. Wang, K.E. Parker, and J.S. Young. 2006. Synthesis and structure of perrhenate sodalite. Microporous and Mesoporous Materials 91:139-144. 
McGrail, B. P., Bacon, D. H., Icenhower, J. P., Mann, F. M., Puigh, R. J., Schaef, H. T., and Mattigod, S. V. 2001. Near-field performance assessment for a low-activity waste glass disposal system: Laboratory testing to modeling results. J. Nucl. Mater. 298, 95-111.

Morris, K., Livens, F. R., Charnock, J. M., Burke, I. T., McBeth, J. M., Begg, J. D. C., Boothman, C., and Lloyd, J. R. 2008. An X-ray absorption study of the fate of technetium in reduced and reoxidised sediments and mineral phases. Applied Geochemistry 23, 603-617.

Murad, E. 1982. The characterization of goethite by Mossbauer spectroscopy. Am. Mineral. 67, 1007-1011.

Navrotsky, A., Mazeina, L., and Majzlan, J. 2008. Size-driven structural and thermodynamic complexity in iron oxides. Science 319, 1635-1638.

Newville, M. 2001. IFFEFIT: interactive XAFS analysis and FEFF fitting. J. Synchrotron Radiat. 8, 322-324.

Pedersen, H. D., Postma, D., Jakobsen, R., and Larsen, O. 2005. Fast transformation of iron oxyhydroxides by the catalytic action of aqueous Fe(II). Geochemica Costmochimica Acta 69(16), 3967-3977.

Pepper, S. E., Bunker, D. J., Bryan, N. D., Livens, F. R., Charnock, J. M., Pattrick, R. A. D., and Collison, D. 2003. Treatment of radioactive wastes: An X-ray absorption spectroscopy study of the reaction of technetium with green rust. J. Colloid Interface Sci. 268, 408-412.

Peretyazhko, T., Zachara, J. M., Heald, S. M., Jeon, B.-H., Kukkadapu, R. K., Liu, C., Moore, D. A., and Resch, C. T. 2009. Heterogeneous reduction of Tc(VII) by Fe(II) at the solid-water interface. Geochim. Cosmochim. Acta 72, 1521-1539.

Poineau, F., M. Fattahi, C. Den Auwer, C. Hennig, and B. Grambow. 2006. Speciation of technetium and rhenium complexes by in situ XAS-electrochemistry. Radiochimica Acta 94:283-289.

Rancourt, D. G. and Ping, J. Y. 1991. Voigt-based methods for arbitrary-shape static hyperfine parameter distributions in Mossbauer spectroscopy. Nuclear Instruments and methods in Physics Research Section B B58, 85-87.

Ravel, B. and Newville, M. 2005. ATHENA, ARTEMIS, HEPHAESTUS: data analysis for X-ray absorption spectroscopy using IFEFFIT. J. Synchrotron Radiat. 12, 537-541.

Rehr, J. J., de Leon, M. M., Zabinsky, S., and Albers, R. C. 1991. Theoretical X-ray absorption fine structure standards. J. Am. Chem. Soc. 113, 5135-5140.

Rogers, R. D., Zhang, J., and Griffin, S. T. 1997. The effects of halide anions on the partitioning behavior of pertechnetate in polyethylene glycol-based aqueous biphasic systems. Separation Science and Technology 32, 699-707.

Rudin, M. J., Stanton, C., Patterson, R. G., and Garcia, R. S. 1992. National Low-Level Waste Management Program Radionuclide Report Series, Vol. 2, Technetium-99, Idaho National Engineering Laboratory Technical Report DOE/LLW-118. INEL, Idaho Falls, Idaho. 
Schwertmann, U. and Cornell, R. M. 1991. Iron Oxides in the Laboratory: Preparation and Characterization. VCH Publishers, Weinheim, Germany.

Serne, R. J., Lokken, R. O., and Criscenti, L. J. 1992. Characterization of grouted low-level waste to support performance assessment. Waste Manage. 12, 271-287.

Shuster, D. L., Vasconcelos, P. M., Heim, J. A., and Farley, K. A. 2005. Weathering geochronology by (U-Th)/He dating of goethite. Geochim. Costmochim. Acta 69(3), 659-673.

Siemer, D. D. 2002. Hydroceramics, a "new" cementitious waste form material for U.S. defense-type reprocessing waste. Mater. Res. Innov. 6, 96-104.

Singh, D., Mandalika, V. R., Parulekar, S. J., and Wagh, A. S. 2006. Magnesium potassium phosphate ceramic for Tc-99 immobilization. J. Nucl. Mater. 348 (3), 272-282.

Smith, R. W. and Walton, J. C. 1993. The role of oxygen diffusion in the release of technetium from reducing cementitious waste forms. Mater. Res. Soc. Symp. Proc.

Sposito, G. 1989. The chemistry of soils. Oxford University Press, New York.

Stumm, W. 1992. Chemistry of the solid-water interface. John Wiley \& Sons, Inc., New York.

Stumm, W. and Morgan, J. J. 1995. Aquatic chemistry. 3rd ed. John Wiley \& Sons, Inc.

Szytulstroka, A., Burewicz, A., Dimitrijevicacute, Z., Krasacutenicki, S., Rzdotany, H., Todorovicacute, J., Wanic, A., and Wolski, W. 1968. Neutron diffraction studies of alphaFeOOH. Phys. Status Solidi B. 26(2), 429-434.

Um, W., Serne, R. N., and Krupka, K. M. 2007. Surface complexation modeling of U(VII) sorption to Hanford sediment with varying geochemical conditions. Environ. Sci. Technol. 41(10), 3587-3592.

Volkovich, V.A., I. May, J.M. Charnock, and B. Lewin. 2002. Reactions and speciation of technetium and rhenium in chloride melts: a spectroscopy study. Physical Chemistry Chemical Physics 4:5753-5760.

Watson, J. H. P., Croudace, I. W., James, P. A. B., Charnock, J. M., and Ellwood, D. 2001. Adsorption of radioactive metals by strongly magnetic iron sulfide nanoparticles produced by sulfatereducing bacteria. Separations Science and Technology 36, 2571-2607.

Wellman, D. M., Mattigod, S. V., Parker, K. E., Heald, S. M., Wang, C., and Fryxell, G. E. 2006. Synthesis of organically templated nanoporous tin(II/IV) phosphate for radionuclide and metal sequestration. Inorganic Chemistry 45, 2382-2384.

Wharton, M. J., Atkins, B., Charnock, J. M., Livens, F. R., Pattrick, P. A. D., and Collison, D. 2000. An X-ray absorption spectroscopy study of the coprecipitation of Tc and Re with mackinawite (FeS). Appl. Geochem. 15, 347-354.

Yang, H., Lu, R., Downs, R. T., and Costin, G. 2006. Goethite, $\alpha-\mathrm{FeO}(\mathrm{OH})$, from single-crystal data. Acta Crystallographica Section E E62, 250-252. 
Zachara, J. M., Heald, S. M., Jeon, B.-H., Kukkadapu, R. K., Liu, C., Mckinley, J. P., Dohnalkova, A. C., and Moore, D. A. 2007. Reduction of pertechnetate [Tc(VII)] by aqueous Fe(II) and the nature of the solid phase redox products. Geochim. Cosmochim. Acta 71, 2137-2157.

Zhang, P.C., J.L. Krumhansl, and P.V. Brady. 2000. Boehmite sorbs perrhenate and pertechnetate. Radiochimica Acta 88:369-373. 
PNNL-19833

\section{Distribution}

No. of

Copies

\section{OFFSITE}

Nicholas P. Machara

Office of Waste Processing, EM-31

Technology Innovation \& Development

Office of Environmental Management

U.S. Department of Energy, Cloverleaf 2163

20400 Century Boulevard

Germantown, MD 20874

Harry Babad

2540 Cordoba Court

Richland, WA 99352-1609

Patrick V. Brady

Geochemistry Department, 6118

Sandia National Laboratories

P.O. Box 5800

Albuquerque, NM 87185-0750

H. Chang

Savannah River Ecology Lab

Aiken, SC 29802

Jon Chorover

Professor - Environmental Chemistry

Department of Soil, Water, and Environmental

Science, Shantz 429, Building \#38

University of Arizona

Tucson, AZ 85721-0038

Dwayne Crumpler

Columbia Energy \& Environmental Services

1806 Terminal Road

Richland, WA 99352

Ken Czerwinski

University of Nevada, Las Vegas

4505 Maryland Parkway

Box 45003

Las Vegas, NV 89154-4003
No. of

Copies

Jonathan P. Icenhower

VSI llc

12100 Hiram Clarke Road

Houston, TX 77045

Daniel I. Kaplan

Westinghouse Savannah River Company

Building 774-43A, Room 215

Aiken, SC 29808

Dr. Jim Krumhansl

Sandia National Laboratory

P.O. Box 5800

Albuquerque, NM 87185-0750

Wayne Lukens

Lawrence Berkeley National Laboratory

1 Cyclotron Road, MS 70A-1150

Berkeley, CA 94720

Eric Pierce

Building 1505, MS 6038

Biological and Environmental Sciences

Directorate Oak Ridge National Laboratory

Oak Ridge, TN 37831

Phil Reed

U.S. Nuclear Regulatory Commission

Office of Nuclear Regulatory Research

Division of Systems Analysis and

Regulatory Effectiveness

Radiation Protection, Env. Risk and Waste

Management Branch, MS T9-F31

Washington, D.C. 20555-0001

Jeff Serne

5735 Cedar Flats Road SW

Olympia, WA 98512-9415

Doug Sherwood

Rivers Edge Environmental

1616 Riverside Drive

West Richland, WA 99353 
No. of

Copies

Stan Sobczyk

Nez Perce Tribal Consultant

P.O. Box 365

Lapwai, ID 83832

Carl I. Steefel

Lawrence Livermore National Laboratory

Earth \& Environmental Sciences Directorate

MS L-204, P.O. Box 808

Livermore, CA 94551-9900

T. T. Chuck Vandergraaf

P.O. Box 857

Pinawa, Manitoba

R0E 1L0 Canada

Jiamin Wan

Lawrence Berkeley National Laboratory

1 Cyclotron Road, MS 70-0127A

Berkeley, CA 94720

Ronald G. Wilhelm

U.S. Environmental Protection Agency

Office of Radiation and Indoor Air

401 M Street, S.W. Mail Code 6603J

Washington, D.C. 20460

W. Alexander Williams

U.S. Department of Energy

Office of Environmental Restoration

EM-33, 19901 Germantown Road

Germantown, MD 20874-1290

\section{ONSITE}

\section{DOE Office of River Protection}

C. J. Kemp

H6-60

R. W. Lober

H6-60

B. M. Mauss

H6-60

DOE Public Reading Room (2)
No. of

\section{Copies}

4 DOE Richland Operations Office

J. P. Hanson

A5-13

K. A. Kapsi

A5-13

J. G. Morse

A6-38

K.M. Thompson

A6-38

6 CH2M HILL Plateau Remediation Company

M. W. Benecke

R3-60

B. H. Ford

$\mathrm{H} 8-43$

S. W. Petersen

R3-50

L. C. Swanson

R3-50

B. A. Williams

$\mathrm{H} 8-51$

M. I. Wood

H8-51

Fluor Federal Services

R. J. Puigh

A0-26

2 U.S. Environmental Protection Agency

D. A. Faulk

B5-01

R. Lobos

B1-46

7 Washington River Protection Solutions

K. A. Colosi

E6-20

M. P. Connelly

E6-31

S. J. Eberlein

E6-31

T. H. May

E6-40

M. A. Melvin

E6-30

D. A. Myers

E6-31

K. E. Smith

E6-30

6 Washington State Department of Ecology

J. A. Caggiano

$\mathrm{H} 0-57$

S. Dahl-Crumpler

$\mathrm{H} 0-57$

J. V. Hedges

$\mathrm{H} 0-57$

J. J. Lyon

$\mathrm{H} 0-57$

J. Price

$\mathrm{H} 0-57$

E. A. Rochette

$\mathrm{H} 0-57$ 
No. of

Copies

54 Pacific Northwest National Laboratory

B. N. Bjornstad

P. R. Bredt

T.M. Brouns

C. F. Brown

E. C. Buck

K. J. Cantrell

M. J. Fayer

A. R. Felmy

M. D. Freshley

J. S. Fruchter

T. J. Gilmore

P. R. Hrma

G. B. Josephson

R. K. Kukkadapu

G. V. Last

M. J. Lindberg

G. J. Lumetta

S. V. Mattigod
No. of

\section{$\underline{\text { Copies }}$}

B. P. McGrail K6-81

R. A. Peterson P7-12

N. Qafoku K8-96

K. M. Rosso K8-96

R. D. Scheele P7-25

M. J. Schweiger K6-24

S. C. Smith P8-08

D. M. Strachan K6-24

J. E. Szecsody K3-81

M. B. Triplett K6-52

M. J. Truex K6-96

W. Um (10) P7-22

J. D. Vienna (3) K6-24

A. L. Ward K9-33

D. Wellman K3-62

J. H. Westsik (5) K7-15

J. M. Zachara K8-96

Hanford Technical Library (2) P8-55

Information Release (2) K1-06 


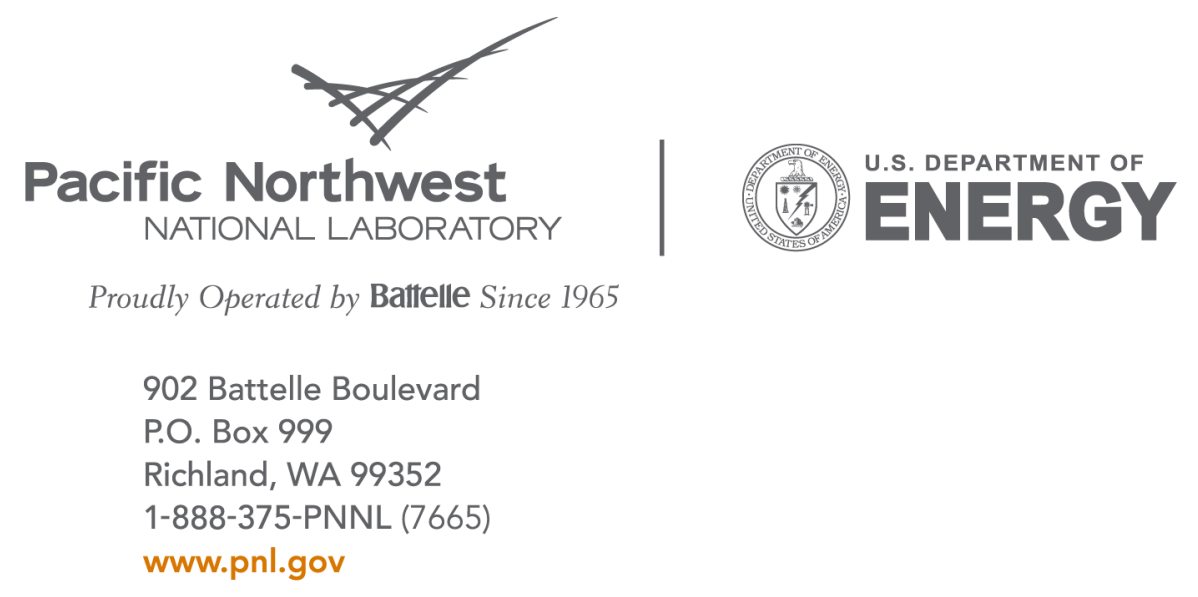

